\title{
Prognostic indicators for patients with degenerative lumbar spinal stenosis
}

Citation for published version (APA):

Burgstaller, J. M. (2016). Prognostic indicators for patients with degenerative lumbar spinal stenosis. [Doctoral Thesis, Maastricht University]. Datawyse / Universitaire Pers Maastricht. https://doi.org/10.26481/dis.20161212jb

Document status and date:

Published: 01/01/2016

DOI:

10.26481/dis.20161212jb

Document Version:

Publisher's PDF, also known as Version of record

\section{Please check the document version of this publication:}

- A submitted manuscript is the version of the article upon submission and before peer-review. There can be important differences between the submitted version and the official published version of record.

People interested in the research are advised to contact the author for the final version of the publication, or visit the DOI to the publisher's website.

- The final author version and the galley proof are versions of the publication after peer review.

- The final published version features the final layout of the paper including the volume, issue and page numbers.

Link to publication

\footnotetext{
General rights rights.

- You may freely distribute the URL identifying the publication in the public portal. please follow below link for the End User Agreement:

www.umlib.nl/taverne-license

Take down policy

If you believe that this document breaches copyright please contact us at:

repository@maastrichtuniversity.nl

providing details and we will investigate your claim.
}

Copyright and moral rights for the publications made accessible in the public portal are retained by the authors and/or other copyright owners and it is a condition of accessing publications that users recognise and abide by the legal requirements associated with these

- Users may download and print one copy of any publication from the public portal for the purpose of private study or research.

- You may not further distribute the material or use it for any profit-making activity or commercial gain

If the publication is distributed under the terms of Article $25 \mathrm{fa}$ of the Dutch Copyright Act, indicated by the "Taverne" license above, 


\section{Prognostic indicators for patients with degenerative lumbar spinal stenosis}


Prognostic indicators for patients with degenerative lumbar spinal stenosis (C) Jakob Martin Burgstaller, Maastricht 2016

Graphic design cover: Giuseppe Pichierri, Switzerland Printed by: Datawyse | Universitaire Pers Maastricht

ISBN: 9789461596444 


\title{
Prognostic indicators for patients with degenerative lumbar spinal stenosis
}

\author{
DISSERTATION \\ to obtain the degree of doctor at Maastricht University, \\ on the authority of the Rector Magnificus, Prof. dr. Rianne M. Letschert \\ in accordance with the decision of the Board of Deans, \\ to be defended in public on \\ Monday $12^{\text {th }}$ of December 2016 at 12.00 hours
}

by Jakob Martin Burgstaller 


\section{Promotor}

Prof. dr. M. van Kleef

\section{Co-promotores}

PD dr. M.M. Wertli

Dr. H.F. Gramke

\section{Beoordelingscommisie}

Prof. dr. J. Verbunt (voorzitter)

Prof. dr. L. van Rhijn

Dr. P. Willems

Prof. dr. A.P. Wolff

Prof. dr. J. van Zundert 


\section{Contents}

$\begin{array}{lll}\text { Chapter } 1 & \text { Introduction }\end{array}$

Chapter 2 Is there an association between pain and magnetic resonance 19 imaging parameters in patients with lumbar spinal stenosis?

Chapter 3 Arguments for the choice of surgical treatments in patients with lumbar spinal stenosis - a systematic appraisal of randomized controlled trials

Chapter 4 The impact of obesity on the outcome of decompression surgery in degenerative lumbar spinal canal stenosis: Analysis of the Lumbar Spinal Outcome Study (LSOS)

Chapter 5 The Influence of Catastrophizing on Treatment Outcome in Patients with Non-Specific Low Back Pain - A Systematic Review

Chapter 6 The influence of pre- and postoperative fear avoidance beliefs on postoperative pain and disability in patients with lumbar spinal stenosis: Analysis of the Lumbar Spinal Outcome Study (LSOS) data

Chapter 7 General discussion

Chapter 8 Summary 157

Chapter 9 Valorization addendum

Curriculum vitae 



\section{Chapter 1}

\section{Introduction}



Lumbar spinal stenosis (LSS) is a highly prevalent condition and the most frequent indication for spine surgery in patients older than 65 years of age [1]. Little is known about its prevalence in the general population as a result of inconsistent definitions of LSS and missing reporting in unselected populations [2]. The economic burden of the surgical treatment of LSS is high: in 2007, the costs of the inpatient treatment in Medicare patients in the United States were nearly $\$ 1.65$ billion [3]. The benefit of the surgery varies widely and one third of patients report no clinically relevant improvement after surgery $[4,5]$. Other treatment options include pain medications, physiotherapy and epidural steroid injections. Therefore, it is difficult for physicians and their patient to choose the best treatment option and the right time when to undergo surgery and what type of surgery to choose. The identification of modifiable prognostic indicators is associated with beneficial or poor outcome, and so prognostic indicators may help clinicians in the choice of individualized treatments. This is for patient-applied treatment of the utmost importance.

\section{Mechanism}

The definition of LSS by the North American Spine Society (NASS) includes both radiological - "[...] diminished space available for the neural and vascular elements in the lumbar spine secondary to degenerative changes in the spinal canal" - and clinical criteria "When symptomatic, this causes a variable clinical syndrome of gluteal and/or lower extremity pain and/or fatigue which may occur with or without back pain. [...]" [6]. Central and lateral stenosis can be caused by loss of disc height and bulging of the intervertebral disc, hypertrophy of the ligamentum flavum and/or the facet joints. Foraminal stenosis can result from decreased disc height, overgrown facet joint capsule and/or posterolateral osteophytes [7]. Separate entities are space-narrowing lesions caused by neoplasm or inflammation and herniated intervertebral discs [8]. With increasing age the coexistence of degenerative findings, disc herniation and hypertrophy of the ligamentum flavum may complicate the decision process on what is the right treatment approach. 


\section{Magnetic resonance imaging findings}

Despite the wide use of Magnetic Resonance Imaging (MRI) studies to establish the diagnosis of LSS [6] and to plan surgery [9], it is unclear how findings on MRI studies correlate with the symptoms [9-13]. It has been shown that radiologic findings often poorly correlate with symptoms [13]. Ishimoto et al. [14] reported that $77.9 \%$ of asymptomatic persons showed a moderate or even severe narrowing of the spinal canal in the MRI. Two other studies also found a relevant proportion of asymptomatic patients ( $21 \%$ and $31.2 \%$, respectively); however, their patient samples were much smaller [13, 15]. Furthermore, there is no commonly agreed standard for a structured radiological report [16]. Researchers used varying radiological criteria to diagnose LSS [17] that impedes the interpretability and the comparison between studies. Despite the complex pathoanatomic changes in the morphological structure of the spine the above mentioned studies investigated only one to three MRI parameters. That seems arbitrary considering that a Delphi survey identified 17 potentially relevant MRI parameters [18]. However, the experts did not agree on the highest ranked parameters in the survey. In a recent consensus process, international experts agreed on a set of five radiological core parameters that should be measured and reported in MRI studies [16]. Whether MRI studies assessed using these radiological criteria correlate with the clinical complaints has not been investigated.

\section{Treatment guidelines}

Although spinal canal stenosis is a very common disease, treatment guidelines remain quite vague how to treat patients. The best management of LSS remains controversial and a decision regarding the treatment should be individualized. This may be due to the lack of data regarding long-term treatment outcome and patient satisfaction. In the absence of evidence for or against any specific treatment, the NASS recommends a primary conservative treatment attempt including medicinal analgesia and physiotherapy if deemed adequate regarding the patient's clinical condition [6]. For short term symptom relief (two weeks to six months), epidural steroid injections are suggested [6]. When symptoms are 
moderate to severe and conservative treatment has failed, an operative intervention may be indicated [6]. The aim of surgery is to decompress the spinal canal and dural sac from degenerative bony and ligamentous overgrowth. For instance, in the metropolitan area of Zurich with around 1.3 million inhabitants approximately 1400 lumbar decompressions are performed every year [19]. The type of surgery that should be performed remains controversial. Depending on the underlying cause of the stenosis this may include decompression alone or, when subsequent instability is expected, additional stabilization of the spine may be added. Despite the latter procedure is more invasive, the rates of complex fusion surgery had a 15-fold increase between 2002 and 2007 [3]. However, it is still unclear which aspects and arguments influence the surgeon's decision to choose the type of surgical treatment for a patient with spinal stenosis.

\section{Weight and outcome}

The surgical management of LSS is challenging in this elderly population with an average age of over 70 years at the time of surgery and the presence of comorbidities [20]. With an increasing prevalence of obesity, a wide variety of degenerative changes of the lumber spine due to the increased load of the body weight is to be expected [21]. On the basis of the latest estimation of the World Health Organization (WHO) in European countries, overweight affects $30 \%$ to $70 \%$ and obesity affects $10 \%$ to $30 \%$ of the adults [22]. The negative impact of obesity on musculoskeletal disease and low back pain has been well documented [23-28]. However, the impact of surgical treatment in patients with LSS is inconsistent. Some studies showed that spinal surgery did not influence the clinical outcome in obese patients $[29,30]$ whereas other studies reported an increased incidence of operative complications [21,31].

In morbidly obese patients impaired gait stability and physical fitness can be observed. It is intuitive to assume that in these patients peri- and postoperative treatment as well as long term outcome may be influenced. However, very few studies investigated this question and found conflicting evidence $[29,30]$. 


\section{Psychological factors}

In low back pain it is well recognized that psychological factors including catastrophizing, fear or depression influence the individual ability to cope with pain and are associated with poor outcome. Low back pain with its global prevalence of $9.4 \%$ constitutes a high health and economic burden on individuals [32], and lumbar spinal stenosis is a relevant subgroup of low back pain patients. In low back pain treatment guidelines psychological factors should be addressed during treatment [33-35]. In the 1990, the fear-avoidance model was developed and is now a widely used theoretical model to explain how psychological factors influence the experience of pain and the development of chronic pain and disability [36]. In the fear-avoidance model, the experience of pain may lead to a catastrophizing response where a patient imagines the worst possible outcome. This response leads to avoidance and fear and can result in a negative and deleterious cycle. While in non-specific low back pain the importance of fear avoidance beliefs on the prognosis and treatment efficacy has been shown [37-40], the impact of catastrophizing on treatment efficacy has not be assessed systematically.

Further, the influence of fear avoidance beliefs on pre- and postoperative improvement in patients with LSS has not yet been fully understood and has hardly been investigated. Few studies have addressed the impact of psychological variables on treatment outcome in patients with LSS. The potential relevance of fear avoidance in LSS patients may be assumed based on a cross-sectional study comparing patients with lumbar spinal stenosis with neurogenic claudication to patients with claudication due to peripheral arterial disease and asymptomatic patients [41]. In this study patients with LSS and neurogenic claudication reported higher fear avoidance beliefs than patients with claudication due to other illnesses. How high fear avoidance influences the treatment outcome in patients with LSS has not been fully understood. There is a wide variation in rates of improvement in patients after surgery. Various factors may influence chronic postsurgical complaints being a major concern because it can affect patient recovery and quality of life after surgery $[42,43]$. Therefore, the identification of prognostic indicators for treatment outcome in patients with LSS is of utmost importance. 


\section{Aim and research questions}

The aim of this thesis was to evaluate and understand important aspects of lumbar spinal stenosis. In view of this aim we addressed the following research questions:

- $\square$ Is it possible to identify specific MRI parameters associated with pain in patients with lumbar spinal stenosis (Chapter 2)?

- $\square$ What are the arguments of surgeons when choosing a specific type of surgical treatment for a patient (Chapter 3)?

- $\square$ Do obese patients have less clinical improvement after surgery for symptomatic degenerative lumbar spinal stenosis compared to non-obese patients (Chapter 4)?

- $\square$ What is the influence of catastrophizing on the treatment response in patients with low back pain (Chapter 5$)$ ?

- $\square$ What is the influence of high pre- and postoperative fear avoidance beliefs on pain and disability in patients with degenerative lumbar spinal stenosis after decompression surgery (Chapter 6)?

The studies were performed at the Horten Center for Patient Oriented Research and Knowledge Transfer, University of Zurich, Switzerland, and the Faculty of Health, Medicine and Life Sciences, Maastricht University, Maastricht, Netherlands. 


\section{References}

1. Deyo RA. Treatment of lumbar spinal stenosis: a balancing act. The spine journal : official journal of the North American Spine Society. 2010 Jul;10(7):625-7. PubMed PMID: 20620984.

2. Kalichman L, Cole R, Kim DH, Li L, Suri P, Guermazi A, et al. Spinal stenosis prevalence and association with symptoms: the Framingham Study. The spine journal : official journal of the North American Spine Society. 2009 Jul;9(7):545-50. PubMed PMID: 19398386. Pubmed Central PMCID: 3775665.

3. Deyo RA, Mirza SK, Martin BI, Kreuter W, Goodman DC, Jarvik JG. Trends, major medical complications, and charges associated with surgery for lumbar spinal stenosis in older adults. JAMA. 2010 Apr 7;303(13):1259-65. PubMed PMID: 20371784. Pubmed Central PMCID: 2885954.

4. Atlas SJ, Keller RB, Wu YA, Deyo RA, Singer DE. Long-term outcomes of surgical and nonsurgical management of lumbar spinal stenosis: 8 to 10 year results from the maine lumbar spine study. Spine (Phila Pa 1976). 2005 Apr 15;30(8):936-43. PubMed PMID: 15834339.

5. Weinstein JN, Tosteson TD, Lurie JD, Tosteson A, Blood E, Herkowitz H, et al. Surgical versus nonoperative treatment for lumbar spinal stenosis four-year results of the Spine Patient Outcomes Research Trial. Spine (Phila Pa 1976). 2010 Jun 15;35(14):1329-38. PubMed PMID: 20453723. Pubmed Central PMCID: 3392200.

6. Kreiner DS, Shaffer WO, Baisden JL, Gilbert TJ, Summers JT, Toton JF, et al. An evidence-based clinical guideline for the diagnosis and treatment of degenerative lumbar spinal stenosis (update). The spine journal : official journal of the North American Spine Society. 2013 Jul;13(7):734-43. PubMed PMID: 23830297.

7. Genevay S, Atlas SJ. Lumbar Spinal Stenosis. Best Pract Res Cl Rh. 2010 Apr;24(2):253-65. PubMed PMID: WOS:000276679600010. English.

8. Amundsen T, Weber H, Nordal HJ, Magnaes B, Abdelnoor M, Lilleas F. Lumbar spinal stenosis: conservative or surgical management?: A prospective 10-year study. Spine (Phila Pa 1976). 2000 Jun 1;25(11):1424-35; discussion 35-6. PubMed PMID: 10828926.

9. Sigmundsson FG, Kang XP, Jonsson B, Stromqvist B. Correlation between disability and MRI findings in lumbar spinal stenosis: a prospective study of 109 patients operated on by decompression. Acta Orthop. 2011 Apr;82(2):204-10. PubMed PMID: 21434811. Pubmed Central PMCID: PMC3235292. English.

10. Geisser ME, Haig AJ, Tong HC, Yamakawa KS, Quint DJ, Hoff JT, et al. Spinal canal size and clinical symptoms among persons diagnosed with lumbar spinal stenosis. Clin J Pain. 2007 Nov-Dec;23(9):780-5. PubMed PMID: 18075405. English.

11. Jensen MC, Brant-Zawadzki MN, Obuchowski N, Modic MT, Malkasian D, Ross JS. Magnetic resonance imaging of the lumbar spine in people without back pain. N Engl J Med. 1994 Jul 14;331(2):69-73. PubMed PMID: 8208267.

12. Kim HJ, Suh BG, Lee DB, Lee GW, Kim DW, Kang KT, et al. The influence of pain sensitivity on the symptom severity in patients with lumbar spinal stenosis. Pain Physician. 2013;16(2):135-44.

13. Haig AJ, Tong HC, Yamakawa KS, Quint DJ, Hoff JT, Chiodo A, et al. Spinal stenosis, back pain, or no symptoms at all? A masked study comparing radiologic and electrodiagnostic diagnoses to the clinical impression. Arch Phys Med Rehabil. 2006 Jul;87(7):897-903. PubMed PMID: 16813774. English.

14. Ishimoto Y, Yoshimura N, Muraki S, Yamada H, Nagata K, Hashizume H, et al. Associations between radiographic lumbar spinal stenosis and clinical symptoms in the general population: the Wakayama Spine Study. Osteoarthritis Cartilage. 2013 Jun;21(6):783-8. PubMed PMID: 23473979. English.

15. Boden SD, Davis D, Dina T, Patronas N, Wiesel S. Abnormal magnetic-resonance scans of the lumbar spine in asymptomatic subjects. A prospective investigation. The Journal of Bone \& Joint Surgery. 1990;72(3):403-8.

16. Andreisek G, Deyo RA, Jarvik JG, Porchet F, Winklhofer SFX, Steurer J, et al. Consensus conference on core radiological parameters to describe lumbar stenosis - an initiative for structured reporting. European Radiology. 2014 Dec;24(12):3224-32. PubMed PMID: WOS:000345141300027. English.

17. Genevay S, Atlas SJ, Katz JN. Variation in Eligibility Criteria From Studies of Radiculopathy due to a Herniated Disc and of Neurogenic Claudication due to Lumbar Spinal Stenosis A Structured Literature Review. Spine. 2010 Apr 1;35(7):803-11. PubMed PMID: WOS:000276833500014. English. 
18. Mamisch N, Brumann M, Hodler J, Held U, Brunner F, Steurer J, et al. Radiologic Criteria for the Diagnosis of Spinal Stenosis: Results of a Delphi Survey. Radiology. 2012 Jul;264(1):174-9. PubMed PMID: WOS:000305626500020. English.

19. Department of Health. Canton of Zurich2013 [Personal Communication in April 2015].

20. Cadosch D, Gautschi OP, Fournier JY, Hildebrandt G. [Lumbar spinal stenosis--claudicatio spinalis. Pathophysiology, clinical aspects and treatment]. Praxis (Bern 1994). 2008 Nov 19;97(23):1231-41. PubMed PMID: 19016422. Lumbale Spinalkanalstenose - Claudicatio spinalis. Pathophysiologie, Klinische Aspekte und Therapie.

21. Patel N, Bagan B, Vadera S, Maltenfort MG, Deutsch H, Vaccaro AR, et al. Obesity and spine surgery: relation to perioperative complications. J Neurosurg Spine. 2007 Apr;6(4):291-7. PubMed PMID: 17436915. Epub 2007/04/18. eng.

22. WHO. The challenge of obesity [February 2016]. Available from: http://www.euro.who.int/en/healthtopics/noncommunicable-diseases/obesity/data-and-statistics.

23. Fransen M, Woodward M, Norton R, Coggan C, Dawe M, Sheridan N. Risk factors associated with the transition from acute to chronic occupational back pain. Spine (Phila Pa 1976). 2002 Jan 1;27(1):92-8. PubMed PMID: 11805644. Epub 2002/01/24. eng.

24. Leboeuf-Yde C, Kyvik KO, Bruun NH. Low back pain and lifestyle. Part II--Obesity. Information from a population-based sample of 29,424 twin subjects. Spine (Phila Pa 1976). 1999 Apr 15;24(8):779-83; discussion 83-4. PubMed PMID: 10222529. Epub 1999/05/01. eng.

25. Marcus DA. Obesity and the impact of chronic pain. Clin J Pain. 2004 May-Jun;20(3):186-91. PubMed PMID: 15100595. Epub 2004/04/22. eng.

26. Pi-Sunyer X. The medical risks of obesity. Postgrad Med. 2009 Nov;121(6):21-33. PubMed PMID: 19940414. Pubmed Central PMCID: 2879283. Epub 2009/11/27. eng.

27. Rihn JA, Kurd M, Hilibrand AS, Lurie J, Zhao W, Albert T, et al. The influence of obesity on the outcome of treatment of lumbar disc herniation: analysis of the Spine Patient Outcomes Research Trial (SPORT). J Bone Joint Surg Am. 2013 Jan 2;95(1):1-8. PubMed PMID: 23192403. Pubmed Central PMCID: 3528022. Epub 2012/11/30. eng.

28. Webb R, Brammah T, Lunt M, Urwin M, Allison T, Symmons D. Prevalence and predictors of intense, chronic, and disabling neck and back pain in the UK general population. Spine (Phila Pa 1976). 2003 Jun 1;28(11):1195202. PubMed PMID: 12782992. Epub 2003/06/05. eng.

29. Gepstein R, Shabat S, Arinzon ZH, Berner Y, Catz A, Folman Y. Does obesity affect the results of lumbar decompressive spinal surgery in the elderly? Clin Orthop Relat R. 2004 Sep(426):138-44. PubMed PMID: WOS:000223708600023. English.

30. Rihn JA, Radcliff K, Hilibrand AS, Anderson DT, Zhao W, Lurie J, et al. Does obesity affect outcomes of treatment for lumbar stenosis and degenerative spondylolisthesis? Analysis of the Spine Patient Outcomes Research Trial (SPORT). Spine (Phila Pa 1976). 2012 Nov 1;37(23):1933-46. PubMed PMID: 22614793. Pubmed Central PMCID: 3757558. Epub 2012/05/23. eng.

31. Shamji MF, Parker S, Cook C, Pietrobon R, Brown C, Isaacs RE. Impact of body habitus on perioperative morbidity associated with fusion of the thoracolumbar and lumbar spine. Neurosurgery. 2009 Sep;65(3):490-8; discussion 8. PubMed PMID: 19687694.

32. Hoy D, March L, Brooks P, Blyth F, Woolf A, Bain C, et al. The global burden of low back pain: estimates from the Global Burden of Disease 2010 study. Ann Rheum Dis. 2014 Jun;73(6):968-74. PubMed PMID: 24665116.

33. van Tulder M, Becker A, Bekkering T, Breen A, del Real MTG, Hutchinson A, et al. Chapter 3 - European guidelines for the management of acute nonspecific low back pain in primary care. European Spine Journal. 2006 Mar;15:S169-S91. PubMed PMID: WOS:000237742400004. English.

34. Hildebrandt J, Ursin H, Mannion AF, Airaksinen O, Brox JI, CEDRASCHI C, et al. European guidelines for the management of chronic non-specific low back pain. Norway: European Commission, Research DirectorateGeneral, Department of Policy, Co-ordination and Strategy. 2004.

35. National Health Committee. New Zealand Acute Low Back Pain Guide. New Zealand: National Advisory Committee on Health and Disability, Accident Rehabilitation and Compensation Insurance Corporation, 2004. 
36. Linton SJ, Shaw WS. Impact of psychological factors in the experience of pain. Phys Ther. 2011 May;91(5):700-11. PubMed PMID: 21451097.

37. Wertli MM, Burgstaller JM, Weiser S, Steurer J, Kofmehl R, Held U. Influence of catastrophizing on treatment outcome in patients with nonspecific low back pain: a systematic review. Spine (Phila Pa 1976). 2014 Feb 1;39(3):263-73. PubMed PMID: 24253796.

38. Wertli MM, Eugster R, Held U, Steurer J, Kofmehl R, Weiser S. Catastrophizing-a prognostic factor for outcome in patients with low back pain: a systematic review. The spine journal : official journal of the North American Spine Society. 2014 Nov 1;14(11):2639-57. PubMed PMID: 24607845.

39. Wertli MM, Rasmussen-Barr E, Held U, Weiser S, Bachmann LM, Brunner F. Fear-avoidance beliefs-a moderator of treatment efficacy in patients with low back pain: a systematic review. The spine journal : official journal of the North American Spine Society. 2014 Nov 1;14(11):2658-78. PubMed PMID: 24614254.

40. Wertli MM, Rasmussen-Barr E, Weiser S, Bachmann LM, Brunner F. The role of fear avoidance beliefs as a prognostic factor for outcome in patients with nonspecific low back pain: a systematic review. The spine journal : official journal of the North American Spine Society. 2014 May 1;14(5):816-36 e4. PubMed PMID: 24412032.

41. Wood DW, Haig AJ, Yamakawa KSJ. Fear of movement/(re)injury and activity avoidance in persons with neurogenic versus vascular claudication. Spine Journal. 2012 Apr;12(4):292-300. PubMed PMID: WOS:000304807900006. English.

42. Brodner G, Mertes N, Buerkle H, Marcus MA, Van Aken H. Acute pain management: analysis, implications and consequences after prospective experience with 6349 surgical patients. Eur J Anaesthesiol. 2000 Sep;17(9):566-75. PubMed PMID: 11029124.

43. Theunissen M, Peters ML, Bruce J, Gramke HF, Marcus MA. Preoperative anxiety and catastrophizing: a systematic review and meta-analysis of the association with chronic postsurgical pain. Clin J Pain. 2012 NovDec;28(9):819-41. PubMed PMID: 22760489. 



\section{Chapter 2}

\section{Is there an association between pain}

and magnetic resonance imaging parameters in patients with lumbar spinal stenosis?

Jakob M. Burgstaller, M.D., D.M.D.

Peter J. Schüffler, Ph.D. Joachim M. Buhmann, Ph.D. Gustav Andreisek, M.D., M.B.A. Sebastian Winklhofer, M.D. Filipo del Grande, M.D. Michèle Mattle, M.Sc. Florian Brunner, M.D., Ph.D. Georgios Karakoumis, M.D. Johann Steurer, M.D. Ulrike Held, Ph.D. 


\section{Abstract}

Study design: Prospective multi-center cohort study.

Objective: To identify an association between pain and magnetic resonance imaging (MRI) parameters in patients with lumbar spinal stenosis (LSS).

Summary of Background Data: To the present, the relationship between abnormal MRI findings and pain in patients with LSS is still unclear.

Methods: First, we conducted a systematic literature search. We identified relationships of relevant MRI parameters and pain in patients with LSS. Second, we addressed the study question with a thorough descriptive and graphical analysis to establish a relationship between MRI parameters and pain using data of the lumbar spinal stenosis outcome study (LSOS).

Results: In the systematic review including four papers about the associations between radiological findings in the $\mathrm{MRI}$ and pain, the authors of two articles reported no association and two of them did. Of the latter, only one study found a moderate correlation between leg pain measured by Visual Analogue Scale (VAS) and the degree of stenosis assessed by spine surgeons. In the data of the LSOS study we could not identify a relevant association between any of the MRI parameters and buttock, leg and back pain, quantified by the Spinal Stenosis Measure (SSM) and the Numeric Rating Scale (NRS). Even by restricting the analysis to the level of the lumbar spine with the most prominent radiological 'stenosis' no relevant association could be shown.

Conclusion: Despite a thorough analysis of the data we were not able to prove any correlation between radiological findings (MRI) and the severity of pain. There is a need for innovative 'methods/techniques' to learn more about the causal relationship between radiological findings and the patients' pain related complaints. 


\section{Introduction}

Lumbar spinal stenosis (LSS) is the most frequent indication for spine surgery in patients older than 65 years [1]. The definition of LSS by the North American Spine Society - "[...] diminished space available for the neural and vascular elements in the lumbar spine secondary to degenerative changes in the spinal canal. When symptomatic, this causes a variable clinical syndrome of gluteal and/or lower extremity pain and/or fatigue which may occur with or without back pain. [...]" - includes both clinical (neurogenic claudication) and radiological (morphological abnormalities) criteria [2]. To the present, the relationship between abnormal magnetic resonance imaging (MRI) findings and pain is still debated [3-7]. It has been shown that symptoms often poorly correlate with radiologic findings [4]. Ishimoto et al. [8] reported that a substantial number of asymptomatic persons showed a moderate or even severe narrowing of the spinal canal (defined as more than $1 / 3$ or $2 / 3$ area loss, respectively) in the MRI. Two other studies also found asymptomatic patients, however, their patient samples were much smaller [4, 9]. Nevertheless, MRI is broadly used in establishing the diagnosis of LSS. Furthermore, MRI is used for recommending treatment to patients with LSS, in particular, radiological findings are used for preoperative planning.

The aims of this article are 1) to systematically identify and analyze published articles on the relationship between MRI findings and pain in patients with lumbar spinal stenosis, and 2) to search for MRI parameters that are associated with pain using data of the LSOS (lumbar spinal stenosis outcome study).

\section{Methods}

The approach to answer the study questions uses a two-step approach. First, we conducted a systematic literature search to identify clinically relevant MRI parameters in patients with lumbar spinal stenosis. Second, we addressed the study question with a thorough descriptive and graphical analysis to establish a relationship between MRI parameters and pain using data of the first 150 patients of the lumbar spinal stenosis outcome study 
(LSOS) who had an MR image. The LSOS is a multi-centre prospective cohort study that includes patients with neurogenic claudication and findings of lumbar spinal stenosis in MRI [10]. The LSOS was conducted in compliance with all international laws and regulations as well as any applicable guidelines. The study was approved by the independent Ethics Committee of the Canton Zurich (KEK-ZH-NR: 2010-0395/0).

\section{Step 1 - Systematic literature review}

\section{Literature Search}

We identified all studies meeting our eligibility criteria (defined in detail below) published in the last 15 years. The following databases were searched in May 2014: Cochrane Library, Embase, and Medline. The search was conducted by an experienced librarian. Search terms included various terms for MRI (e.g., magnetic resonance imaging, MR imaging, MRI) and questionnaires to assess pain (e.g. Spinal Stenosis Measure). The detailed search strategy in Embase is shown in Appendix 2.1. In addition, bibliographies of included studies relevant to the research question were searched and potential eligible references included in the full text review.

\section{Eligibility Criteria}

All studies were considered eligible for inclusion in further analyses that met the following criteria: the term "stenosis" must be mentioned in title or abstract, assessed the relationship between MRI parameters and validated questionnaires on pain in patients with symptomatic lumbar spinal stenosis. Studies were included if they were published within the last 15 years. No limits for the study setting or language of the publication were applied. Excluded were studies with patients of an age younger than 50 years, receiving or received any treatment, with neoplasia/cancer, fractures, injuries, infectious spine diseases, fibromyalgia, syndromes (e.g. Marfan syndrome), tuberculosis, cervical and thoracic spinal disorders, and examined/investigated by SPECT (single-photon emission computed tomography). 


\section{Study selection, data extraction and synthesis}

The bibliographic details of all retrieved articles were stored in an EndNote file [11]. Two reviewers (JB and $\mathrm{UH}$ ) independently screened all references by title and abstract. The full text of included studies was reviewed by both reviewers independently (JB and UH). Disagreements were discussed and resolved by consensus or by third party arbitration (JS). Alternative researchers with specific language proficiencies were used for non-English language references. In case of several publications for the same cohort without change in outcome or follow-up duration the most recent publication was chosen and missing information from the previous publication was added.

The search and inclusion/exclusion process is summarized in Figure 2.1. Out of 2030 records, 73 were reviewed in full text. For the final analysis we could include four publications. Reasons for the exclusion of 69 studies are provided in Figure 2.1.

Step 2 - Evaluation of association between pain and MRI parameters in patients of the LSOS study

\section{Patient selection}

The Lumbar Stenosis Outcome Study (LSOS) was conducted at eight medical centers (with approximately two million inhabitants in the catchment area) with Rheumatology and Spine Surgery Units in Switzerland. Patients with a history of neurogenic claudication and lumbar spinal stenosis verified by Magnetic Resonance Imaging (MRI) or Computer Tomography (CT) were eligible. Patients had no evidence of stenosis caused by tumor, fracture, infection, or significant deformity ( $>15^{\circ}$ lumbar scoliosis), and were aged 50 years or more. None of the patients had prior lumbar spine surgery. Furthermore, patients had no clinical peripheral artery occlusive disease (confirmed by a vascular specialist in patients without palpable pulses in the lower limb). 
Figure 2.1: Study flow

Number of records identified

through database search:

Embase $\mathrm{n}=1620$

Cochrane $n=151$

Medline $\mathrm{n}=907$

Total $\mathbf{n}=\mathbf{2 6 7 8}$

Number of records after
removal of duplicates:
Embase $\mathrm{n}=1102$
Cochrane $\mathrm{n}=\mathbf{3 6}$
Medline $\mathrm{n}=\mathbf{8 9 2}$
Total $\mathbf{n}=\mathbf{2 0 3 0}$
$\begin{aligned} & \text { Number of records screened } \\ & \text { for title and abstract: } \\ & \text { Total } \mathbf{n}=\mathbf{2 0 3 0}\end{aligned}$

Number of full-text articles assessed for eligibility:

Total $\mathbf{n}=\mathbf{7 3}$

Number of studies included in the analysis:

Total $n=4$
Number of records excluded after reading of title and abstract:

Total $\mathbf{n}=1957$

Number of full-text articles excluded:

Relationship/association not $n=21$ evaluated

No or partly stenosis patients* $\quad n=16$

No pain questionnaire $\quad n=5$

No questionnaire used $\quad n=5$

CT scans only or partly** $\quad n=5$

No clinical study $\quad n=4$

(Partly) asymptomatic subjects $\quad n=3$

(with stenosis)

Asymptomatic subjects $\quad n=3$

(at baseline)

Guideline or protocol $n=2$

No MRI scans $\quad n=2$

Letter to editor $n=1$

Review $n=1$

Questionnaire validating $\quad n=1$

Total $\mathbf{n}=\mathbf{6 9}$

* Partly stenosis patients: the study group consisted of stenosis and not stenosis patients

**CT scans partly: CT or MRI scans (not only MRI scans) 


\section{MRI parameters}

Data on 23 different MRI parameters, prospectively measured in each of the five lumbar spine levels, were available for each patient. The image analysis started at the superior endplate of the L1 and ended at the level of the vertebral disc L5/S1. Parameters, such as the compromise of the central zone, were assessed for each level at the height of the most severe stenosis, typically at the intervertebral disc level (e.g. L3/L4). Other parameters, such as vertebral body fracture, were evaluated at the corresponding vertebral body level (e.g. L3). The 23 parameters were measured in the context of the LSOS study because they were identified as important parameters prior to the start of LSOS in a consensus meeting among experts in the field [12]. The list of parameters is shown in Appendix 2.2 . Among those 23 parameters, Andreisek et al. [12] identified five core parameters which were: "compromise of central zone", "relation of fluid to nerve roots in the central canal", "nerve root compression in the lateral recess (right/left)", "compromise of the foraminal zone (right/left)", and "foraminal nerve root impingement (right/left)".

\section{Definition of outcome measures (pain)}

The instrument to quantify the outcome in the LSOS study is the pain domain of the Spinal Stenosis Measure (SSM) (also known as Swiss Spinal Stenosis Questionnaire, Zurich Claudication Questionnaire, or Brigham Spinal Stenosis Questionnaire) [13], a validated selfadministered questionnaire for patients with lumbar spinal stenosis. We did not restrict our pain outcomes to the SSM, but included all relevant and validated questionnaires in the literature review. Among others, these included the Numeric Rating Scale (NRS), the visual analogue scale (VAS), and the McGill Pain Questionnaire (MPQ).

\section{Subscales of the Spinal Stenosis Measure (SSM)}

There are three subscales of the SSM: the symptom severity scale (seven items), the physical function scale (five items), and the satisfaction scale (six items). The symptom severity scale consists of two subdomains: pain domain ( 3 items) and neuroischemic ( 4 items). The SSM has been shown to be reproducible, internally consistent, valid, and reliable. The 
internal consistency ranged from 0.64 to 0.92 , the test-retest reliability from 0.82 to 0.96 $[13,14]$. For the evaluation in this paper, we focused on pain subdomain of the SSM (SSM pain), ranging from 1-5 (best-worst).

\section{Numeric Rating Scale (NRS)}

The NRS is used for general assessment of lumbar spinal stenosis symptoms such as lower back and/or leg pain and discomfort. Score range from 0-10 (best-worst) $[15,16]$.

\section{Association between SSM pain / NRS and MRI parameters}

For each patient there was one single value for each SSM pain and NRS, but MRI parameters were evaluated on five spinal levels (L1-L5). First, we searched for associations between MRI parameters in all five levels (full analysis). Second, we reduced each of the MRI parameters individually to the level with the most prominent value (restricted analysis).

\section{Statistical analysis}

We used descriptive statistics for the clinical findings, socio-demographic variables, and MRI parameters. For continuous variables, median and interquartile ranges were calculated; categorical variables were displayed as number and percentage of total. Graphical representations including scatter plots and Spearman correlation coefficients were used to search for an association between SSM pain / NRS and MRI measurements at baseline. Analyses were performed using the R statistical software for Windows [17]. 


\section{Results}

Findings from the systematic review of the literature

\section{Study characteristics}

We identified two studies, including 138 patients, published 2011 and 2012 demonstrating an association between MRI parameters and pain. We identified two further studies, including 144 patients, published 2007 and 2013, which showed no association between MRI parameters and pain.

\section{Findings}

Table 2.1 summarizes the MRI and clinical parameters as well as the applied statistical method and the author's conclusion for both studies that found a relation. One study [18] used the degree (none, mild, moderate, severe) of stenosis (overall, central, lateral recess, foramen) as MRI parameter, the other study [7] the cross-sectional area $\left(\mathrm{mm}^{2}\right)$ of the dural sac. In both studies VAS was used to quantify pain. The statistical methods were different between both studies.

Table 2.2 summarizes the relevant information from the studies showing no association. One study [3] used the anteroposterior spinal canal diameter and the other study [6] a grading of canal stenosis (ratio: cerebrospinal fluid/rootlet, based on the method by Schizas [19]) as MRI parameters. The former assessed pain with VAS whereas the latter used the MPQ. 
Table 2.1: Summary of studies that found a specific relation between MRI parameters and clinical parameters

\begin{tabular}{|c|c|c|c|c|}
\hline Study, year & $\begin{array}{l}\text { MRI parame- } \\
\text { ter }\end{array}$ & $\begin{array}{l}\text { Clinical parame- } \\
\text { ter }\end{array}$ & Statistical method & Result/conclusion \\
\hline $\begin{array}{l}\text { Lavelle, } \\
2012^{18}\end{array}$ & $\begin{array}{l}\text { Degree of } \\
\text { stenosis } \\
\text { (none, mild, } \\
\text { moderate, } \\
\text { severe) }\end{array}$ & VAS leg pain & Linear regression & $\begin{array}{l}\text { VAS leg pain was found to } \\
\text { correlate well with surgeon } \\
\text { assessed MRI imaging findings } \\
\text { (overall stenosis } p=0.012 \text {, cen- } \\
\text { tral } p=0.05 \text {, lateral recess } \\
p=0.023 \text {, foramen } p=0.074 \text { ). }\end{array}$ \\
\hline $\begin{array}{l}\text { Sigmunds- } \\
\text { son, } 2011^{7}\end{array}$ & $\begin{array}{l}\text { Cross- } \\
\text { sectional area } \\
\text { of the dural } \\
\operatorname{sac}\left(\mathrm{mm}^{2}\right)\end{array}$ & $\begin{array}{l}\text { VAS }(100 \mathrm{~mm}) \\
\text { low back / leg } \\
\text { pain }\end{array}$ & $\begin{array}{l}\text { Pearson's correla- } \\
\text { tion }\end{array}$ & $\begin{array}{l}\text { Patients with multilevel stenosis } \\
\text { had better general health ( } p= \\
0.04 \text { ) and less leg and back pain } \\
\text { despite having smaller dural sac } \\
\text { area than patients with single- } \\
\text { level stenosis. There was a poor } \\
\text { correlation between walking } \\
\text { distance, ODI, the SF-36, EQ-5D, } \\
\text { and leg and back pain levels on } \\
\text { the one hand and dural sac area } \\
\text { on the other. }\end{array}$ \\
\hline
\end{tabular}

MRI, magnetic resonance imaging; ODI, Oswestry Disability Index; VAS: Visual Analog Scale

Table 2.2: Summary of studies that found no specific relation between MRI parameters and clinical parameters

\begin{tabular}{|c|c|c|c|c|}
\hline Study, year & $\begin{array}{l}\text { MRI parame- } \\
\text { ter }\end{array}$ & $\begin{array}{l}\text { Clinical parame- } \\
\text { ter }\end{array}$ & $\begin{array}{l}\text { Statistical meth- } \\
\text { od }\end{array}$ & Result/conclusion \\
\hline $\begin{array}{l}\text { Geisser, } \\
2007^{3}\end{array}$ & $\begin{array}{l}\text { Osseous } \\
\text { anteroposte- } \\
\text { rior spinal } \\
\text { canal diame- } \\
\text { ter }\end{array}$ & $\mathrm{MPQ}$ & $\begin{array}{l}\text { Pearson's corre- } \\
\text { lation }\end{array}$ & $\begin{array}{l}\text { Anteroposterior spinal canal } \\
\text { diameter is not predictive of } \\
\text { clinical symptoms associated } \\
\text { with lumbar spinal stenosis. } \\
\text { (Anterior-posterior spinal canal } \\
\text { diameter was not significantly } \\
\text { associated with any of the } \\
\text { clinical symptom measures } \\
\text { examined.) }\end{array}$ \\
\hline Kim, $2013^{6}$ & $\begin{array}{l}\text { Grading of } \\
\text { canal stenosis } \\
\text { (ratio: cere- } \\
\text { brospinal fluid } \\
\text { / rootlet, } \\
\text { based on the } \\
\text { method by } \\
\text { Schizas }^{19} \text { ) }\end{array}$ & $\begin{array}{l}\text { VAS (100 mm) } \\
\text { back / leg pain }\end{array}$ & $\begin{array}{l}\text { Analysis of vari- } \\
\text { ance }\end{array}$ & $\begin{array}{l}\text { There was no significant associa- } \\
\text { tion between the grade of canal } \\
\text { stenosis and VAS for back } \\
\text { pain/leg pain and ODI. }\end{array}$ \\
\hline
\end{tabular}


Association between SSM pain / NRS and most prominent MRI parameters in patients of the LSOS study

\section{Patient characteristics}

A total of 150 patients were included in this analysis (Table 2.3). Median patient age was 75 years (interquartile range (IQR): 67-80). Seventy-six patients were female (50.7\%), and $99(66 \%)$ suffered from symptoms more than twelve months. Of the study population 101 (67.3\%) patients hold higher education degree (no university) and 17 (11.3\%) hold a university degree. Median SSM pain was 4 (IQR: 3.3-4), and median NRS value was 7 (IQR: $5-8)$.

\section{Results from lumbar spine MRIs}

Descriptive statistics for radiologic parameters indicating lumbar spinal stenosis of the 150 patients are summarized in Table 2.4. To assess relationships between segment-wise MRI readouts and pain outcomes, we started with calculating Spearman correlation coefficients. In addition, we produced scatterplots of these pairs. We only found very weak correlations between any MRI parameters and clinical outcomes. We restricted the analysis to the most prominent segment for the five core [12] and three additional quantitative MRI parameters ("anteroposterior diameter of dural sac", "cross-sectional area of dural tube/sac", "depth of lateral recess (right/left)"). The Spearman correlation coefficients for the restricted analysis varied between -0.22 (compromise of the foraminal zone, left) and 0.1 (depth of lateral recess, right) for SSM pain. Similar values were found for the correlation with NRS: the Spearman correlations varied between -0.26 (foraminal nerve root impingement, left) and 0.24 (depth of lateral recess, right). The resulting scatterplots for the five core and three additional quantitive MRI parameters (resulting in 12 parameters when right/left was differentiated) read out by a senior radiologist (board certified, fellowship-trained, with 13 years in spinal imaging) versus SSM pain domain and NRS is shown in Figures 2.2 and 2.3. 
Table 2.3: Baseline characteristics of the 150 patients of the LSOS study

\begin{tabular}{ll} 
Characteristics $(\mathbf{n}=\mathbf{1 5 0})$ & \\
\hline Age, median (IQR) (years) & $75(67-80)$ \\
Gender, $\mathrm{n}(\%)$ & $76(50.7)$ \\
Female & $74(49.3)$ \\
Male & $168(160-174.8)$ \\
Height, median (IQR) (cm) & $78(67.3-89.3)$ \\
Weight, median (IQR) (kg) & $26.7(24-30.5)$ \\
BMI, median (IQR) (kg/m²) & \\
Educational level, $\mathrm{n}(\%)$ & $31(20.7)$ \\
Compulsory education & $101(67.3)$ \\
High school & $17(11.3)$ \\
College, university & $1(0.7)$ \\
Not specified & \\
Duration of symptoms, $\mathrm{n}(\%)$ & $11(7.3)$ \\
$<3$ months & $16(10.7)$ \\
3-6 months & $18(12)$ \\
6-12 months & $99(66)$ \\
$>12$ months & $6(4)$ \\
Not specified & $10(6.5-12.5)$ \\
CIRS total score, median (IQR) & \\
SSM, median (IQR) & $4(3.3-4)$ \\
SSM Pain domain & $7(5-8)$ \\
NRS &
\end{tabular}

BMI: Body Mass Index; CIRS, Cumulative Illness Rating Scale; IQR, interquartile range; NRS, Numeric Rating Scale; SSM, Spinal Stenosis Measure 
Table 2.4: Baseline MRI parameters of the 150 patients of the LSOS study measured at each of five segments (read out by senior radiologist)

\begin{tabular}{|c|c|c|}
\hline MRI parameter & n segments analyzed & \\
\hline Axial images not available, $\mathrm{n}$ segments (\%) & & 89 (11.9) \\
\hline Segment fracture, $\mathrm{n}$ segments (\%) & 750 & $20(2.7)$ \\
\hline Discus grading (Pfirrman classification), $\mathrm{n}$ segments (\%) & 747 & \\
\hline Grade 1 & & $12(1.6)$ \\
\hline Grade 2 & & $96(12.9)$ \\
\hline Grade 3 & & $202(27)$ \\
\hline Grade 4 & & $303(40.6)$ \\
\hline Grade 5 & & 134 (17.9) \\
\hline Modic classification, $\mathrm{n}$ segments (\%) & 750 & \\
\hline Normal & & $448(59.7)$ \\
\hline 1 & & $33(4.4)$ \\
\hline 2 & & $258(34.4)$ \\
\hline 3 & & $11(1.5)$ \\
\hline Listhesis, $\mathrm{n}$ segments (\%) & 750 & $115(15.3)$ \\
\hline Osteoarthritis facet joint right, $\mathrm{n}$ segments (\%) & 654 & $502(76.8)$ \\
\hline Osteoarthritis facet joint left, $\mathrm{n}$ segments (\%) & 655 & $503(76.8)$ \\
\hline Flavum hypertrophy right, $\mathrm{n}$ segments (\%) & 656 & $353(53.8)$ \\
\hline Flavum thickness right, median (IQR) (mm) & 654 & $5(4-6)$ \\
\hline Flavum hypertrophy left, $\mathrm{n}$ segments (\%) & 656 & $360(54.9)$ \\
\hline Flavum thickness left, median (IQR) (mm) & 655 & $5(4-6)$ \\
\hline Lipomatosis grade (Borré classification), n segments (\%) & 662 & \\
\hline Grade 0 & & $593(89.6)$ \\
\hline Grade 1 & & $62(9.4)$ \\
\hline Grade 2 & & $6(0.9)$ \\
\hline Grade 3 & & $1(0.2)$ \\
\hline Compromise of central zone, $\mathrm{n}$ segments (\%) & 659 & \\
\hline no & & $129(19.6)$ \\
\hline mild & & $314(47.6)$ \\
\hline moderate & & $119(18.1)$ \\
\hline severe & & $97(14.7)$ \\
\hline Relation from fluid to cauda equina, $\mathrm{n}$ segments (\%) & 659 & \\
\hline Grade A1 & & $291(44.2)$ \\
\hline Grade A2 & & 95 (14.4) \\
\hline Grade A3 & & $74(11.2)$ \\
\hline Grade A4 & & $14(2.1)$ \\
\hline Grade B & & $61(9.3)$ \\
\hline Grade C & & $97(14.7)$ \\
\hline Grade D & & $27(4.1)$ \\
\hline
\end{tabular}


Table 2.4 continued

MRI parameter

Nerve root compression in the lateral recess right, $\mathrm{n}$ segments

(\%)

Grade 0

Grade 1

Grade 2

Grade 3

Nerve root compression in the lateral recess left, $\mathrm{n}$ segments (\%)

Grade 0

Grade 1

Grade 2

Grade 3

Foraminal nerve root impingement right, $\mathrm{n}$ segments (\%)

Grade 0

Grade 1

Grade 2

Grade 3

Foraminal nerve root impingement left, $\mathrm{n}$ segments (\%)

Grade 0

Grade 1

Grade 2

Grade 3

Compromise of the foraminal zone right, $\mathrm{n}$ segments (\%)

no

mild

moderate

severe

Compromise of the foraminal zone left, $\mathrm{n}$ segments (\%)

no

mild

moderate

severe

Anteroposterior diameter of dural sac, median (IQR) (mm)

Cross-sectional area of dural tube/sac, median (IQR) $\left(\mathrm{mm}^{2}\right)$

Depth of lateral recess right, median (IQR) (mm)

Depth of lateral recess left, median (IQR) (mm)

$I Q R$, interquartile range n segments analyzed

659

$225(34.1)$

$193(29.3)$

97 (14.7)

144 (21.9)

659

216 (32.8)

$196(29.7)$

98 (14.9)

149 (22.6)

750

$558(74.4)$

113 (15.1)

39 (5.2)

40 (5.3)

750

575 (76.7)

108 (14.4)

32 (4.3)

35 (4.7)

750

333 (44.4)

245 (32.7)

99 (13.2)

73 (9.7)

749

320 (42.7)

259 (34.6)

108 (14.4)

62 (8.3)

659

$10(8-12)$

659

120 (80-168)

659

4 (2-5)

659

$3(2-5)$ 
Figure 2.2: Scatter plots of Spinal Stenosis Measure (SSM) Pain Domain against each of the five core and three additional quantitive MRI parameters. Most extreme value (maximum or minimum) over the five spinal levels is plotted for each MRI variable. Spearman correlation coefficient $=r$.
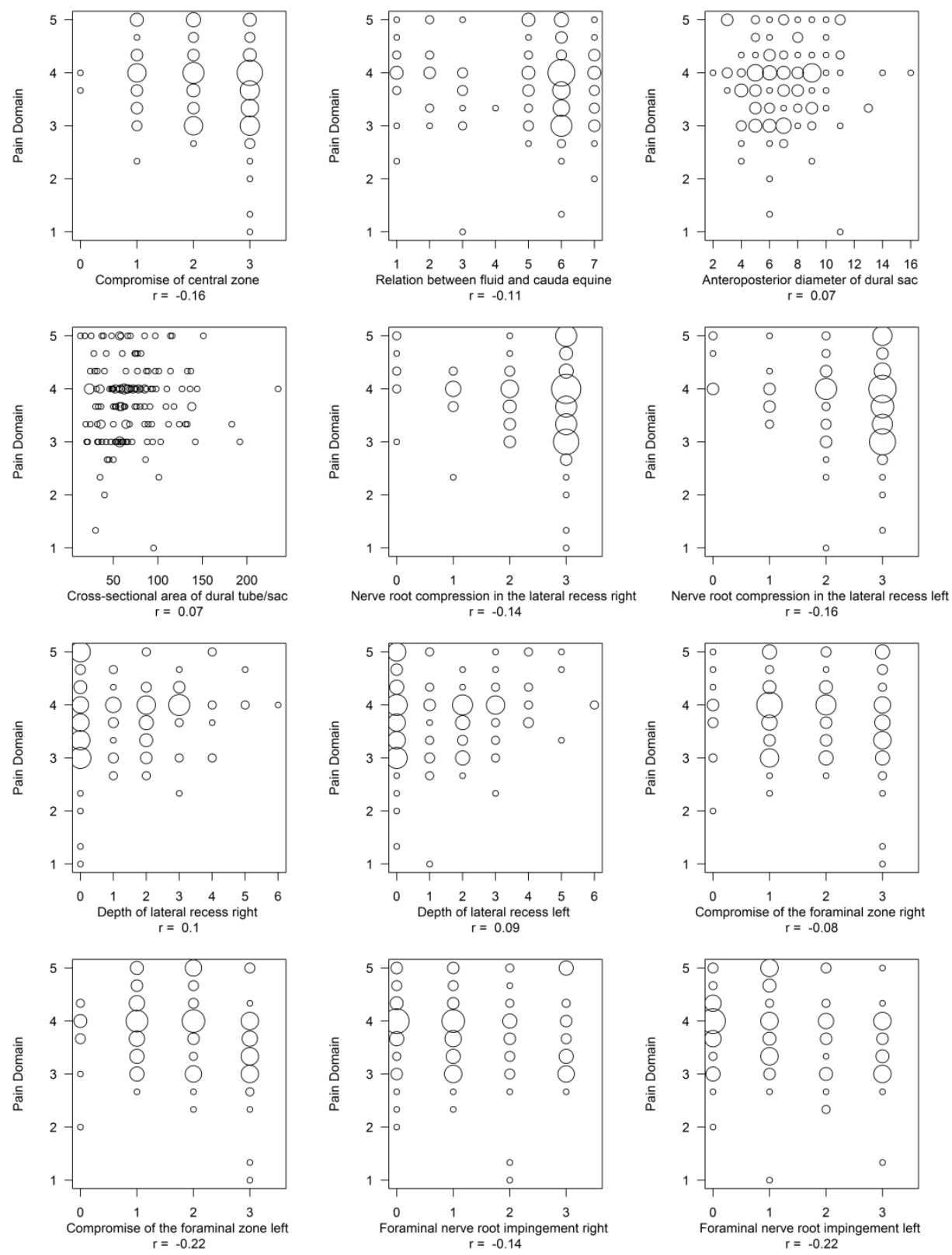
Figure 2.3: Scatter plot of Numeric Rating Scale (NRS) against each of the five core and three additional quantitive MRI parameters. Most extreme value (maximum or minimum) over the five spinal levels is plotted for each MRI variable. Spearman correlation coefficient $=r$.
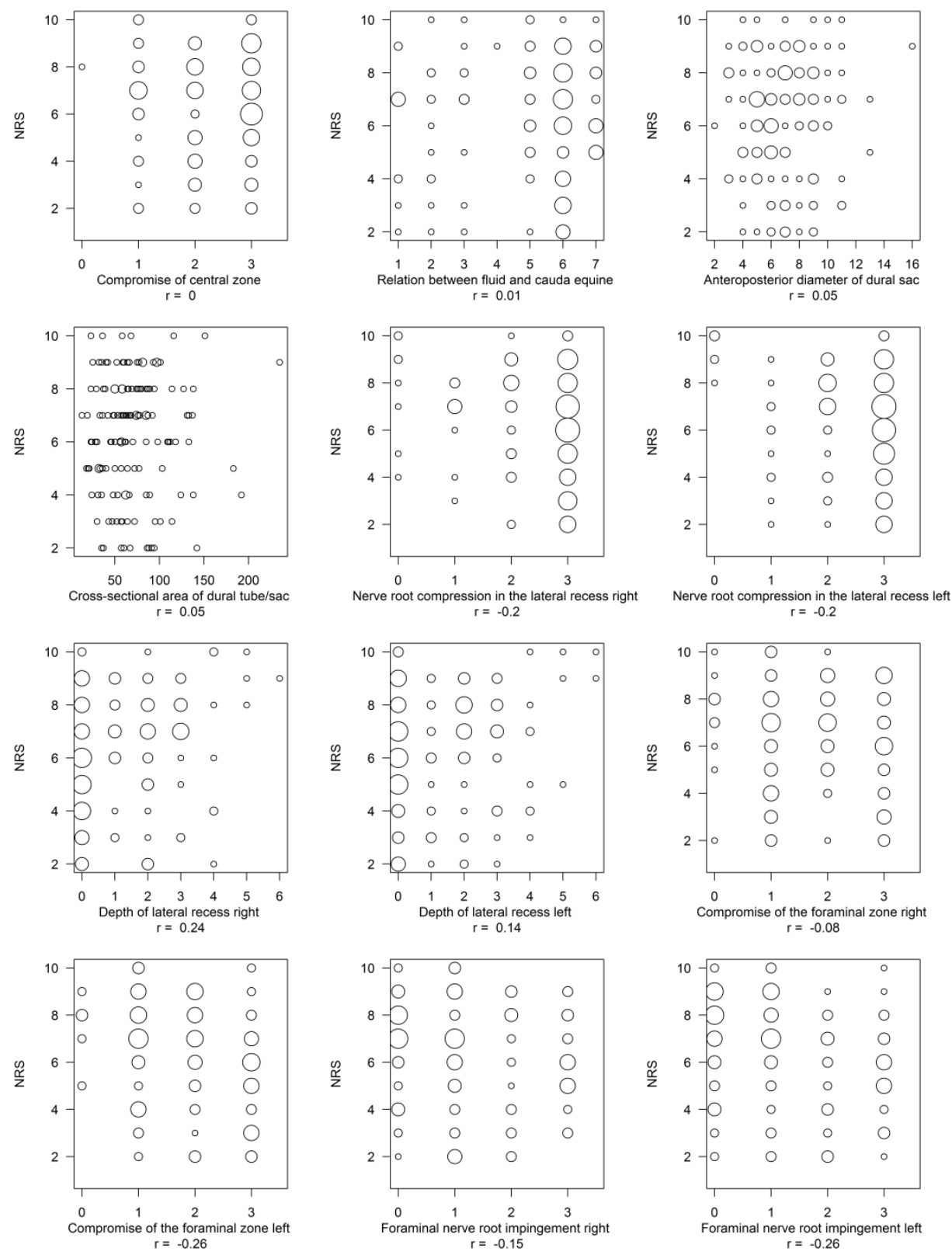


\section{Discussion}

\section{Main findings}

The results of this paper are twofold. In the systematic review, including four papers about the associations between radiological findings in the MRI and pain, the authors of two articles reported no association and two of them did. Lavelle et al. [18] stated that the degree of stenosis, assessed by spine surgeons in the MRI, was associated with leg pain quantified by a Visual Analogue Scale (VAS). Sigmundsson et al. [7] reported a weak correlation between leg/back pain (VAS) and the size of the dural sac area. In the data of the LSOS study we could not identify a statistically relevant association between any of the multiple MRI parameters and buttock, leg and back pain, quantified by SSM pain. Even by restricting the analysis to the level of the lumbar spine with the most prominent radiological 'stenosis' no relevant association could be shown.

In contrast to our analysis the four studies $[3,6,7,18]$ included in the systematic review assessed only up to three different MRI parameters with various clinical outcomes. The results of our study support the results of at least two of the earlier studies $[3,6]$ whereas the other two studies found no strong associations $[7,18]$.

\section{Implications for practice}

In some patients the diagnosis of lumbar spinal stenosis is straightforward. At least in patients who complain about neurogenic claudication - pain in buttocks and/or legs provoked by walking or standing and relieved by sitting and bending forward - and a stenosis on only one spinal level verified by MRI. In such cases it seems reasonable to assume that the singular narrowing causes the symptoms and surgical decompression on the corresponding level will relieve symptoms of the patient with high probability. In many patients with neurogenic claudication the lumbar spine MRI shows not a singular stenosis, but rather stenoses on more than one level. In the SPORT's trial about $60 \%$ of included patients had moderate or severe stenoses on two or more levels of the lumbar spine [20]. In the LSOS cohort $43 \%$ had stenoses on more than one level. These multilocular stenoses in 
the MRI are a major challenge for the surgeons. So far MRI findings seem not to be very helpful to tell the surgeon which radiological findings are causal for the symptoms what makes it difficult to decide which stenoses the surgeon needs to decompress. The nonexistent or weak association between radiological findings and symptoms might explain to some extent that more than one third of patients report no clinically relevant improvement after surgery $[20,21]$.

\section{Implications for research}

It is crucial to understand the causal associations between clinical symptoms and radiologic findings, in particular for spine surgeons in planning the kind of surgery. Multiple dependencies between the MRI parameters, measured at each of five spinal levels, require variable selection before model fitting. Due to the large number of potential multiple models, more sophisticated statistical methods like machine learning approaches or model averaging could be applied. Furthermore, other imaging procedures should be considered. The spinal canal is a dynamic structure and the diameters vary by changing posture and by bodily activities [6]. Consequently, a static image of the lumbar canal in the supine (position) may not represent the dimensions of the spinal canal during standing or walking. Another approach to get to know more about why these patients suffer from intermittent episodes of pain could be the assessment of blood circulation in the spinal region or the functional assessment of the nerve roots and peripheral nerves. It is assumed and some evidence supports the thesis that obstruction of the blood circulation - arterial and/or venous - is causal for the intermittent character of the pain [22]. Nerve function might be assessed by new imaging modalities such as high resolution MR neurography or diffusion tensor imaging $[23,24]$. These latter approaches might raise the question whether morphological-based MRI parameters represent valuable biomarkers at all.

\section{Strengths and limitations}

One limitation of this study is that different MRI scanners were in charge for the image acquisition of the multicenter LSOS study, which could have led to some bias as only 
standard sagittal T1 and T2 weighted as well as axial T2 weighted images were available for image analysis. Fat-suppressed fluid-sensitive MR images are considered standard of care for lumbar spine imaging but they have not been implemented in all participating study centers of the LSOS study and were thus not considered mandatory for this study population. However, with respect to the recent literature and to our own experience, we recommend the inclusion of fluid-sensitive MRI sequences (such as Short-Tau Inversion Recovery [STIR] sequences) in patients with known or suspected LSS to detect unexpected subtle fractures, tumor involvement or Modic 1 end-plate changes of the lumbar spine [25-27]. Furthermore, MRI scans were performed in supine position which is currently standard of care. In addition, we did not investigate into the inter-reader reliability of the MRI image analysis.

Our study has several strengths. The $23 \mathrm{MRI}$ parameters which we used for the evaluation of our own data, were predefined in an international consensus meeting [12] and based on the best available evidence in the literature [28-30]. Compared to studies analysed in the systematic review, our approach included eight different MRI parameters. In addition to the frequently used NRS or VAS, respectively, our study was the only one that measured pain with the pain domain subscale of the SSM as recommended by the North American Spine Society (NASS) [31] to be the "gold standard" to quantify complaints in patients with lumbar spinal stenosis. However, complaints of pain severity are extremely subjective and depend on the individual processing of nociceptive information [32, 33].

\section{Conclusion}

Despite a thorough analysis of the data we were not able to prove any correlation between radiological findings (MRI) and the severity of pain. There is a need for innovative 'methods/techniques' to learn more about the causal relationship between radiological findings and the patients' pain related complaints. 


\section{References}

1. Deyo RA: Treatment of lumbar spinal stenosis: a balancing act. The spine journal : official journal of the North American Spine Society 2010, 10(7):625-627.

2. Kreiner DS, Shaffer WO, Baisden JL, Gilbert TJ, Summers JT, Toton JF, Hwang SW, Mendel RC, Reitman CA: An evidence-based clinical guideline for the diagnosis and treatment of degenerative lumbar spinal stenosis (update). Spine Journal 2013, 13(7):734-743.

3. Geisser ME, Haig AJ, Tong HC, Yamakawa KS, Quint DJ, Hoff JT, Miner JA, Phalke VV: Spinal canal size and clinical symptoms among persons diagnosed with lumbar spinal stenosis. Clin J Pain 2007, 23(9):780-785.

4. Haig AJ, Tong HC, Yamakawa KS, Quint DJ, Hoff JT, Chiodo A, Miner JA, Choksi VR, Geisser ME, Parres CM: Spinal stenosis, back pain, or no symptoms at all? A masked study comparing radiologic and electrodiagnostic diagnoses to the clinical impression. Arch Phys Med Rehabil 2006, 87(7):897-903.

5. Jensen MC, Brant-Zawadzki MN, Obuchowski N, Modic MT, Malkasian D, Ross JS: Magnetic resonance imaging of the lumbar spine in people without back pain. N Engl J Med 1994, 331(2):69-73.

6. Kim HJ, Suh BG, Lee DB, Lee GW, Kim DW, Kang KT, Chang BS, Lee CK, Yeom JS: The influence of pain sensitivity on the symptom severity in patients with lumbar spinal stenosis. Pain Physician 2013, 16(2):135-144.

7. Sigmundsson FG, Kang XP, Jonsson B, Stromqvist B: Correlation between disability and MRI findings in lumbar spinal stenosis: a prospective study of 109 patients operated on by decompression. Acta Orthop 2011, 82(2):204-210.

8. Ishimoto Y, Yoshimura N, Muraki S, Yamada H, Nagata K, Hashizume H, Takiguchi N, Minamide A, Oka H, Kawaguchi $\mathrm{H}$ et al: Associations between radiographic lumbar spinal stenosis and clinical symptoms in the general population: the Wakayama Spine Study. Osteoarthritis Cartilage 2013, 21(6):783-788.

9. Boden SD, Davis D, Dina T, Patronas N, Wiesel S: Abnormal magnetic-resonance scans of the lumbar spine in asymptomatic subjects. A prospective investigation. The Journal of Bone \& Joint Surgery 1990, 72(3):403-408.

10. Steurer J, Nydegger A, Held U, Brunner F, Hodler J, Porchet F, Min K, Mannion AF, Michel B, LumbSten Research C: LumbSten: the lumbar spinal stenosis outcome study. BMC Musculoskelet Disord 2010, 11:254.

11. EndNote [http://www.endnote.com/]

12. Andreisek G, Deyo RA, Jarvik JG, Porchet F, Winklhofer SF, Steurer J, On behalf of the Lwg: Consensus conference on core radiological parameters to describe lumbar stenosis - an initiative for structured reporting. European radiology 2014

13. Stucki G, Daltroy L, Liang MH, Lipson SJ, Fossel AH, Katz JN: Measurement properties of a self-administered outcome measure in lumbar spinal stenosis. Spine 1996, 21(7):796-803.

14. Wertli MM, Steurer J, Wildi LM, Held U: Cross-cultural adaptation of the German version of the spinal stenosis measure. European spine journal : official publication of the European Spine Society, the European Spinal Deformity Society, and the European Section of the Cervical Spine Research Society 2014, 23(6):1309-1319.

15. Downie WW, Leatham PA, Rhind VM, Wright V, Branco JA, Anderson JA: Studies with pain rating scales. Ann Rheum Dis 1978, 37(4):378-381.

16. Kremer E, Atkinson JH, Ignelzi RJ: Measurement of pain: patient preference does not confound pain measurement. Pain 1981, 10(2):241-248.

17. R: A language and environment for statistical computing. [http://www.R-project.org/]

18. Lavelle WF, Tallarico R, Madom IA, Palumbo MA, Metkar US, Marawar S, Butzen BP, Fredrickson BE: Comparison of surgeon assessed stenosis and validated patient functional outcome scores. Spine Journal 2012, 12(9):117S-118S.

19. Schizas C, Theumann N, Burn A, Tansey R, Wardlaw D, Smith FW, Kulik G: Qualitative grading of severity of lumbar spinal stenosis based on the morphology of the dural sac on magnetic resonance images. Spine 2010, 35(21):1919-1924.

20. Weinstein JN, Tosteson TD, Lurie JD, Tosteson A, Blood E, Herkowitz H, Cammisa F, Albert T, Boden SD, Hilibrand A et al: Surgical versus nonoperative treatment for lumbar spinal stenosis four-year results of the Spine Patient Outcomes Research Trial. Spine (Phila Pa 1976) 2010, 35(14):1329-1338. 
21. Atlas SJ, Keller RB, Wu YA, Deyo RA, Singer DE: Long-term outcomes of surgical and nonsurgical management of lumbar spinal stenosis: 8 to 10 year results from the maine lumbar spine study. Spine (Phila Pa 1976) 2005, 30(8):936-943.

22. Kobayashi S, Suzuki Y, Meir A, Al-Khudairi N, Nakane T, Hayakawa K: Circulatory dynamics of the cauda equina in lumbar canal stenosis using dynamic contrast-enhanced magnetic resonance imaging. The spine journal : official journal of the North American Spine Society 2015.

23. Eppenberger $P$, Andreisek G, Chhabra A: Magnetic resonance neurography: diffusion tensor imaging and future directions. Neuroimaging Clin N Am 2014, 24(1):245-256.

24. Birnbaum J, Duncan T, Owoyemi K, Wang KC, Carrino J, Chhabra A: Use of a novel high-resolution magnetic resonance neurography protocol to detect abnormal dorsal root Ganglia in Sjogren patients with neuropathic pain: case series of 10 patients and review of the literature. Medicine (Baltimore) 2014, 93(3):121-134.

25. Del Grande F, Santini F, Herzka DA, Aro MR, Dean CW, Gold GE, Carrino JA: Fat-suppression techniques for 3T MR imaging of the musculoskeletal system. Radiographics 2014, 34(1):217-233.

26. Gellhorn AC, Katz JN, Suri P: Osteoarthritis of the spine: the facet joints. Nat Rev Rheumatol 2013, 9(4):216224.

27. Lalkadamyali H, Tarhan NC, Ergun T, Cakir B, Agildere AM: STIR Sequence for Depiction of Degenerative Changes in Posterior Stabilizing Elements in Patients with Lower Back Pain. Am J Roentgenol 2008, 191(4):973979.

28. Andreisek G, Imhof M, Wertli M, Winklhofer S, Pfirrmann CW, Hodler J, Steurer J, Lumbar Spinal Stenosis Outcome Study Working Group Z: A systematic review of semiquantitative and qualitative radiologic criteria for the diagnosis of lumbar spinal stenosis. AJR American journal of roentgenology 2013, 201(5):W735-746.

29. Mamisch N, Brumann M, Hodler J, Held U, Brunner F, Steurer J, Lumbar Spinal Stenosis Outcome Study Working Group Z: Radiologic criteria for the diagnosis of spinal stenosis: results of a Delphi survey. Radiology 2012, 264(1):174-179.

30. Steurer J, Roner S, Gnannt R, Hodler J, LumbSten Research C: Quantitative radiologic criteria for the diagnosis of lumbar spinal stenosis: a systematic literature review. BMC musculoskeletal disorders 2011, 12:175.

31. Watters WC, Baisden J, Gilbert TJ, Kreiner S, Resnick DK, Bono CM, Ghiselli G, Heggeness MH, Mazanec DJ, O'Neill C: Degenerative lumbar spinal stenosis: an evidence-based clinical guideline for the diagnosis and treatment of degenerative lumbar spinal stenosis. The spine journal 2008, 8(2):305-310.

32. Edwards RR, Sarlani E, Wesselmann U, Fillingim RB: Quantitative assessment of experimental pain perception: multiple domains of clinical relevance. Pain 2005, 114(3):315-319.

33. Ruscheweyh R, Verneuer B, Dany K, Marziniak M, Wolowski A, Colak-Ekici R, Schulte TL, Bullmann V, Grewe S, Gralow I et al: Validation of the pain sensitivity questionnaire in chronic pain patients. Pain 2012, 153(6):12101218. 
Appendix 2.1: Search History for Embase May 2014

\begin{tabular}{|c|c|c|}
\hline \# & Query & Results \\
\hline 1 & 'nuclear magnetic resonance imaging'/exp & $520 ’ 594$ \\
\hline 2 & $\begin{array}{l}\text { (('magnetization transfer' OR 'magnetisation transfer' OR 'magnetic resonance' } \\
\text { OR mr OR nmr OR 'proton spin' OR 'chemical shift') NEAR/3 (imaging OR tomogra- } \\
\text { phy)):ab,ti }\end{array}$ & $198^{\prime} 652$ \\
\hline 3 & \#1 OR \#2 & $543 ’ 591$ \\
\hline 4 & $\begin{array}{l}\text { 'hospital anxiety and depression score':ab,ti OR 'spinal stenosis measure- } \\
\text { ment':ab,ti OR 'fear avoidance believes questionnaire':ab,ti OR 'hopkins scl-k- } \\
\text { 9':ab,ti OR 'hopkins symptom checklist short version-9':ab,ti OR 'euroquol':ab,ti } \\
\text { OR 'roland and morris questionnaire':ab,ti OR 'core outcome measures in- } \\
\text { dex':ab,ti OR 'oswestry disability index':ab,ti OR 'short-form } 36 \text { ':ab,ti }\end{array}$ & $10^{\prime} 011$ \\
\hline 5 & $\begin{array}{l}\text { hads:ab,ti OR ssm:ab,ti OR fabq:ab,ti OR fess:ab,ti OR 'eq 5d':ab,ti OR rmq:ab,ti OR } \\
\text { rdq:ab,ti OR comi:ab,ti OR omi:ab,ti OR 'sf } 36 \text { ':ab,ti }\end{array}$ & $29^{\prime} 906$ \\
\hline 6 & 'short form 36'/exp & $11^{\prime} 736$ \\
\hline 7 & 'questionnaire'/exp & $390 ’ 522$ \\
\hline 8 & ((scoring OR rating OR measur* OR assess*) NEAR/3 (scale OR system)):ab,ti & $118^{\prime} 978$ \\
\hline 9 & $\begin{array}{l}\text { ((scor* OR rating OR measur* OR assess*) NEAR/5 (pain OR function OR satisfac- } \\
\text { tion)):ab,ti }\end{array}$ & $199^{\prime} 068$ \\
\hline 10 & \#4 OR \#5 OR \#6 OR \#7 OR \#8 OR \#9 & $684^{\prime} 079$ \\
\hline 11 & \#3 AND \#10 & $16^{\prime} 036$ \\
\hline 12 & 'backache'/exp OR 'spine disease'/exp & $201^{\prime} 429$ \\
\hline 13 & $\begin{array}{l}\text { 'back pain':ab,ti OR 'back pains':ab,ti OR 'back ache':ab,ti OR 'back aches':ab,ti OR } \\
\text { backache*:ab,ti }\end{array}$ & $41^{\prime} 123$ \\
\hline 14 & $\begin{array}{l}\text { ((lowback OR lumbal OR lumbar OR lumbosacral) NEAR/3 (pain* OR ache* OR } \\
\text { syndrome)):ab,ti }\end{array}$ & $5^{\prime} 276$ \\
\hline 15 & $\begin{array}{l}\text { lumbago:ab,ti OR lumbalgia:ab,ti OR lumbalgesia:ab,ti OR (lumbosacroiliac } \\
\text { NEAR/3 strain):ab,ti }\end{array}$ & $1^{\prime} 779$ \\
\hline 16 & ('intervertebral disc' NEAR/3 (degeneration OR displacement)):ab,ti & $1^{\prime} 213$ \\
\hline 17 & (spinal NEAR/3 (curvatures OR stenosis OR osteochondrosis)):ab,ti & $5 ’ 075$ \\
\hline 18 & spondylitis:ab,ti OR spondylosis:ab,ti & $19^{\prime} 438$ \\
\hline 19 & \#12 OR \#13 OR \#14 OR \#15 OR \#16 OR \#17 OR \#18 & $210^{\prime} 920$ \\
\hline 20 & \#11 AND \#19 & $1^{\prime} 544$ \\
\hline 21 & 'backache'/exp/dm_ep & 2'573 \\
\hline 22 & 'spine disease'/exp/dm_ep & 3’927 \\
\hline 23 & \#21 OR \#22 & $6 ’ 295$ \\
\hline 24 & 'epidemiology'/de OR 'morbidity'/de OR 'incidence'/exp OR 'prevalence'/exp & $949 ’ 826$ \\
\hline 25 & associat*:ti OR caus*:ti OR epidemiol*:ti OR correlat*:ti OR relat*:ti & $1^{\prime} 725^{\prime} 329$ \\
\hline 26 & \#24 OR \#25 & $2^{\prime} 534^{\prime} 701$ \\
\hline 27 & \#23 AND \#26 & $3^{\prime} 284$ \\
\hline 28 & \#3 AND \#27 & 243 \\
\hline
\end{tabular}


Appendix 2.1 continued

\begin{tabular}{llc}
$\#$ & Query & Results \\
\hline 29 & \#20 OR \#28 & 1 1'774 \\
30 & \#20 OR \#28 AND [animals]/lim & 27 \\
31 & \#20 OR \#28 AND [animals]/lim AND [humans]/lim & 15 \\
32 & \#30 NOT \#31 & 12 \\
33 & \#29 NOT \#32 & $1^{\prime} 762$ \\
34 & \#29 NOT \#32 AND [1998-2014]/py & $1^{\prime} 694$ \\
35 & \#34 AND 'case report'/de & 74 \\
36 & \#34 NOT \#35 & $1^{\prime} 620$ \\
37 & \#36 AND 'conference abstract'/it & 387 \\
38 & \#36 NOT \#37 & $1^{\prime 2} 233$
\end{tabular}

Appendix 2.2: MRI parameters per level (according to Andreisek et al. [12])

\begin{tabular}{|c|c|c|c|}
\hline No & MRI Parameter & Classification / Parameter Description & $\begin{array}{l}\text { Refer- } \\
\text { ence }\end{array}$ \\
\hline 1 & Segment Fracture & Yes / No & \\
\hline 2 & $\begin{array}{l}\text { Discus grading (Pfirr- } \\
\text { mann classification) }\end{array}$ & $\begin{array}{l}\text { Grade 1-5 according to structure, distinction of nucle- } \\
\text { us/anulus, signal intensity, and height of the disc }\end{array}$ & [34] \\
\hline 3 & Modic classification & $\begin{array}{l}\text { Normal; Modic 1: bone marrow oedema; } 2 \text { : bone marrow } \\
\text { conversion into fatty marrow; } 3 \text { : sclerosis }\end{array}$ & [35] \\
\hline 4 & Listhesis & Yes / No & {$[36]$} \\
\hline 5 & $\begin{array}{l}\text { Osteoarthritis facet } \\
\text { joint right }\end{array}$ & Yes / No & {$[37,38]$} \\
\hline 6 & $\begin{array}{l}\text { Osteoarthritis facet } \\
\text { joint left }\end{array}$ & Yes / No & {$[37,38]$} \\
\hline 7 & $\begin{array}{l}\text { Flavum hypertrophy } \\
\text { right }\end{array}$ & Yes / No & [37] \\
\hline 8 & Flavum thickness right & Measured in millimeters [mm] & {$[37,39]$} \\
\hline 9 & $\begin{array}{l}\text { Flavum hypertrophy } \\
\text { left }\end{array}$ & Yes / No & [37] \\
\hline 10 & Flavum thickness left & Measured in millimeters [mm] & {$[37,39]$} \\
\hline 11 & $\begin{array}{l}\text { Lipomatosis grading } \\
\text { (Borré classification) }\end{array}$ & $\begin{array}{l}\text { Grade } 0 \text { : normal amount of epidural fat; } 1 \text { : mild, 2: moderate; } \\
3 \text { : severe epidural fat overgrowth }\end{array}$ & {$[40]$} \\
\hline 12 & $\begin{array}{l}\text { Compromise of central } \\
\text { zone }\end{array}$ & $\begin{array}{l}\text { No: no compromise; mild: compromise of } \leq 1 / 3 \text {; moderate: } \\
\text { compromise of } 1 / 3-2 / 3 \text {; severe: compromise of }>2 / 3 \text { of its } \\
\text { normal size }\end{array}$ & [41] \\
\hline
\end{tabular}




\begin{tabular}{|c|c|c|c|}
\hline No & MRI Parameter & Classification / Parameter Description & $\begin{array}{l}\text { Refer- } \\
\text { ence }\end{array}$ \\
\hline 13 & $\begin{array}{l}\text { Relation between fluid } \\
\text { and cauda equine }\end{array}$ & $\begin{array}{l}\text { Grading based on the rootlet/cerebrospinal fluid ratio in axial } \\
\text { MRI images. Grades A1-A4 and B show cerebrospinal fluid } \\
\text { presence while grades } C \text { and D show none at all }\end{array}$ & [19] \\
\hline 14 & $\begin{array}{l}\text { Foraminal nerve root } \\
\text { impingement right }\end{array}$ & $\begin{array}{l}\text { Contact of disc material with nerve root; Grade 0: normal; } 1 \text { : } \\
\text { contact; } 2 \text { : deviation; } 3 \text { : compression }\end{array}$ & [42] \\
\hline 15 & $\begin{array}{l}\text { Foraminal nerve root } \\
\text { impingement left }\end{array}$ & see parameter No.14 & {$[42]$} \\
\hline 16 & $\begin{array}{l}\text { Nerve root compres- } \\
\text { sion in the lateral } \\
\text { recess right }\end{array}$ & $\begin{array}{l}\text { Grade } 0 \text { : no narrowing; } 1 \text { : narrowing, but no root compres- } \\
\text { sion; } 2 \text { : significant narrowing with the nerve root flattened } \\
\text { but with preservation of cerebrospinal fluid; } 3 \text { : severe root } \\
\text { compression }\end{array}$ & [43] \\
\hline 17 & $\begin{array}{l}\text { Nerve root compres- } \\
\text { sion in the lateral } \\
\text { recess left }\end{array}$ & see parameter No.16 & [43] \\
\hline 18 & $\begin{array}{l}\text { Compromise of the } \\
\text { foraminal zone right }\end{array}$ & $\begin{array}{l}\text { No: no compromise; mild: compromise of } \leq 1 / 3 \text {; moderate: } \\
\text { compromise of } 1 / 3-2 / 3 \text {; severe: compromise of }>2 / 3 \text { of its } \\
\text { normal size }\end{array}$ & [41] \\
\hline 19 & $\begin{array}{l}\text { Compromise of the } \\
\text { foraminal zone left }\end{array}$ & see parameter No. 18 & [41] \\
\hline 20 & $\begin{array}{l}\text { Anteroposterior diame- } \\
\text { ter of dural sac }\end{array}$ & Measured in millimeters [mm] & {$[46,47]$} \\
\hline 21 & $\begin{array}{l}\text { Cross-sectional area of } \\
\text { dural tube/sac }\end{array}$ & Measured in square millimeters $\left[\mathrm{mm}^{2}\right]$ & {$[42,43]$} \\
\hline 22 & $\begin{array}{l}\text { Depth of lateral recess } \\
\text { right }\end{array}$ & Measured in millimeters [mm] & {$[42,43]$} \\
\hline 23 & $\begin{array}{l}\text { Depth of lateral recess } \\
\text { left }\end{array}$ & Measured in millimeters [mm] & {$[42,43]$} \\
\hline
\end{tabular}






\section{Chapter 3}

\section{Arguments for the choice of surgical treatments in patients with lumbar}

\section{spinal stenosis - a systematic appraisal of randomized controlled trials}




\section{Abstract}

Background: Lumbar spinal stenosis is the most common reason for spinal surgery in elderly patients. However, the surgical management of spinal stenosis is controversial. The aim of this review was to list aspects a surgeon considers when choosing a specific type of treatment.

Methods: Appraisal of arguments reported in randomized controlled trials (RCTs) included in systematic reviews published or indexed in the Cochrane library studying surgical treatments in patients with spinal stenosis.

Results: Eight out of nine RCTs listed arguments for the choice of their treatments under investigation. The argument for decompression alone was the high success rate, the argument against was a potential increase in vertebral instability. The argument for decompression and fusion without instrumentation was that it is a well-established technique with a high fusion success rate, the argument against it was that the indication for fusion in spinal stenosis has remained unclear. The argument for decompression and fusion with instrumentation was an increased fusion rate compared to decompression and fusion without instrumentation, the argument against this was that the invasive procedure is associated with more complications.

Conclusions: The main argument identified in this appraisal for and against decompression alone in patient with lumbar spinal stenosis was whether or not instability should be treated with (instrumented) fusion procedures. However, there is disagreement on how instability should be defined. In a first step it is important that researchers and clinicians agree on definitions for important key concepts such as instability and reoperations. 


\section{Background}

The clinical entity lumbar spinal stenosis is the most common reason for spinal surgery in patients 65 years of age and older in the United States [1]. The clinical definition includes "buttock or lower extremity pain, which may occur with or without low back pain, associated with diminished space available for the neural and vascular elements in the lumbar spine" [2]. Herniated intervertebral discs and space-narrowing lesions caused by neoplasm or inflammation are in the strictest sense also causes of stenosis, but they usually are regarded as separate entities [3]. Neurogenic claudication (pain in the legs during walking with or without low back pain) is the main complaint of patients, caused by increased compression of intracanalar nervous structures. It has been shown that symptoms often poorly correlate with imaging studies [4].

The management of spinal stenosis is still controversial. For mild symptoms conservative treatment seems to be the natural choice although controlled clinical studies comparing conservative and surgical treatment are rare and little is known about the short- and long-term course of this approach [3]. When symptoms are severe and conservative treatment has failed, surgery is suggested. The type of surgery that should be performed remains also controversial [5]. Decompression seems to be the logical procedure that has the potential to give the patient immediate relief [3]. However, instability of the spine is a potential consequence that needs to be considered. The additional value of decompression and arthrodesis compared to decompression is debated [5]. It is still unclear which aspects and arguments influence the decision to choose the type of surgical treatment for a patient with spinal stenosis.

Therefore, the aim of this systematic appraisal of arguments for or against a type of surgical treatment was to list aspects a surgeon considers when choosing a specific type of treatment for a patient. 


\section{Methods}

\section{Study design}

Appraisal of arguments reported in randomized controlled trials (RCTs) included in systematic reviews published or indexed in the Cochrane library studying surgical treatments in patients with spinal stenosis. The Cochrane Collaboration Guideline has published guidelines for the standardized assessment of study quality in randomized controlled trials. Therefore, systematic reviews published or indexed in the Cochrane library meet high quality standards [6]. While this study is not a systematic review our reporting will be based on the recommendations of the PRISMA statement.

\section{Literature Search}

We searched the Cochrane library for the term "spinal stenosis" in the title, abstract, or keywords. Of the returned reviews, only RCTs that investigated efficacy of surgical treatments for patients with lumbar spinal stenosis were eligible for further analysis. Nonrandomized trials and observational studies were excluded. In published study protocol of systematic reviews which were potentially eligible, the authors were contacted for additional information.

\section{Eligibility Criteria}

Included were all RCTs that studied efficacy of surgical treatments for lumbar spinal stenosis. No limits for the study setting or language of the publication were applied. Excluded were RCTs that reported about disc replacement procedures, intradiscal electrotherapy, or RCTs with a control group which was treated with conservative methods.

\section{Study selection, data extraction and data synthesis}

The bibliographic details of all retrieved articles were stored in an Endnote file. Two reviewers (JB and $\mathrm{MW}$ ) independently screened all systematic reviews by title and abstract. All potentially eligible RCTs were included for the full text analysis. The full text was re- 
viewed by both reviewers independently (JB and MW) in all RCTs that met the pre-defined eligibility criteria $(n=63)$. Alternative researchers with specific language proficiencies were used for non-English language references. Arguments in study reports were extracted by two reviewers independently (JB and MW). Disagreements were discussed and resolved by consensus or by third party arbitration (FP). Arguments were assigned to the following groups by one reviewer (JB): decompression, decompression and fusion without instrumentation (hereinafter abbreviated to 'fusion' or 'fusion without instrumentation'), and decompression and fusion with instrumentation (hereinafter abbreviated to 'fusion with instrumentation' or 'instrumented fusion').

\section{Surgical procedures}

Decompression is defined as "the relief of pressure on one or many pinched nerves (neural impingement) of the spinal column" [7]. Several different techniques are summarized under the term decompression: partial or total laminectomy, hemilaminectomy, laminotomy, and medial facetectomy.

Fusion, also known as spondylodesis, is defined as "a surgical technique used to join two or more vertebrae". Bone graft, either from the patient (autograft), a donor (allograft), or bone substitute, is used in conjunction with the body's natural bone growth (osteoblastic) processes to fuse the vertebrae.

Fusion with instrumentation utilizes stainless steel, titanium (-alloy), or non-metallic devices to stabilize the spine.

Table 3.1 presents a more detailed overview over all surgical procedures.

\section{Ethics Statement}

This study does not involve human subjects. No ethical approval was required. No protocol was published or registered. All methods were determined a priori. 


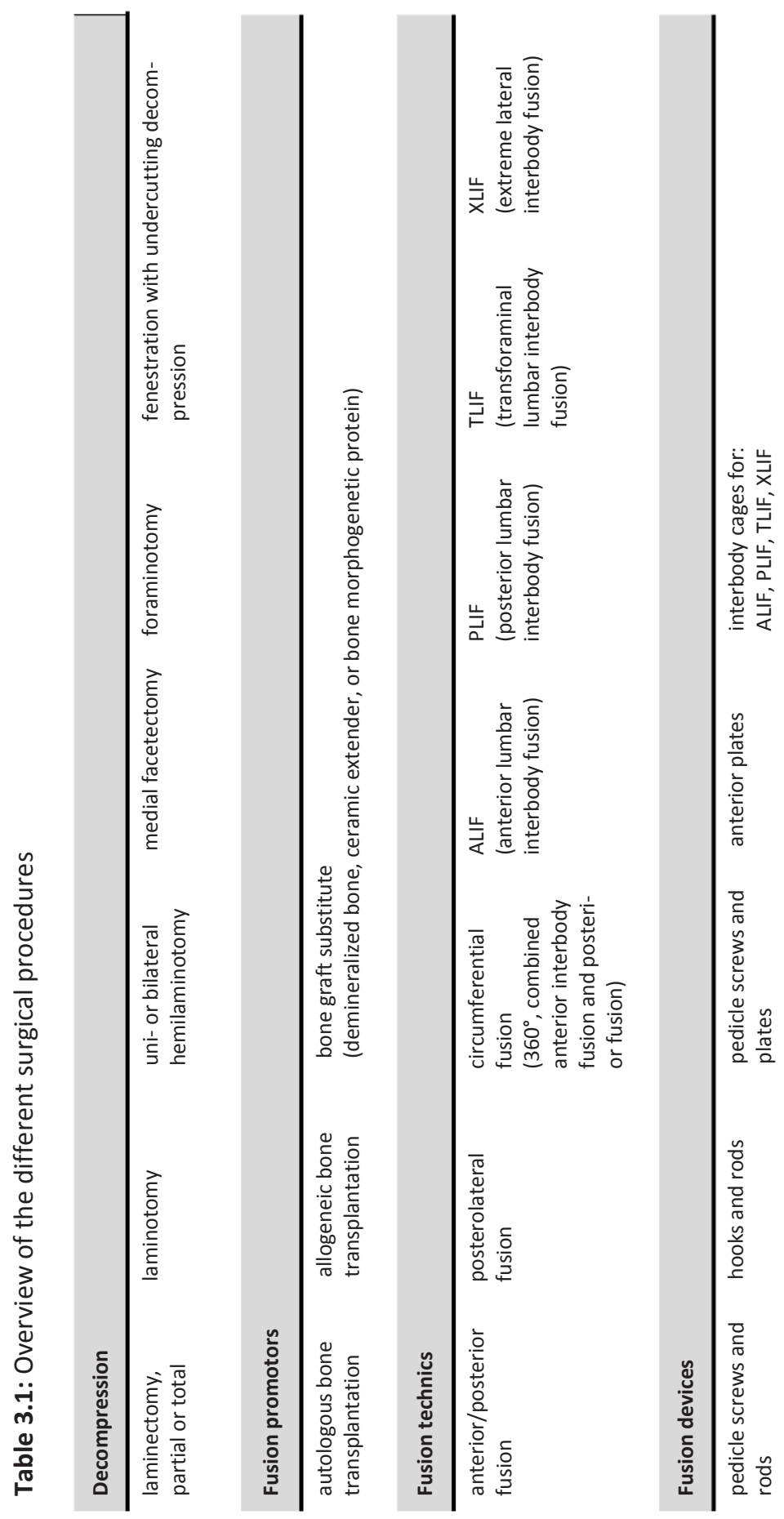




\section{Results}

\section{Study selection}

Figure 3.1 summarizes the search and inclusion process. Out of 24 systematic reviews, 6 systematic reviews were eligible for the current appraisal. Of the 6 systematic reviews 63 RCTs were reviewed in full text, resulting in exclusion of 54 RCTs. In total, the appraisal included 9 RCTs. Reasons for exclusion of 54 publications are given in Figure 3.1.

\section{Study characteristics}

The most recent systematic review identified was published in 2013 [8]. Six systematic reviews addressed the efficacy of surgical treatments for lumbar spinal stenosis (Table 3.2). The characteristics of the RCTs included in the current appraisal and the surgical procedures under investigation as well as the definitions of instability are summarized in Additional file 3.1. Two RCTs compared posterolateral fusion with posterolateral instrumented fusion [9, 10]. One RCT compared fusion and decompression [11]. One RCT compared instrumented fusion and decompression [12]. Two RCTs compared two different instrumented fusion procedures $[13,14]$. Two RCTs compared two decompression procedures $[15,16]$. One RCT compared fusion, instrumented fusion, and decompression [17]. Furthermore, only two RCTs $[12,16]$ defined the term "instability".

The most recent RCT was conducted in 2005 (range of year of publications 1991 2005). 
Figure 3.1: Study flow

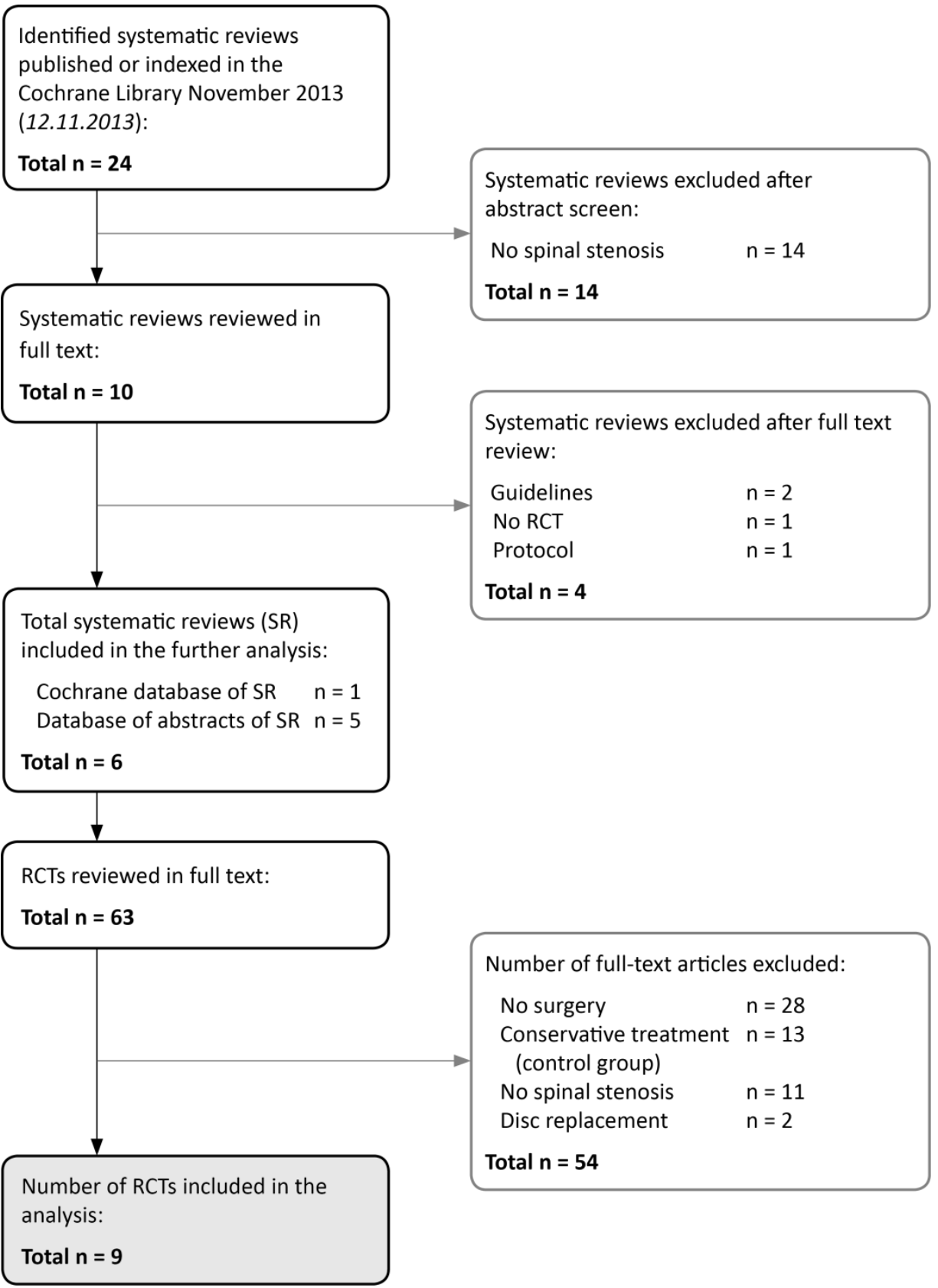




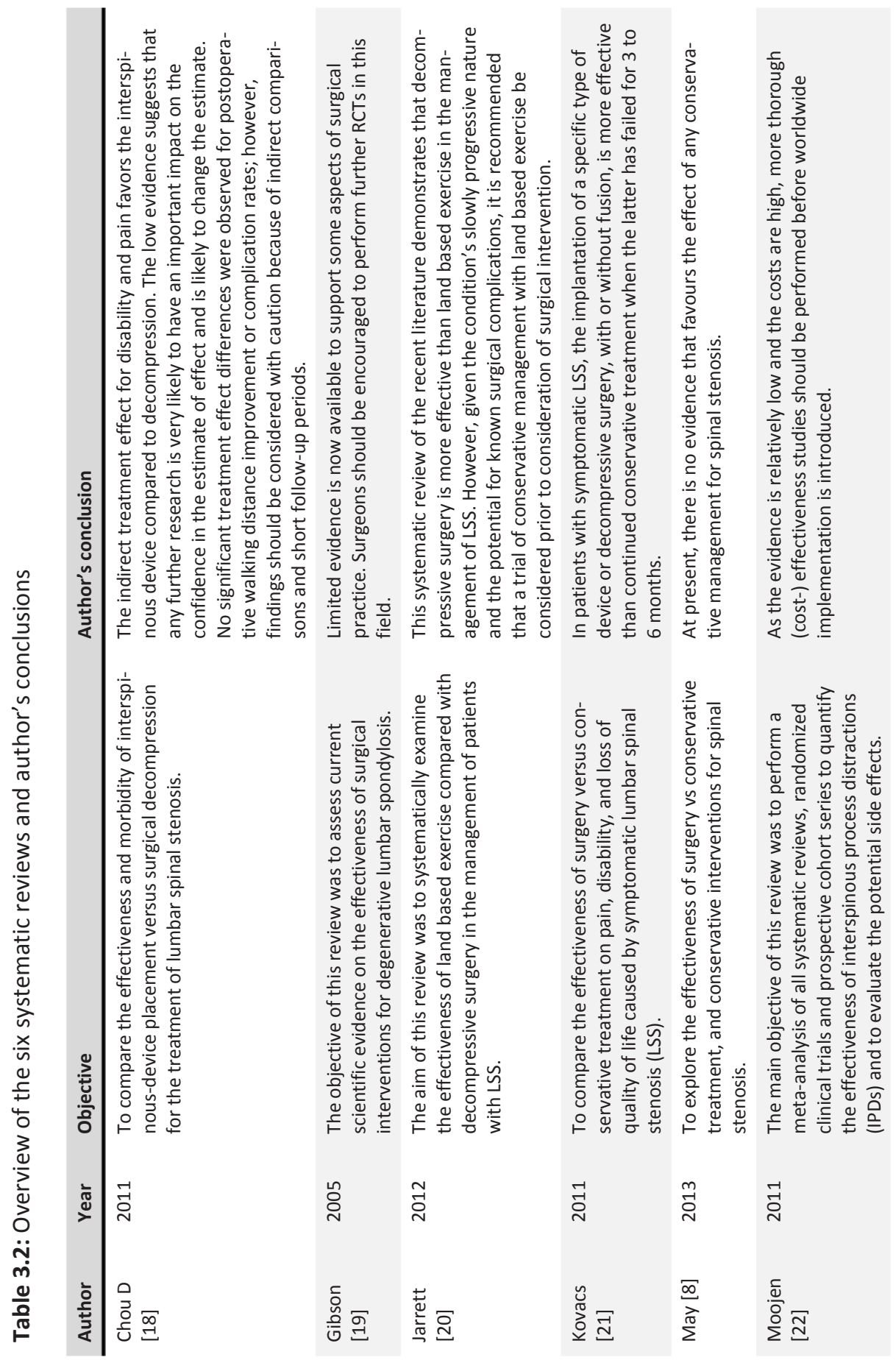




\section{Appraisal of Arguments for or against a surgical technique}

Of the 9 RCTs one provided no arguments for the choice of their treatments under investigation [17]. Of 8 RCTs arguments for or against a surgical technique were extracted. The arguments are summarized in Table $\mathbf{3} . \mathbf{3}$ and grouped into arguments for or against decompression alone, fusion, and fusion with instrumentation.

In three RCTs authors argued in favor of decompression alone compared to fusion with or without instrumentation. Three RCTs provided arguments against decompression alone. While four RCTs argued for fusion without instrumentation, two argued against. Three RCTs listed arguments for fusion with instrumentation and two RCTs against this surgical procedure.

\section{Decompression}

Arguments for decompression surgery emphasize the high success rates of decompression $(n=3)[11,13,16]$. The main argument against a decompression alone was an increase or cause of vertebral instability, respectively the spondylolisthesis progression after decompression alone $(n=3)[12,15,16]$. One RCT further argued that the continuous motion of the stenotic segments might compress the nerve roots as well as "produce osteophytes" $(n=1)[12]$.

\section{Decompression and fusion}

Most authors argued for posterolateral fusion because this technique is "done frequently" and well established $(n=2)[10,14]$, shows excellent results for degenerative spondylolisthesis $(n=1)$ [13], has a high observed fusion rates $(n=1)$ [10], and shows a significant improvement in clinical outcome $(n=1)$ [9]. The arguments against a posterolateral fusion were that less invasive procedure used for decompression leave the relative stability of the spine undisturbed $(n=1)$ [12], that degenerative changes (osteophytes, decreased disc height, calcified ligaments) increase the stability of the spine and thereby decreasing the need for an arthrodesis $(n=1)$ [12], and that the indications for fusion in spinal stenosis and degenerative lumbar spondylolisthesis have remained unclear $(n=1)$ [11]. 


\section{Decompression and fusion with instrumentation}

Arguments in favor of fusion with instrumentation included: increased fusion rate $(n=2)$ $[10,14]$, prevention of spondylolisthesis progression $(n=1)[10]$, and a high fusion rate and a high level of patient satisfaction in $360^{\circ}$ (circumferential) fusion $(n=1)$ [14]. Some authors quoted that fusion with instrumentation may improve fusion rate $(n=1)$ [9], may reduce rehabilitation time $(n=1)$ [9] and may improve patient outcome $(n=1)$ [9]. Further, that $270^{\circ}$ fusion may be effective $(n=1)$ [14], that pedicle screw fixation increases rigidity despite resection of the posterior elements $(n=1)[10]$, and that semirigid systems have been advocated of obtaining spinal stability without sacrificing vertebral body bone density $(n=1)[10]$. Authors that argued against instrumented fusion highlighted potential associated complications $(n=1)[10]$ as device related osteoporosis. Additionally, they quote the costs and use of great health care resources of the $360^{\circ}$ (circumferential) procedure $(n=1)$ [14]. 


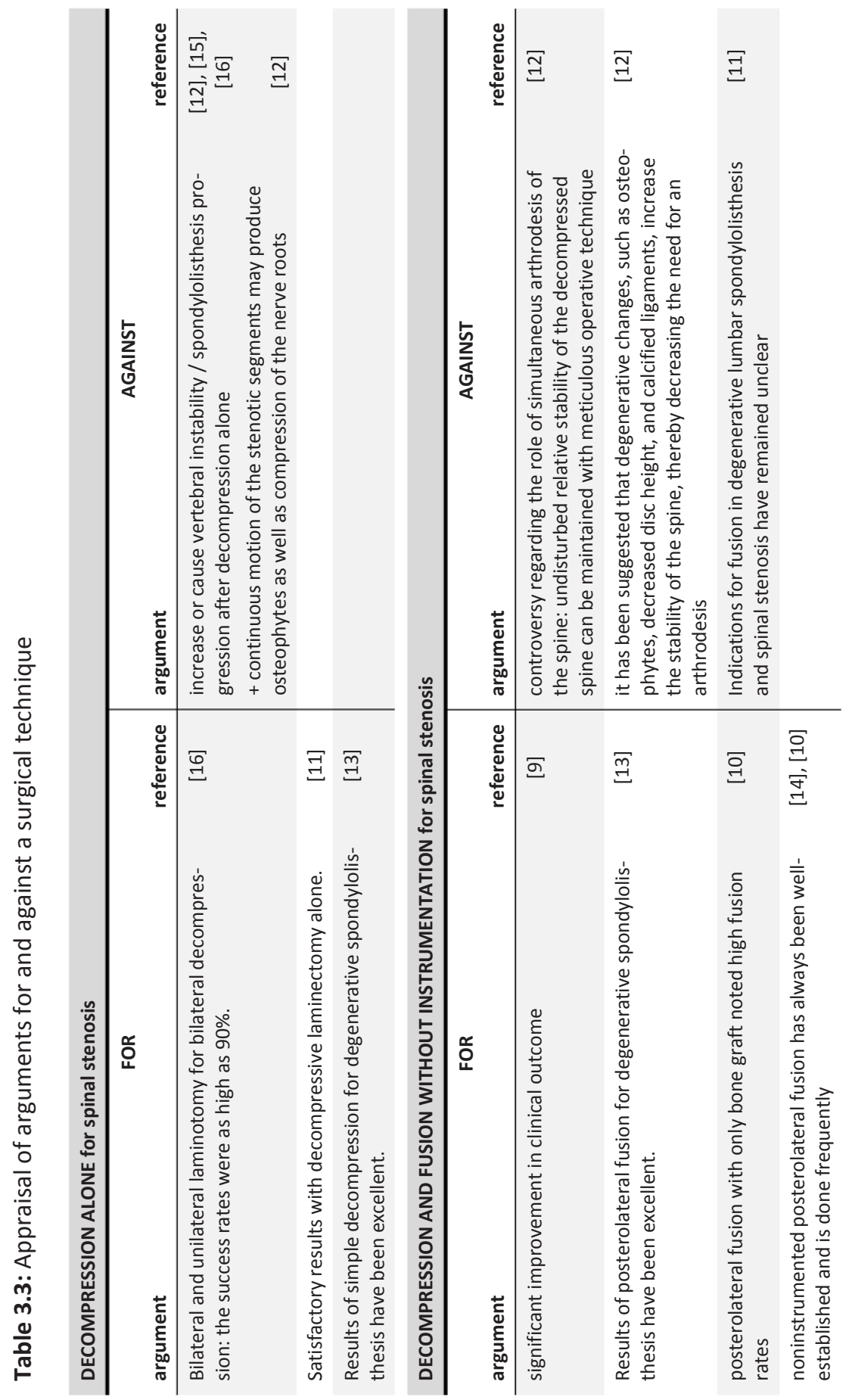




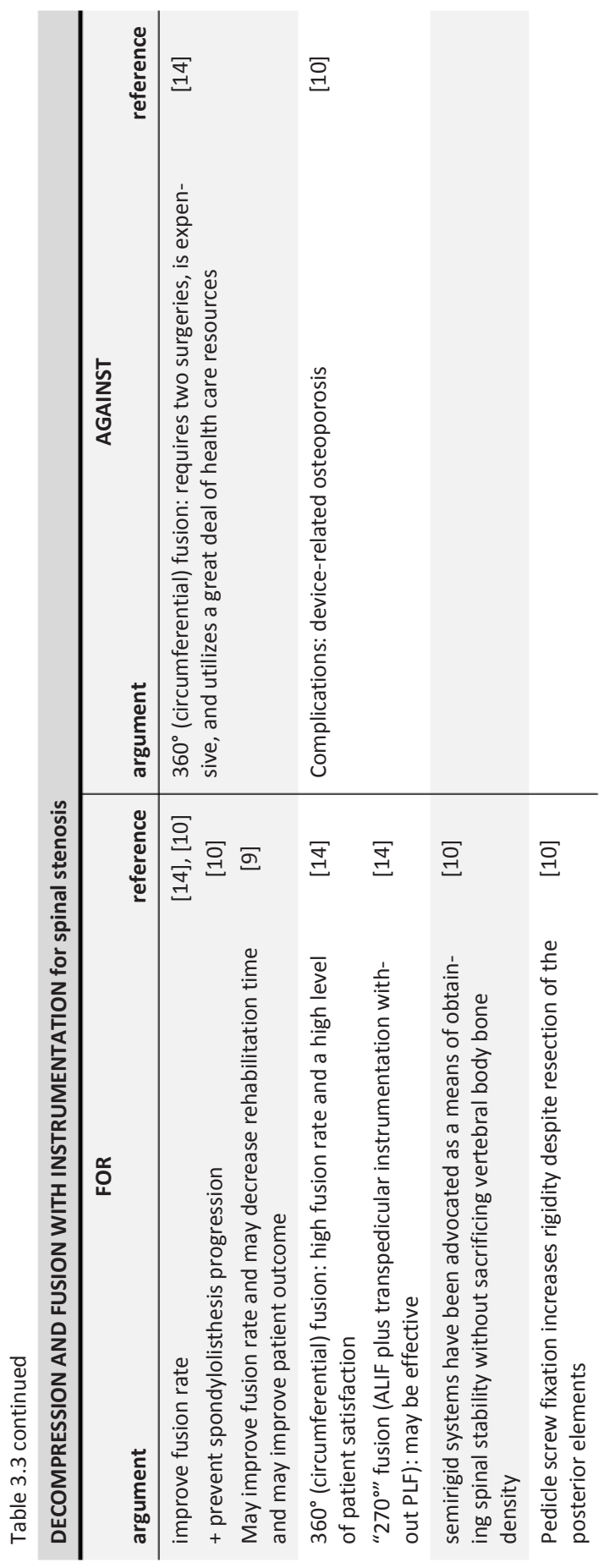




\section{Discussion}

\section{Main findings}

In this review of arguments for or against choosing a specific type of treatment for a patient with lumbar spinal stenosis nine randomized trials (RCTs) were appraised. The main argument for decompression surgery only was a high success rate (three RCTs). Furthermore, decompression alone is less invasive than fusion surgery (one RCT) and maintains the relative stability of the spine (one RCT). The main argument for fusion was that it is a well-established technique with a high fusion success rate (two RCTs) and statistically significant improvement in clinical outcome compared to decompressive lumbar laminectomy alone (one RCT). Arguments for the choice of fusion with instrumentation were an increased fusion rate compared to fusion (two RCTs) and prevention of spondylolisthesis progression (two RCTs).

Main arguments against decompression alone were an increase in vertebral instability and a progression of spondylolisthesis (three RCTs). The main argument against fusion was that the indication for fusion in spinal stenosis has remained unclear (one RCT). In particular, degenerative changes (osteophytes, decreased disc height, calcified ligaments) increase the stability of the spine and thereby reduce the need for arthrodesis (one RCT). The main arguments against fusion with instrumentation were that the invasive procedures are associated with more complications as, e.g., device related osteoporosis (one $\mathrm{RCT}$ ) and are more expensive (one RCT).

\section{Comparison with the literature}

The main argument identified in this appraisal for and against decompression alone in patient with lumbar spinal stenosis was whether or not instability should be treated with (instrumented) fusion procedures. Increased vertebral instability may lead to progression and compression of nerve roots and therefore require reoperation. Further, by reading the original papers we noticed that key terms including instability as well as reoperation are not clearly and unambiguously defined. Authors of different papers used various defi- 
nitions for these terms. For the interpretation of study results and the appraisal of the clinical implications, or the synthesis of the results of original studies in a systematic review it is necessary to know what the different terms denote and how the different concepts, e.g., instability, are operationalized and quantified.

Various definitions of the term instability have been published that vary among experts. The meaning is different for clinicians, radiologists, and bioengineers [23]. An example for a clinical definition of instability is presented by White and Panjabi [24, 25] as follows: "The loss of the spine's ability to maintain its pattern of displacement under physiologic loads so there is no initial or additional neurologic deficit, no major deformity, and no incapacitating pain." A radiological definition reported by Sonntag and Marciano [26]: "Increased angulatory or translatory motion noted on active flexion-extension lateral or anteroposterior bending radiographs that exceeds $4 \mathrm{~mm}$ or $10^{\circ}$ angulation [...]" According to Frymoyer [27] from a bioengineers point of view segmental instability is defined as "a loss of spinal motion segment stiffness, such that force application to that motion segment produces greater displacement than would be seen in a normal structure, resulting in a painful condition, the potential for progressive deformity, and neurologic structures at risk."

And even between physicians of the same discipline, opinions on what instability means, differ exemplified by a further definition from radiology reported by White and Panjabi [24]. They defined criteria for diagnosing instability from flexion-extension radiographs as "sagittal plane translation greater than $4.5 \mathrm{~mm}$ or greater than $15 \%$ of the vertebral body width, or sagittal plane rotation of greater than $15^{\circ}$ at L1/L2, L2/L3 or L3/L4, greater than $20^{\circ}$ at L4/L5, or greater than $25^{\circ}$ at L5/S1" [28].

An additional hurdle is that the association between clinical signs and radiological findings remains controversial and challenging $[23,29]$. A study conducted by Pitkanen et al. [30] found only poor correlation between radiological abnormalities identified in functional radiographs and clinical signs suggesting lumbar instability. It remains unclear whether the radiological approach is poor, or the definition of clinical instability is not that appropriate [30]. 
Recently an international and interdisciplinary expert panel was unable to agree on a definition of instability and its clinical relevance in symptomatic lumbar degenerative spondylolisthesis [31]. As a consequence of a lack of a broadly accepted definition and method of quantification of instability, researchers use different methods to quantify instability. This impedes the appraisal of the clinical impact of study results and hinders the synthesis of results from original studies in a systematic review. There is a need for a broadly accepted definition to facilitate the meaningful interpretation of study results.

An important question that needs to be addressed in future studies is whether a second surgery is necessary as a consequence of the first intervention or because of the progression of a preexisting degenerative disease. Many authors don't define how they classify reoperations and the descriptions of reasons for repeat surgery vary [32], e.g., Martin et al. [33] defined in their study reoperation as "any lumbar operation in a patient who had at least 1 previous lumbar spine procedure. It was not necessarily a repeat of the same procedure or performed at the same vertebral location, but in all cases, it was still within the lumbar region."

For the interpretation of study results it is important for clinicians and researchers that the reasons for a follow-up surgery in studies are clearly defined. Early reoperation can be necessary because of a surgical complication, such as spinal fluid leak, hematoma, infection, neurologic deficit, or mislocated instrumentation. For a reader these reoperations are clearly related to the prior surgery. This relation is less evident at a later stage. Nonunion or complications resulting from surgical implants can be a reason for a reoperation at a later stage. Nevertheless, reoperations at a later stage may be performed because of recurrent or persistent pain symptoms, pseudoarthrosis, or progressive degeneration at another spine level [33]. Therefore, a detailed description, classification or definition is important to compare the results of different studies.

\section{Limitations}

The main limitation of this study is the small number of randomized controlled trials comparing surgical procedures and therefore limited discussion on arguments for or against 
specific techniques. While spinal stenosis is a prevalent disease in elderly patients and surgical interventions are performed on a regular base only nine RCTs were available for the current appraisal.

Another limitation of this study is the missing distinction of different types of decompression procedures used (e.g. complete facetectomy or complete laminectomy). The extent of laminectomy or facetectomy may influence postoperative instability and should be addressed in all studies.

\section{Implication for research}

It is important that researchers and clinicians agree on definitions for important key concepts such as instability and description of reasons for reoperation. Clear definitions of concepts and methods for the quantification or categorization facilitate the interpretation of study results and the synthesis of the results of different studies.

\section{Implication for clinical practice}

For clinicians it is important to know when to recommend a certain intervention to their patient. The lack of high quality RCTs that addresses these important clinical questions impedes clinicians from an evidence-based treatment algorithm in patients with lumbar spinal stenosis. Indications for conservative or surgical intervention are oftentimes based on clinical judgment of the treating physician and depend on personal beliefs and experiences. Future research is needed to provide more robust evidence for such treatment choices.

\section{Conclusion}

The main argument identified in this appraisal for and against decompression alone in patient with lumbar spinal stenosis was whether or not instability should be treated with (instrumented) fusion procedures. However, there is disagreement on how instability should be defined. In a first step it is important that researchers and clinicians agree on definitions for important key concepts such as instability and reoperations. 


\section{References}

1. Ciol MA, Deyo RA, Howell E, Kreif S: An assessment of surgery for spinal stenosis: time trends, geographic variations, complications, and reoperations. J Am Geriatr Soc 1996, 44(3):285-290.

2. Evidence Based Clinical Guidelines for Multidisciplinary Spine Care: Diagnosis and Treatment of Degenerative Lumbar Spinal Stenosis. Burr Ridge: North American Spine Society 2007.

3. Amundsen T, Weber H, Nordal HJ, Magnaes B, Abdelnoor M, Lilleas F: Lumbar spinal stenosis: conservative or surgical management?: A prospective 10-year study. Spine (Phila Pa 1976) 2000, 25(11):1424-1435; discussion 1435-1426.

4. Kalichman L, Cole R, Kim DH, Li L, Suri P, Guermazi A, Hunter DJ: Spinal stenosis prevalence and association with symptoms: the Framingham Study. The Spine Journal 2009, 9(7):545-550.

5. Carragee EJ: Single-level posterolateral arthrodesis, with or without posterior decompression, for the treatment of isthmic spondylolisthesis in adults. A prospective, randomized study. J Bone Joint Surg Am 1997, 79(8):1175-1180.

6. Cochrane Handbook for Systematic Reviews of Interventions [www.cochrane-handbook.org]

7. Heritage A: The American Heritage Medical Dictionary: Houghton Mifflin Company; 2008.

8. May S, Comer C: Is surgery more effective than non-surgical treatment for spinal stenosis, and which nonsurgical treatment is more effective? A systematic review. Physiotherapy 2013, 99(1):12-20.

9. Fischgrund JS, Mackay M, Herkowitz HN, Brower R, Montgomery DM, Kurz LT: 1997 Volvo Award winner in clinical studies - Degenerative lumbar spondylolisthesis with spinal stenosis: A prospective, randomized study comparing decompressive laminectomy and arthrodesis with and without spinal instrumentation. Spine 1997, 22(24):2807-2812.

10. Zdeblick TA: A prospective, randomized study of lumbar fusion. Preliminary results. Spine (Phila Pa 1976) 1993, 18(8):983-991.

11. Herkowitz HN, Kurz LT: Degenerative lumbar spondylolisthesis with spinal stenosis. A prospective study comparing decompression with decompression and intertransverse process arthrodesis. J Bone Joint Surg Am 1991, 73(6):802-808.

12. Grob D, Humke T, Dvorak J: Degenerative lumbar spinal stenosis. Decompression with and without arthrodesis. J Bone Joint Surg Am 1995, 77(7):1036-1041.

13. Kitchel S, Matteri R: Prospective randomized evaluation of posterior lumbar interbody fusion in degenerative spondylolisthesis patients over 60 years old. The Spine Journal 2002, 2(2, Supplement 1):21.

14. Schofferman J, Slosar P, Reynolds J, Goldthwaite N, Koestler M: A prospective randomized comparison of 270 degrees fusions to 360 degrees fusions (circumferential fusions). Spine (Phila Pa 1976) 2001, 26(10):E207212.

15. Postacchini F, Cinotti G, Perugia D, Gumina S: The surgical treatment of central lumbar stenosis. Multiple laminotomy compared with total laminectomy. J Bone Joint Surg Br 1993, 75(3):386-392.

16. Thome C, Zevgaridis D, Leheta O, Bazner H, Pockler-Schoniger C, Wohrle J, Schmiedek P: Outcome after lessinvasive decompression of lumbar spinal stenosis: a randomized comparison of unilateral laminotomy, bilateral laminotomy, and laminectomy. J Neurosurg Spine 2005, 3(2):129-141.

17. Bridwell $\mathrm{KH}$, Sedgewick TA, O'Brien MF, Lenke LG, Baldus C: The role of fusion and instrumentation in the treatment of degenerative spondylolisthesis with spinal stenosis. J Spinal Disord 1993, 6(6):461-472.

18. Chou D, Lau D, Hermsmeyer J, Norvell D: Efficacy of interspinous device versus surgical decompression in the treatment of lumbar spinal stenosis: a modified network analysis. Evidence-based spine-care journal 2011, 2(1):45-56.

19. Gibson JN, Waddell G: Surgery for degenerative lumbar spondylosis. The Cochrane database of systematic reviews 2005(4):CD001352.

20. Jarrett MS, Orlando JF, Grimmer-Somers K: The effectiveness of land based exercise compared to decompressive surgery in the management of lumbar spinal-canal stenosis: a systematic review. BMC Musculoskelet Disord 2012, 13:30. 
21. Kovacs FM, Urrutia G, Alarcon JD: Surgery versus conservative treatment for symptomatic lumbar spinal stenosis: a systematic review of randomized controlled trials. Spine (Phila Pa 1976) 2011, 36(20):E1335-1351.

22. Moojen WA, Arts MP, Bartels RH, Jacobs WC, Peul WC: Effectiveness of interspinous implant surgery in patients with intermittent neurogenic claudication: a systematic review and meta-analysis. Eur Spine J 2011, 20(10):1596-1606.

23. Leone A, Guglielmi G, Cassar-Pullicino VN, Bonomo L: Lumbar intervertebral instability: a review. Radiology 2007, 245(1):62-77.

24. White AA, PANJABI MMA: Clinical Biomechanics of the Spine, 2nd edn. Philadelphia: Lippincott Williams \& Wilkins; 1990.

25. Panjabi MM: Clinical spinal instability and low back pain. Journal of electromyography and kinesiology : official journal of the International Society of Electrophysiological Kinesiology 2003, 13(4):371-379.

26. Sonntag VK, Marciano FF: Is fusion indicated for lumbar spinal disorders? Spine (Phila Pa 1976) 1995, 20(24 Suppl):138S-142S.

27. Frymoyer J: Segmental instability: overview and classification. The Adult Spine: Principles and Practice New York, NY, Raven Press, Ltd 1991:1873-1891.

28. Fritz JM, Piva SR, Childs JD: Accuracy of the clinical examination to predict radiographic instability of the lumbar spine. European Spine Journal 2005, 14(8):743-750.

29. Nizard RS, Wybier M, Laredo JD: Radiologic assessment of lumbar intervertebral instability and degenerative spondylolisthesis. Radiologic clinics of North America 2001, 39(1):55-71, v-vi.

30. Pitkanen MT, Manninen HI, Lindgren KA, Sihvonen TA, Airaksinen O, Soimakallio S: Segmental lumbar spine instability at flexion-extension radiography can be predicted by conventional radiography. Clinical radiology 2002, 57(7):632-639.

31. Mannion AF, Pittet V, Steiger F, Vader JP, Becker HJ, Porchet F, The Zurich Appropriateness of Spine Surgery G: Development of appropriateness criteria for the surgical treatment of symptomatic lumbar degenerative spondylolisthesis (LDS). Eur Spine J 2014.

32. Deyo RA, Martin BI, Kreuter W, Jarvik JG, Angier H, Mirza SK: Revision Surgery Following Operations for Lumbar Stenosis. Journal of Bone and Joint Surgery-American Volume 2011, 93A(21):1979-1986.

33. Martin BI, Mirza SK, Comstock BA, Gray DT, Kreuter W, Deyo RA: Reoperation rates following lumbar spine surgery and the influence of spinal fusion procedures. Spine (Phila Pa 1976) 2007, 32(3):382-387. 


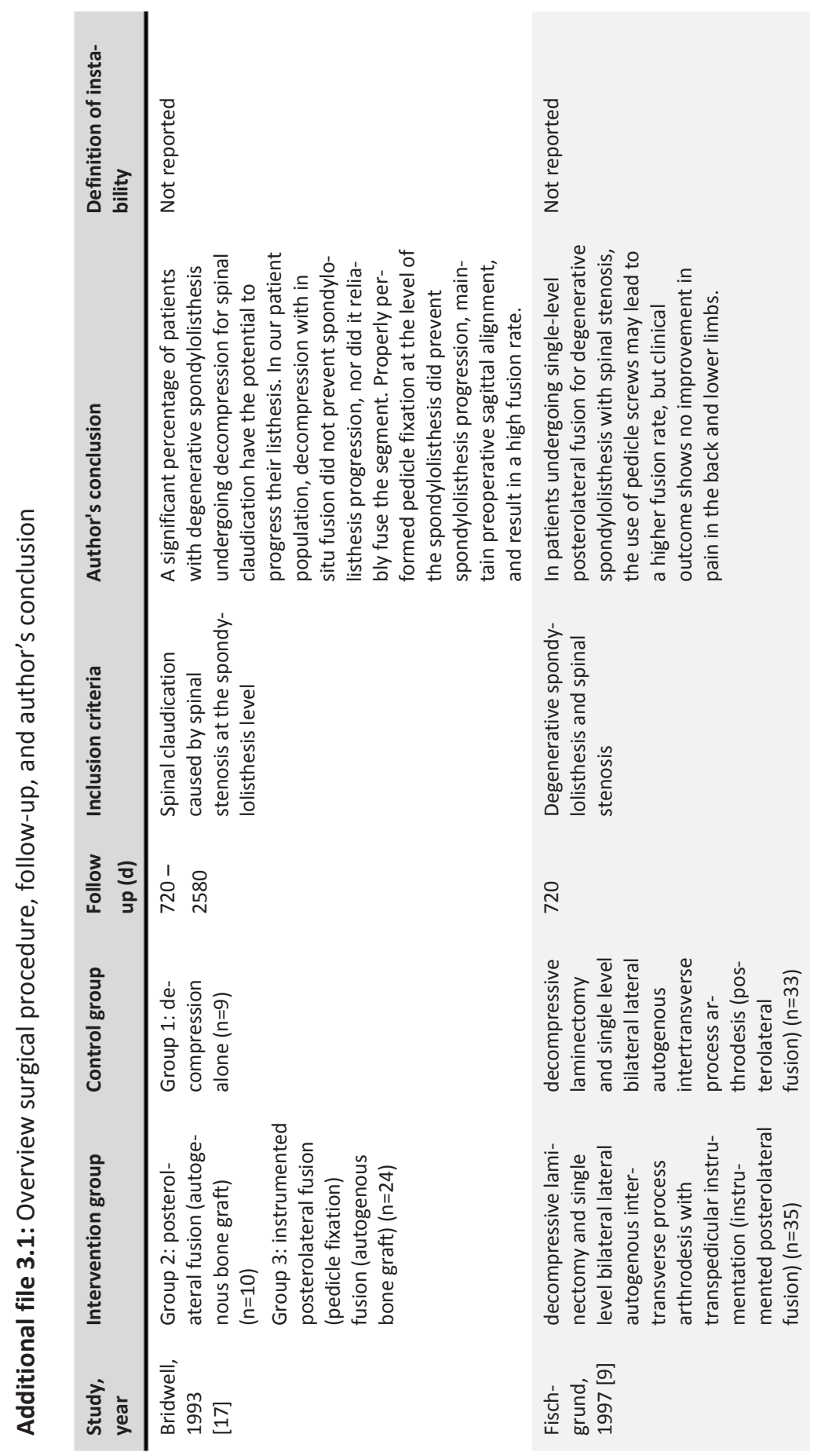




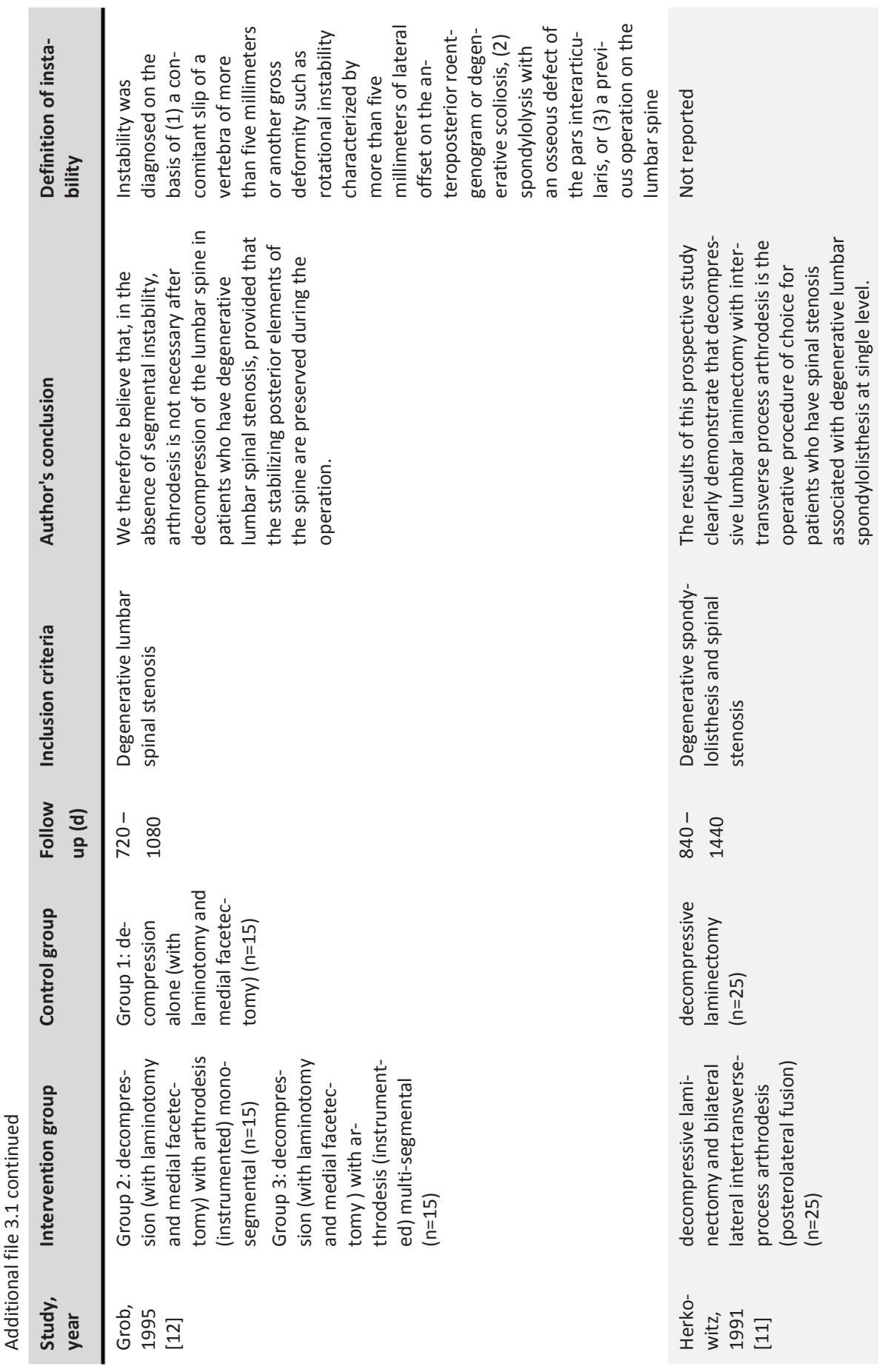




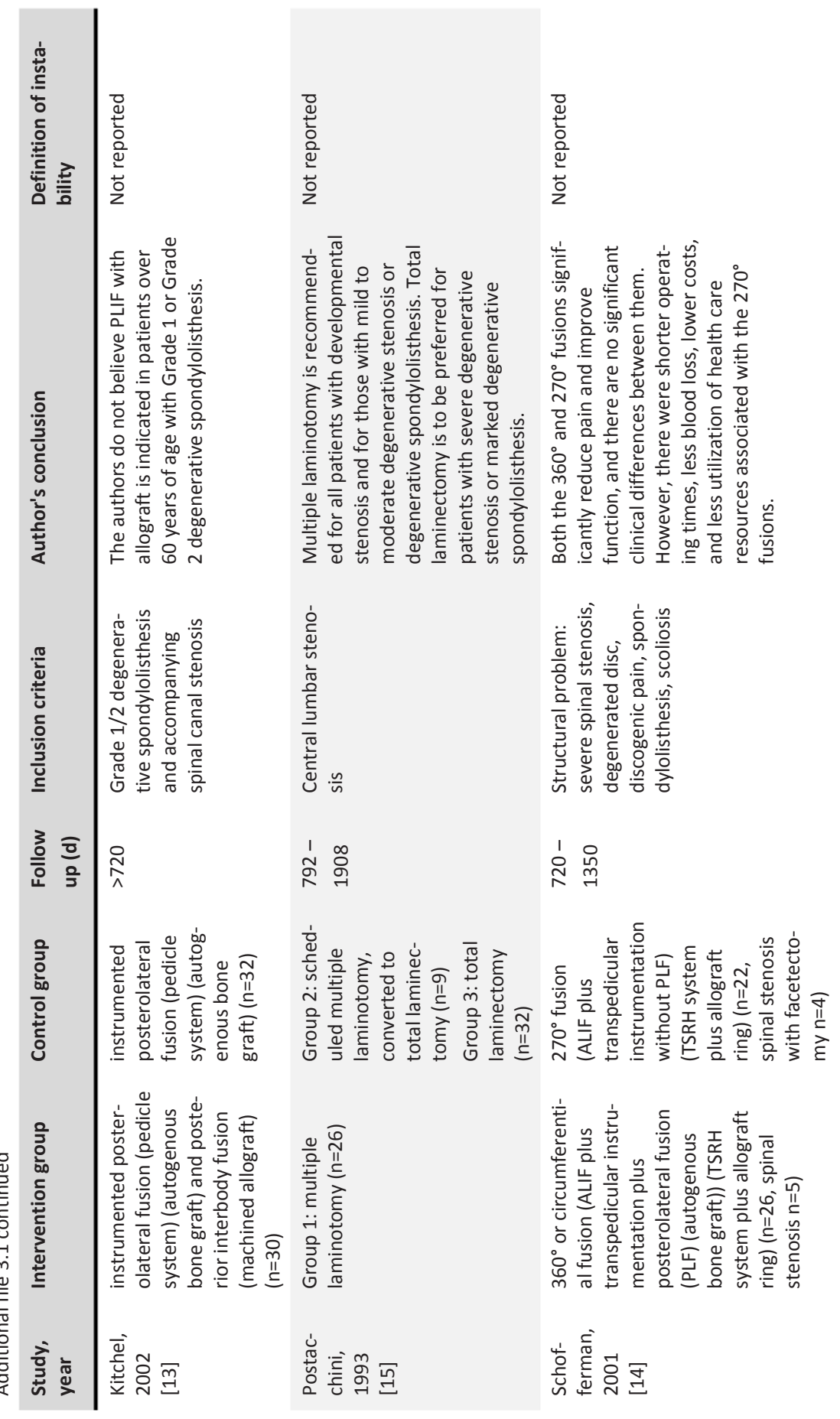




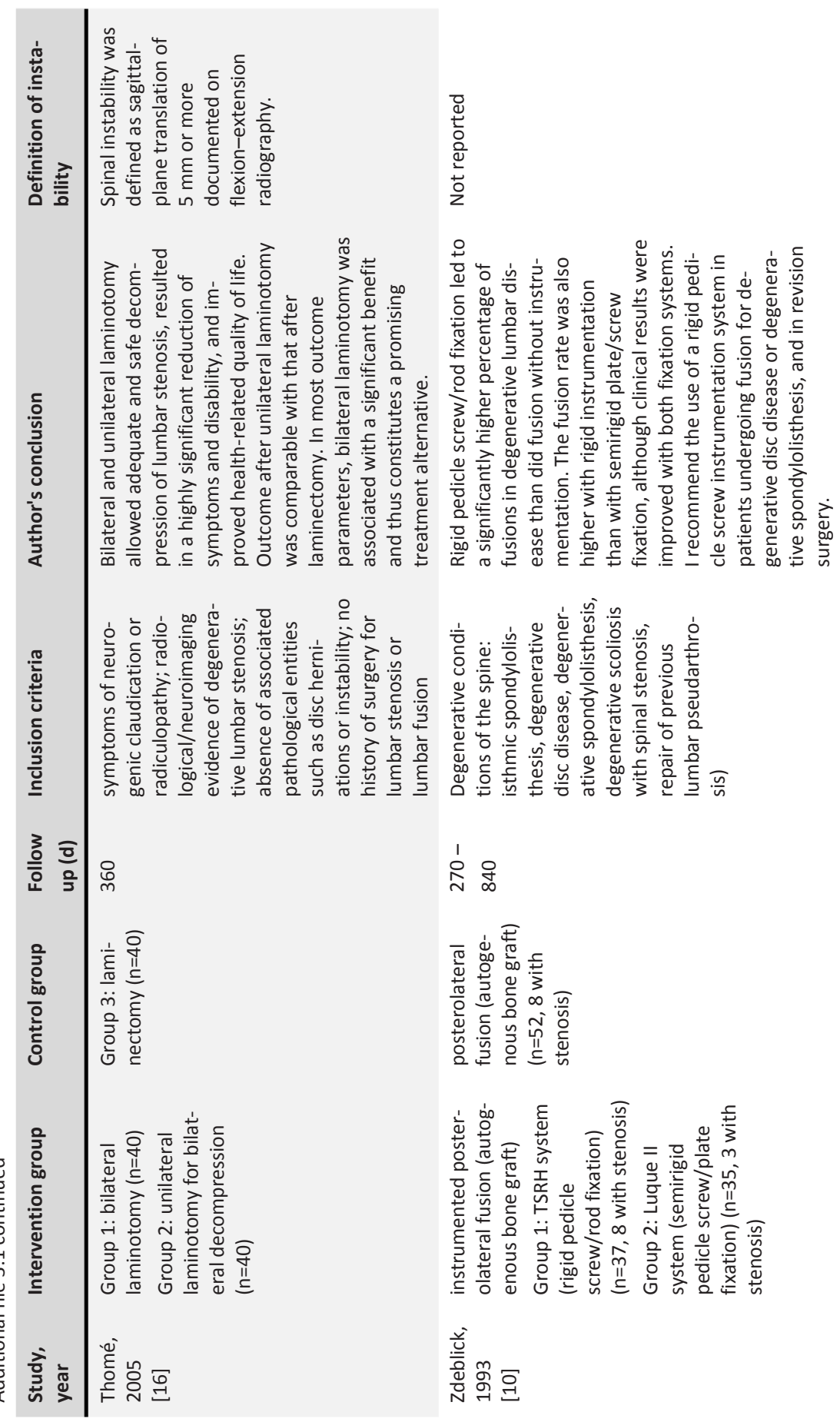





\section{Chapter 4}

\section{The impact of obesity on the}

\section{outcome of decompression surgery}

in degenerative lumbar spinal canal stenosis: Analysis of the Lumbar

Spinal Outcome Study (LSOS)

Jakob M. Burgstaller, M.D., D.M.D.

Ulrike Held, Ph.D.

Florian Brunner, M.D., Ph.D.

Madza Farshad, M.D., M.P.H.

Johann Steurer, M.D.

Nils H. Ulrich, M.D.

on behalf of the LSOS Study Group 


\section{Abstract}

Study design: Prospective, multicenter cohort study including eight medical centers of the Cantons Zurich, Lucerne, and Thurgau, Switzerland.

Objective: To assess whether obese patients benefit after decompression surgery for degenerative lumbar spinal stenosis (DLSS).

Summary and Background Data: Lumbar decompression surgery has been shown to improve quality of life in patients with degenerative lumbar spinal stenosis. In the existing literature the efficacy of lumbar decompression in the obese population remains controversial.

Methods: Baseline patient characteristics and outcomes were analyzed at 6 months and 12 months follow-up with the Spinal Stenosis Measure (SSM), the Numeric Rating Scale (NRS), Feeling Thermometer (FT), the EQ-5D-EL, and the Roland and Morris Disability Scale (RMDS). Body mass index (BMI) was classified into three categories according to the WHO. Minimal clinically important improvement (MCIDs) in SSM for different BMI categories was considered as main outcome.

Results: Of the 656 patients in the LSOS-database as of end of October 2014, one hundred and sixty-six patients met the inclusion criteria. Fifty (30.1\%) had a BMI <25 (underweight and normal weight group), 72 (43.4\%) had a BMI between 25-<30 (pre-obesity group) and $44(26.5 \%)$ patients had a $\mathrm{BMI} \geq 30$ (obese group). We found for the main outcome that in obese patients $36 \%$ reached MCID at six months, and $48 \%$ at 12 months. The estimated odds ratios for MCID in the obese group were $0.78(0.34-1.82)$ at 6 months and $0.99(0.44$ 2.23) at 12 months in a logistic regression model adjusting for levels of laminectomy. In the additional outcomes SSM, NRS, FT, and RMDQ showed statistically significant mean improvements in the 6 and 12 months follow-up.

Conclusion: Obese patients can expect clinical improvement after lumbar decompression for DLSS, but the percentage of patients with a meaningful improvement is lower than in the group of patients with under-, normal and pre-obese weight at 6 and 12 months. 


\section{Introduction}

Spine surgeons are increasingly confronted with a wide variety of degenerative changes of the lumbar spine in obese patients. Obesity affects one-third of the adult U.S. population and is associated with numerous clinical problems [1-3]. Based on the latest estimation of the WHO in European countries overweight affects $30-70 \%$ and obesity affects $10-30 \%$ of the adults [4]. The impact of obesity on musculoskeletal, degenerative spinal disease, quality of life and back pain has been well documented [5-13]. Obesity and musculoskeletal disease may lead to degenerative lumbar spinal stenosis (DLSS) [14]. DLSS is a major factor in the development of back pain for millions of people in the U.S. and worldwide. DLSS may compress the spinal cord and nerve roots causing back and leg pain making it difficult to maintain an exercise regimen. The inability to exercise, in turn, can limit the ability to maintain a healthy weight.

Failure of conservative treatment permits the indication for surgery. The aim of surgery is to decompress the spinal canal and dural sac from degenerative bony and ligamentous overgrowth. For instance, in the metropolitan area of Zurich with around 1.3 million inhabitants over 970 lumbar decompressions without fusions are done every year [15].

Owing to the lack of relevance that obesity might play in patients after decompression with DLSS, we used data from the Lumbar Stenosis Outcome Study (LSOS) [16] to further explore this issue. In some patients postsurgical improvement is not satisfactory and obesity may be associated with less favorable outcome $[8,17]$, therefore we test the hypothesis [18] that obese patients have less clinical improvement after surgery for symptomatic DLSS in comparison to non-obese patients.

\section{Materials and Methods}

\section{Patient Selection}

Patients were recruited from outpatient clinics at all participating centers. The study population consists of patients with a history of neurogenic claudication. Patients had no evidence of stenosis caused by tumor, fracture, infection or significant deformity $\left(>15^{\circ}\right.$ 
lumbar scoliosis). Magnetic Resonance Imaging (MRI) verified lumbar spinal canal stenosis. None of the patients had prior lumbar spine surgery. Furthermore, patients had no clinical peripheral artery occlusive disease (confirmed by a vascular specialist in patients without palpable pulses in the lower limb). We also excluded patients with a diagnosis of diabetes mellitus.

\section{Surgical Procedure}

Surgery consisted of a standard open posterior lumbar laminectomy or laminotomy at the affected level or levels without instrumentation. Decompression of the lateral recessus and foramina was performed when necessary to decompress the local nerve roots. The use of loops or the microscope was at the preference of the spinal surgeon but was not recorded as part of the LSOS-study.

\section{Data Collection and Follow-up}

Parts of the basic data sheet were interview-administered and recorded by a study coordinator. All other questionnaires were self-administered and filled in by the patients themselves. All data were collected at baseline, and at six months. Long-term outcome data was gathered after one year.

\section{Questionnaires}

Spinal Stenosis Measure (SSM): The SSM, an instrument specifically developed for spinal stenosis patients by Stucki et al. [19], targets to measure severity of symptoms and quantifies disability of the lumbar spinal stenosis population. It is recommended by the North American Spine Society (NASS) and used in different studies on lumbar spinal stenosis [2023]. It consists of three different subscales; the symptom severity subscale, the physical function subscale and the satisfaction subscale. The symptom severity scale can be divided into a pain domain (severity, frequency and back pain) and a neuroischemic domain (leg pain, weakness, numbness and balance disturbance). Score range is from 1-5 and 1-4 (best-worst). 
Feeling Thermometer (FT) and Numeric Rating Scale (NRS): General assessment of lumbar spinal stenosis symptoms such as lower extremity pain and discomfort were measured. Score range is from 0-100 and 0-10 (best-worst).

EQ-5D-3L: The EQ-5D-3L is an assessment tool to measure health-related quality of life. It measures general non-disease specific health-related quality of life, including physical, mental and social dimensions [24]. The health status measures five dimensions of health (mobility, self-care, usual activities, pain/discomfort and anxiety/depression) which can be calculated as a sum score (score range 0-100, worst-best) [24]. The second part of the questionnaire estimates patient's actual health status (score range 0-100, worst-best).

Roland and Morris Disability Questionnaire (RMDQ): The Roland and Morris Disability Questionnaire is a back pain specific, self-rated physical disability questionnaire developed by Roland and Morris in 1983 [25]. Disability is measured respective to the following categories: physical function activities and activities of daily living including eating and sleeping. Score range is from 0-24 (best-worst).

Cumulative IIIness Rating Scale (CIRS): Comorbidity was measured using CIRS that rates the presence and severity of comorbid diseases in 14 organ systems (according to modified version by Miller et al. [26]). Score range was from 0-56 (best-worst).

\section{Minimal Clinically Important Difference (MCID)}

The MCID is defined as "the smallest difference in a score that is considered to be worthwhile or important" [27]. Thus, the MCID is threshold for a relevant change in an outcome measure. Patients who reached or even exceed this threshold consider a change as meaningful and worthwhile. According to Stucki et al. [19], MCID for SSM is reached when "Symptom Severity scale" improve at least 0.48 points and "Physical Function scale" at least 0.52 points at the 6 -month follow-up.

\section{Outcomes}

The main outcome of this study was clinically meaningful improvement in SSM, which is denoted as MCID (minimal clinically important difference), after six and twelve months. 
Additional outcomes of interest were changes in SSM, NRS, FT, EQ-5D-EL sum score and actual health status, and RMDQ within BMI categories from baseline to six months.

\section{Ethics}

This cohort study was conducted in compliance with all international laws and regulations as well as any applicable guidelines. The study was approved by the independent Ethics Committee of the Canton Zurich (KEK-ZH-NR: 2010-0395/0).

\section{Statistical analyses}

Analysis of data consisted of descriptive statistics of patient demographics and outcomes. Continuous variables were shown as median and interquartile ranges and categorical variables were shown as numbers and percentages of total. For each patient, we evaluated whether MCID was reached at 6 and 12 months from baseline (within categories of $\mathrm{BMI})$. In a multiple logistic regression model, we assessed whether BMI categories had a significant influence on reaching $\mathrm{MCID}$, and we quantified the impact of $\mathrm{BMI}$ categories with MCID as outcome variable and adjustment for number of levels of laminectomy. In addition to Wald tests for single categories of BMI, we also used the global F-test to assess the importance of all three BMI-categories as a whole. For the additional outcomes, we calculated changes from baseline at 6 months. To assess whether these changes differed significantly from zero, we used paired Wilcoxon tests. For graphical representations of the changes within BMI categories over time, box plots were used.

\section{Results}

\section{Patient characteristics}

At baseline, a total of 166 patients met the inclusion criteria. In our patient population the median age was 74 years (IQR 12) and 80 (48\%) were female patients. The median CIRS total score was 8, IQR 4.8 at baseline. Sixty-two (37.3\%) patients had a one level laminectomy and 104 (62.7\%) had a laminectomy on two or more levels. Of the study population 
110 (66.3\%) patients hold higher education degree (no university) and 23 (13.9\%) hold a university degree (Table 4.1). In the BMI category $<25$, there were 50 patients with a median CIRS score or value of 8, IQR 3. Seventy-two patients were pre-obese and had a median CIRS of 8, IQR 5. Forty-four patients were obese and had a median CIRS of 9, IQR 4. Further patient's characteristics are summarized in Table 4.1.

Table 4.1: Patients characteristics

\begin{tabular}{|c|c|c|c|c|}
\hline & $\begin{array}{l}\text { Total } \\
\text { Population }\end{array}$ & BMI $<25$ & BMI $25-<30$ & BMI $\geq 30$ \\
\hline$n$ & 166 & 50 & 72 & 44 \\
\hline $\begin{array}{l}\text { Age at time of surgery, medi- } \\
\text { an (IQR) }\end{array}$ & $74(12)$ & $74(11.5)$ & $74.5(12)$ & 73.5 (12.5) \\
\hline Gender female (\%) & $80(48.2)$ & $31(62)$ & $29(40.3)$ & $20(45.5)$ \\
\hline CIRS, median (IQR) & $8(4.8)$ & $8(3)$ & $8(5)$ & $9(4)$ \\
\hline \multicolumn{5}{|l|}{ Levels of laminectomy } \\
\hline 1 Level (\%) & $62(37.3)$ & $18(36)$ & 28 (38.9) & $16(36.4)$ \\
\hline > 1 Level (\%) & $104(62.7)$ & $32(64)$ & $44(61.1)$ & $28(63.6)$ \\
\hline \multicolumn{5}{|l|}{ Level of education } \\
\hline $\begin{array}{l}\text { compulsory education } \\
\text { (1-9 years) (\%) }\end{array}$ & 33 (19.9) & $9(18)$ & $14(19.4)$ & $10(22.7)$ \\
\hline $\begin{array}{l}\text { Higher education/vocational } \\
\text { training (no university) } \\
\text { (10-12 years) }(\%)\end{array}$ & $110(66.3)$ & $27(54)$ & $54(75)$ & $29(65.9)$ \\
\hline University degree (\%) & 23 (13.9) & $14(28)$ & $4(5.6)$ & $5(11.4)$ \\
\hline
\end{tabular}

Main outcome: MCID in the SSM

$B M I<25$ category (underweight and normal weight group)

Twenty-one patients (42\%) showed MCID at the 6 months follow-up. At the 12 months follow-up 24 patients (48\%) showed MCID (Table 4.2a) 
BMI 25-<30 category (pre-obesity group)

Forty-one patients (56.9\%) showed MCID at the 6 months follow-up. At the 12 months follow-up 44 patients (61.1\%) showed MCID (Table 4.2a).

$B M I \geq 30$ category (obese group)

Sixteen patients (36.4\%) showed MCID at the 6 months follow-up. At the 12 months follow-up 21 patients (47.7\%) showed a MCID (Table 4.2a).

Table 4.2a: MCID (meaningful clinically important difference) after 6 and 12 months from baseline:

\begin{tabular}{lcc} 
BMI & $\begin{array}{c}6 \text { months } \\
n / \text { total (\%) }\end{array}$ & $\begin{array}{c}12 \text { months } \\
n / \text { total (\%) }\end{array}$ \\
\hline$<25$ & $21 / 50(42)$ & $24 / 50(48)$ \\
$25-<30$ & $41 / 72(56.9)$ & $44 / 72(61.1)$ \\
$\geq 30$ & $16 / 44(36.4)$ & $21 / 44(47.7)$
\end{tabular}

\section{Odds ratio for meaningful improvement}

We fitted a multiple logistic regression model to MCID depending on BMI category and levels of laminectomy. The estimated odds ratio (OR) for reaching MCID in BMI $25-<30$ category versus the $B M I<25$ category was $1.82(0.87-3.8 ; p=0.11)$ at the 6 months followup. At the 12 months follow-up the estimated OR was 1.69 (0.81-3.52; $p=0.16)$. In the category of $\geq 30 \mathrm{BMI}$ versus category of $<25 \mathrm{BMI}$ we estimated an OR of 0.78 (0.34-1.82; $p=0.57$ ) at the 6 months follow-up. At the 12 months follow-up we estimated OR of 0.99 (0.44-2.23; $p=0.98)$. None of the single ORs for MCID was significantly different from 1 . When the global F-test was used to assess the importance of the variable BMI with all three categories at once, the resulting $p$-values were $p=0.067$ at the 6 months follow-up and $p=0.236$ at the 12 months follow-up. All results are summarized in Table $\mathbf{4 . 2 b}$. 
Table 4.2b: Estimated odds ratios for meaningful improvement from a multiple logistic regression model including BMI category and levels of laminectomy.

\begin{tabular}{lllll} 
& \multicolumn{1}{c}{6 months } & \multicolumn{1}{c}{12 months } \\
& Odds ratio $(95 \% \mathrm{Cl})$ & p value & Odds ratio $(95 \% \mathrm{Cl})$ & p value \\
\hline BMI* & & & & \\
$25-<30$ versus $<25$ & $1.82(0.87-3.8)$ & 0.112 & $1.69(0.81-3.52)$ & 0.161 \\
$\geq 30$ versus $<25$ & $0.78(0.34-1.82)$ & 0.569 & $0.99(0.44-2.23)$ & 0.975 \\
Levels of laminectomy & & & & 0.135 \\
$>1$ versus 1 & $0.54(0.28-1.04)$ & 0.065 & $0.61(0.32-1.17)$ & \\
& $*$ global F-test $p$-value $=0.0675$ & $*$ global F-test $p$-value $=0.2360$
\end{tabular}

\section{Additional outcome at baseline, 6 months and 12 months follow-up}

In Additional Table $\mathbf{4 . 1}$ descriptive statistics are summarized for the SSM and subdomains, NRS, FT, EQ-5D-EL sum score and actual health status, and RMDQ within BMI categories and over time. Figure 4.1 shows the changes with BMI categories over time in SSM and subdomains with box plots. Each box plot contains a notch that displays a confidence interval around the median. If the notches of two box plots do not overlap this is 'strong evidence' that the two medians differ significantly [28]. The corresponding box plots for the other scales can be found in Figure 4.2.

\section{Changes in additional outcomes from baseline to 6 months in the three BMI categories}

We found statistically significant median improvements in all additional outcomes over all BMI categories (Table 4.3). These improvements varied between 0.6 and 1 for the SSM subdomains. In the obese patients, there was a non-significant worsening in the outcome EQ-5D-EL actual heath status. 
Figure 4.1: SSM and subdomains in categories of BMI at baseline, 6 months, and 12 months
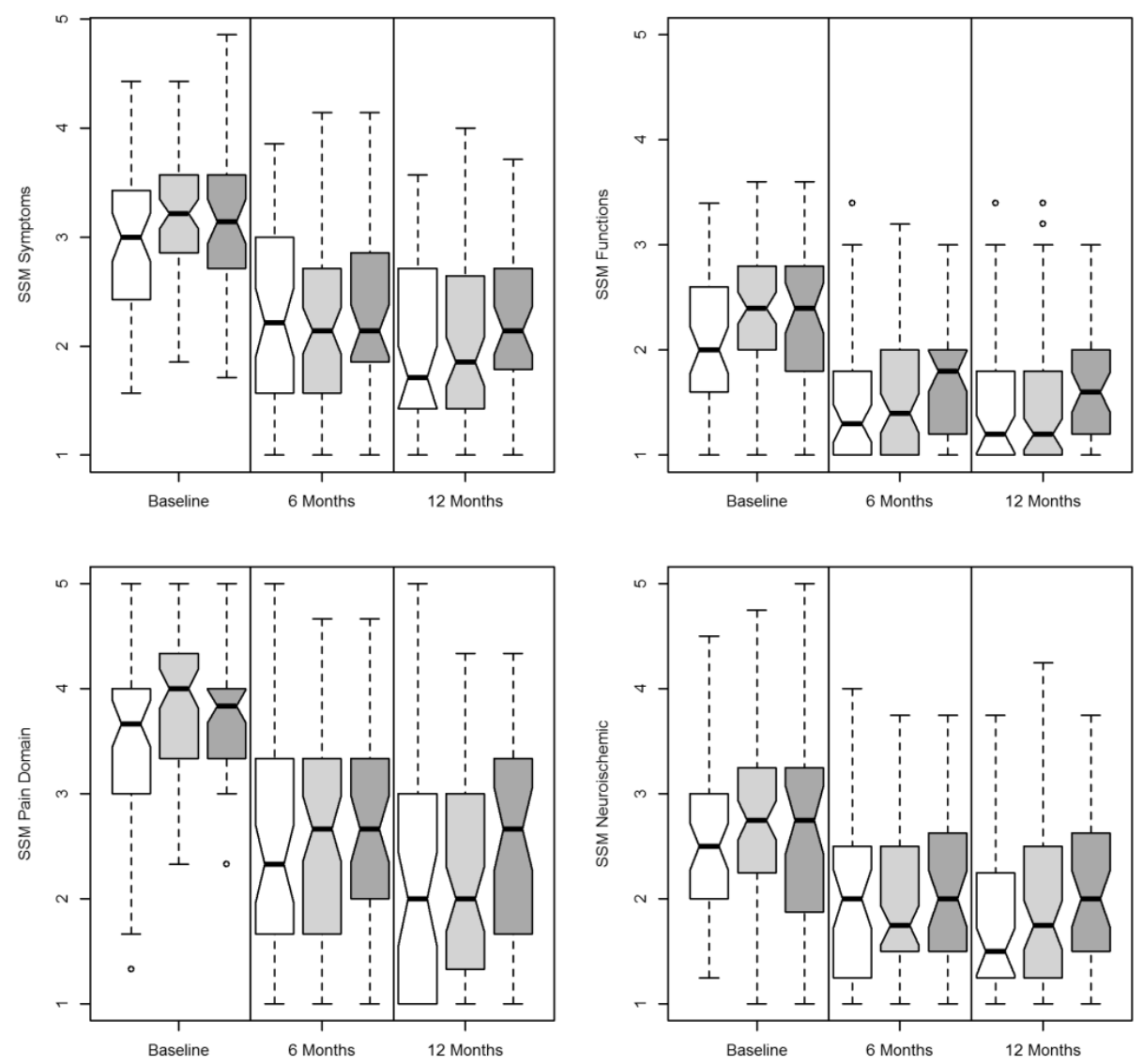

BMI $<25 \square \mathrm{BMI} 25-<30 \square \mathrm{BMI} \geq 30$ 
Figure 4.2: NRS, Feeling Thermometer, EQ-5D-EL sum score and actual health status, and RMDQ in categories of BMI at baseline, 6 months, and 12 months
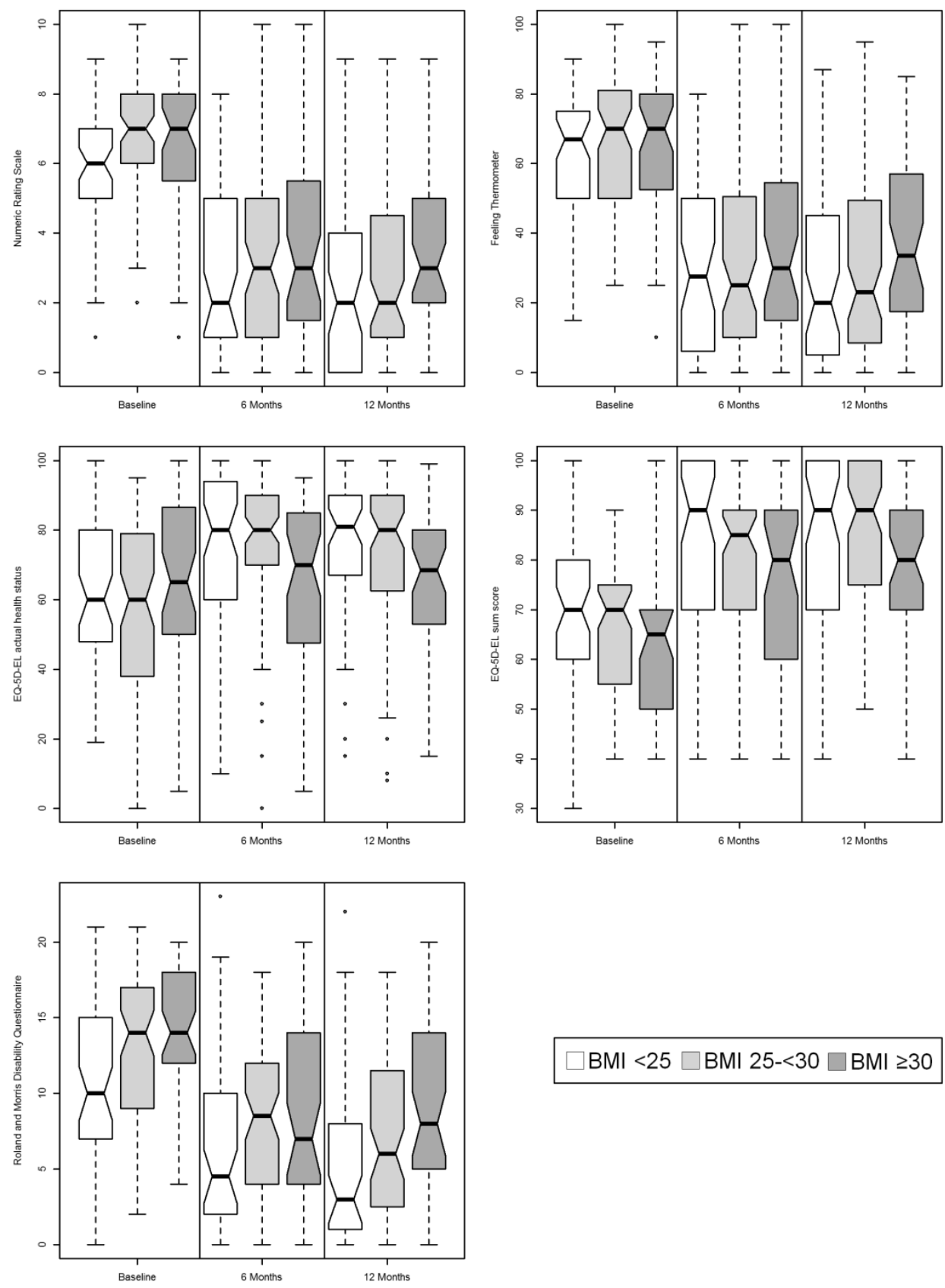

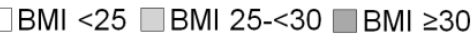




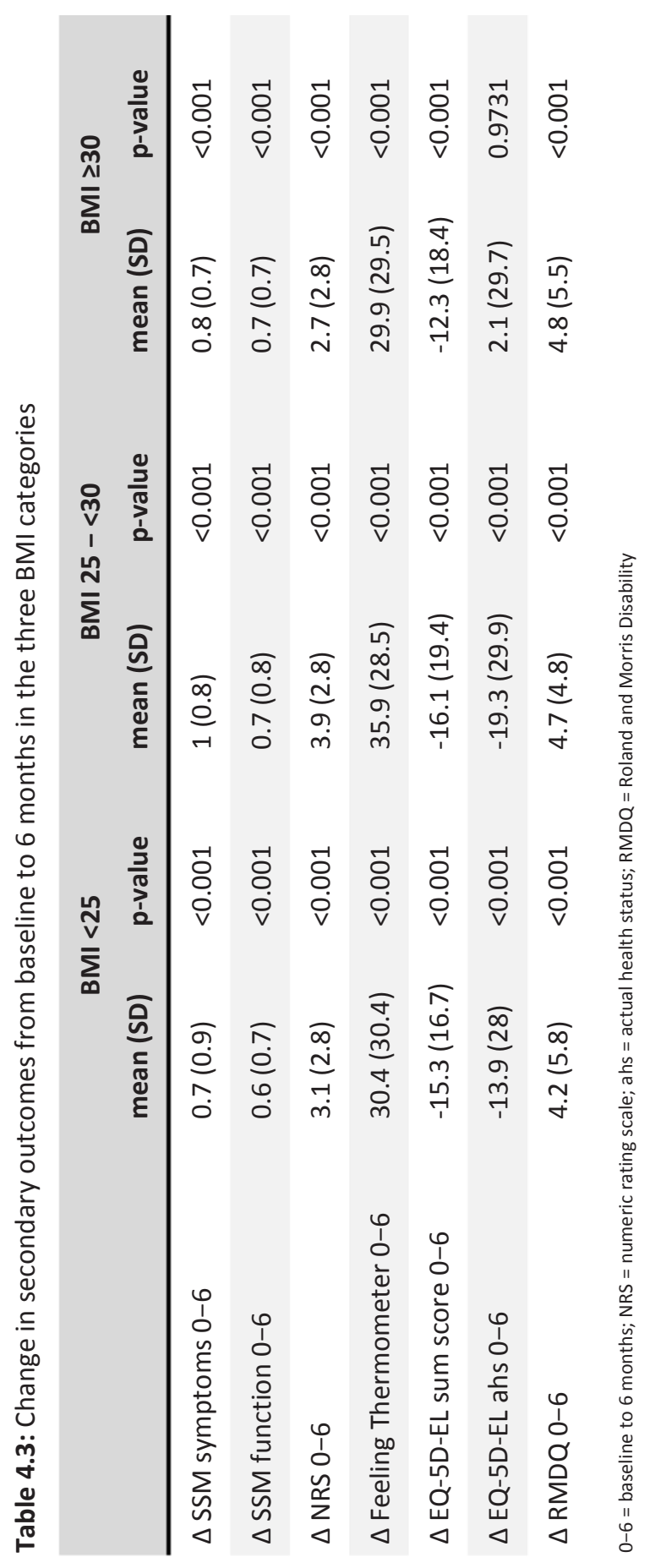




\section{Discussion}

This study investigated 166 consecutive patients treated with lumbar decompression due to symptomatic lumbar spinal stenosis. Of these, 44 (27\%) were obese according to the WHO classification by having a $\mathrm{BMI} \geq 30$. The percentage of patients in the obese group with a minimal clinically important improvement was $36 \%$ six months after baseline and even $48 \% 12$ months after baseline. With respect to changes in the SSM over time, median score values significantly improved in the obese patients from baseline to 6 months. Our study provided further evidence that simple decompression without fusion was an effective treatment for some patients with DLSS even with a BMI $\geq 30$. Forty-eight percent of the patients in the underweight and normal weight group, $61 \%$ in the pre-obese group, and $48 \%$ in the obese group reached MCID. Thus, our results do not support the hypothesis [18] that obesity is associated with worse outcome after decompression surgery in DLSS-patients compared to non-obese.

Two studies have shown a strong relationship between obesity and increased incidence of operative complications $[8,29]$. In addition, those authors concluded that patients with a higher BMI sustained increased transfusion requirements and may rise the

prevalence of perioperative complications. Further Ou et al. [30] presented their results of the impact of BMI on adjacent segment disease after lumbar fusion for degenerative spine disease. The authors concluded in their retrospective study of 190 patients that BMI is a risk factor for adjacent segment disease. Other studies of spinal surgery found no influence of obesity on clinical outcome $[18,31]$. In a retrospective subgroup analysis Rihn et al. [18] concluded that obesity does not affect the clinical outcome of operative treatment for lumbar spinal canal stenosis. Gepstein et al. [31] evaluated the effect of lumbar decompression in the aged obese patients and showed similar reduction in pain and overall improvement in obese and non-obese patients [31]. Furthermore, Djurasovic et al. [32] showed in a retrospective analysis of obese and non-obese patients undergoing lumbar fusion non-significant differences in back- and leg-pain as well as in ODI-score at two-year follow-up. Rosen et al. [33] showed no significant differences between body habitus and 
outcome after lumbar spine fusion surgery in terms of self-reported outcome measures, operative time and length of hospital stay.

Whether type of surgery is a predictor for outcome remains controversial and was not part of our study. We used a standard open posterior lumbar laminectomy or laminotomy at the affected level or levels without fusion. The decompression of the lateral recessus and foramina was performed when necessary. We included the number of levels of laminectomy in our multiple logistic model to obtain adjusted effects of BMI categories.

Our obese patient population had a slightly worse comorbidity score (CIRS) than the non-obese population reflecting some differences at baseline and in the perioperative situation. A prospective study by Andreshak et al. [7] comparing perioperative findings between obese and non-obese patients undergoing lumbar spine surgery demonstrated no differences in operative time, blood loss or hospital stay. BMI categories could also be associated with higher blood loss, longer hospital stay, higher reoperation-rate or higher postoperative infection rate. This was not part of our study and should be included in future studies with the LSOS-database. In addition, patients with higher risk factors (e.g., higher CIRS than in our cohort) may not have been recommended for surgery and were not included in our study.

Our study provides evidence that obesity is no contraindication for decompression surgery in DLSS-patients. BMI is clinically objective and modifiable. The control of body weight before and after operation may provide opportunities to reduce the rate of DLSS and could improve the outcome of decompression surgery.

There are two limitations to our study. First, different distributions of prognostic indicators, including gender, level of education and income between the three groups of patients may have an impact on the results. Second, we did not reassess BMI at specific postoperative time points. The reassessment of BMI at specific time-points would improve the understanding of the effect whether pain from a spine etiology restricts the ability of obese patients to lose weight.

As part of the lumbar spinal outcome study (LSOS; www.lumbalstenose.ch) [16], we will present our 2- and 3-year results in the future. A follow-up period of 2 years would 
strengthen our study to evaluate the continued effect of MCID. A longer follow-up period would evaluate and compare our results with other long-term studies [9, 34, 35] like the Main Lumbar Spine Study [36], or the Spine Patient Outcomes Trial (SPORT) [37].

Our results do not support the hypothesis that obesity is associated with worse outcome after decompression surgery in DLSS-patients compared to non-obese [18]. At the 6 months follow-up evaluation the obese and non-obese patient population showed significant mean improvements in all additional outcome categories. The only exception was the EQ-5D-EL (actual health status) that showed no significant improvement in the obese population. To our knowledge our study is the first one about the evaluation of decompression surgery in obesity to consider MCID in SSM. These MCID reflects changes after clinical interventions that are meaningful for the patient and reveal worthwhile changes in the outcome measures. Our study shows that even obese patients benefit from surgical treatment.

Obese patients can expect meaningful clinical improvement after lumbar decompression for symptomatic DLSS, but the percentage is smaller than in the group of pre-obese, normal weight and underweight patients. 


\section{References}

1. Body mass index - BMI [http://www.euro.who.int/en/health-topics/disease-prevention/nutrition/a-healthylifestyle/body-mass-index-bmi]

2. Flegal KM, Graubard BI, Williamson DF, Gail MH: Cause-specific excess deaths associated with underweight, overweight, and obesity. JAMA 2007, 298(17):2028-2037.

3. Borrell LN, Samuel L: Body mass index categories and mortality risk in US adults: the effect of overweight and obesity on advancing death. Am J Public Health, 104(3):512-519.

4. The challenge of obesity [http://www.euro.who.int/en/health-topics/noncommunicable-diseases/obesity /data-and-statistics]

5. Fransen $M$, Woodward $M$, Norton R, Coggan C, Dawe $M$, Sheridan N: Risk factors associated with the transition from acute to chronic occupational back pain. Spine (Phila Pa 1976) 2002, 27(1):92-98.

6. Ohba T, Saito T, Kawasaki N, Maekawa S, Haro H: Symptomatic spinal epidural lipomatosis with severe obesity at a young age. Orthopedics, 34(6):233.

7. Andreshak TG, An HS, Hall J, Stein B: Lumbar spine surgery in the obese patient. J Spinal Disord 1997, 10(5):376-379.

8. Patel N, Bagan B, Vadera S, Maltenfort MG, Deutsch H, Vaccaro AR, Harrop J, Sharan A, Ratliff JK: Obesity and spine surgery: relation to perioperative complications. J Neurosurg Spine 2007, 6(4):291-297.

9. Rihn JA, Kurd M, Hilibrand AS, Lurie J, Zhao W, Albert T, Weinstein J: The influence of obesity on the outcome of treatment of lumbar disc herniation: analysis of the Spine Patient Outcomes Research Trial (SPORT). The Journal of bone and joint surgery American volume, 95(1):1-8.

10. Pi-Sunyer X: The medical risks of obesity. Postgrad Med 2009, 121(6):21-33.

11. Marcus DA: Obesity and the impact of chronic pain. Clin J Pain 2004, 20(3):186-191.

12. Leboeuf-Yde C, Kyvik KO, Bruun NH: Low back pain and lifestyle. Part II--Obesity. Information from a population-based sample of 29,424 twin subjects. Spine (Phila Pa 1976) 1999, 24(8):779-783; discussion 783-774.

13. Webb R, Brammah T, Lunt M, Urwin M, Allison T, Symmons D: Prevalence and predictors of intense, chronic, and disabling neck and back pain in the UK general population. Spine (Phila Pa 1976) 2003, 28(11):1195-1202.

14. Liuke M, Solovieva S, Lamminen A, Luoma K, Leino-Arjas P, Luukkonen R, Riihimaki H: Disc degeneration of the lumbar spine in relation to overweight. International journal of obesity 2005, 29(8):903-908.

15. Department of Health. In. Canton of Zurich; 2013 [Personal Communication in April 2015].

16. Steurer J, Nydegger A, Held U, Brunner F, Hodler J, Porchet F, Min K, Mannion AF, Michel B: LumbSten: the lumbar spinal stenosis outcome study. BMC musculoskeletal disorders, 11:254.

17. Tomasino A, Parikh K, Steinberger J, Knopman J, Boockvar J, Hartl R: Tubular microsurgery for lumbar discectomies and laminectomies in obese patients: operative results and outcome. Spine (Phila Pa 1976) 2009, 34(18):E664-672.

18. Rihn JA, Radcliff K, Hilibrand AS, Anderson DT, Zhao W, Lurie J, Vaccaro AR, Freedman MK, Albert TJ, Weinstein JN: Does obesity affect outcomes of treatment for lumbar stenosis and degenerative spondylolisthesis? Analysis of the Spine Patient Outcomes Research Trial (SPORT). Spine (Phila Pa 1976) 2012, 37(23):1933-1946.

19. Stucki G, Liang MH, Fossel AH, Katz JN: Relative responsiveness of condition-specific and generic health status measures in degenerative lumbar spinal stenosis. J Clin Epidemiol 1995, 48(11):1369-1378.

20. Tuli SK, Yerby SA, Katz JN: Methodological approaches to developing criteria for improvement in lumbar spinal stenosis surgery. Spine 2006, 31(11):1276-1280.

21. Zucherman JF, Hsu KY, Hartjen CA, Mehalic TF, Implicito DA, Martin MJ, Johnson DR, 2nd, Skidmore GA, Vessa PP, Dwyer JW et al: A multicenter, prospective, randomized trial evaluating the $X$ STOP interspinous process decompression system for the treatment of neurogenic intermittent claudication: two-year follow-up results. Spine 2005, 30(12):1351-1358.

22. Hansraj KK, O'Leary PF, Cammisa FP, Jr., Hall JC, Fras Cl, Cohen MS, Dorey FJ: Decompression, fusion, and instrumentation surgery for complex lumbar spinal stenosis. Clin Orthop Relat Res 2001(384):18-25. 
23. Fokter SK, Yerby SA: Patient-based outcomes for the operative treatment of degenerative lumbar spinal stenosis. European spine journal : official publication of the European Spine Society, the European Spinal Deformity Society, and the European Section of the Cervical Spine Research Society 2006, 15(11):1661-1669.

24. Hinz A, Klaiberg A, Brahler E, Konig HH: [The Quality of Life Questionnaire EQ-5D: modelling and norm values for the general population]. Psychother Psychosom Med Psychol 2006, 56(2):42-48.

25. Roland M, Morris R: A study of the natural history of low-back pain. Part II: development of guidelines for trials of treatment in primary care. Spine 1983, 8(2):145-150.

26. Miller MD, Paradis CF, Houck PR, Mazumdar S, Stack JA, Rifai AH, Mulsant B, Reynolds CF: Rating Chronic Medical IIIness Burden in Geropsychiatric Practice and Research - Application of the Cumulative Illness RatingScale. Psychiat Res 1992, 41(3):237-248.

27. Beaton DE, Boers M, Wells GA: Many faces of the minimal clinically important difference (MCID): a literature review and directions for future research. Current opinion in rheumatology 2002, 14(2):109-114.

28. Chambers JM, Cleveland WS, Kleiner B, Tukey PA: Graphical Methods for Data Analysis: Wadsworth \& Brooks/Cole; 1983.

29. Shamji MF, Parker S, Cook C, Pietrobon R, Brown C, Isaacs RE: Impact of body habitus on perioperative morbidity associated with fusion of the thoracolumbar and lumbar spine. Neurosurgery 2009, 65(3):490-498; discussion 498.

30. Ou CY, Lee TC, Lee TH, Huang YH: Impact of Body Mass Index on Adjacent Segment Disease After Lumbar Fusion for Degenerative Spine Disease. Neurosurgery 2015, 76(4):396-401.

31. Gepstein R, Shabat S, Arinzon ZH, Berner Y, Catz A, Folman Y: Does obesity affect the results of lumbar decompressive spinal surgery in the elderly? Clin Orthop Relat Res 2004(426):138-144.

32. Djurasovic M, Bratcher KR, Glassman SD, Dimar JR, Carreon LY: The effect of obesity on clinical outcomes after lumbar fusion. Spine (Phila Pa 1976) 2008, 33(16):1789-1792.

33. Rosen DS, Ferguson SD, Ogden AT, Huo D, Fessler RG: Obesity and self-reported outcome after minimally invasive lumbar spinal fusion surgery. Neurosurgery 2008, 63(5):956-960; discussion 960.

34. McGuire KJ, Khaleel MA, Rihn JA, Lurie JD, Zhao W, Weinstein JN: The effect of high obesity on outcomes of treatment for lumbar spinal conditions: subgroup analysis of the spine patient outcomes research trial. Spine, 39(23):1975-1980.

35. Weinstein JN, Lurie JD, Tosteson TD, Zhao W, Blood EA, Tosteson AN, Birkmeyer N, Herkowitz H, Longley M, Lenke $L$ et al: Surgical compared with nonoperative treatment for lumbar degenerative spondylolisthesis. fouryear results in the Spine Patient Outcomes Research Trial (SPORT) randomized and observational cohorts. The Journal of bone and joint surgery American volume 2009, 91(6):1295-1304.

36. Atlas SJ, Keller RB, Wu YA, Deyo RA, Singer DE: Long-term outcomes of surgical and nonsurgical management of lumbar spinal stenosis: 8 to 10 year results from the maine lumbar spine study. Spine 2005, 30(8):936-943.

37. Birkmeyer NJ, Weinstein JN, Tosteson AN, Tosteson TD, Skinner JS, Lurie JD, Deyo R, Wennberg JE: Design of the Spine Patient outcomes Research Trial (SPORT). Spine (Phila Pa 1976) 2002, 27(12):1361-1372. 


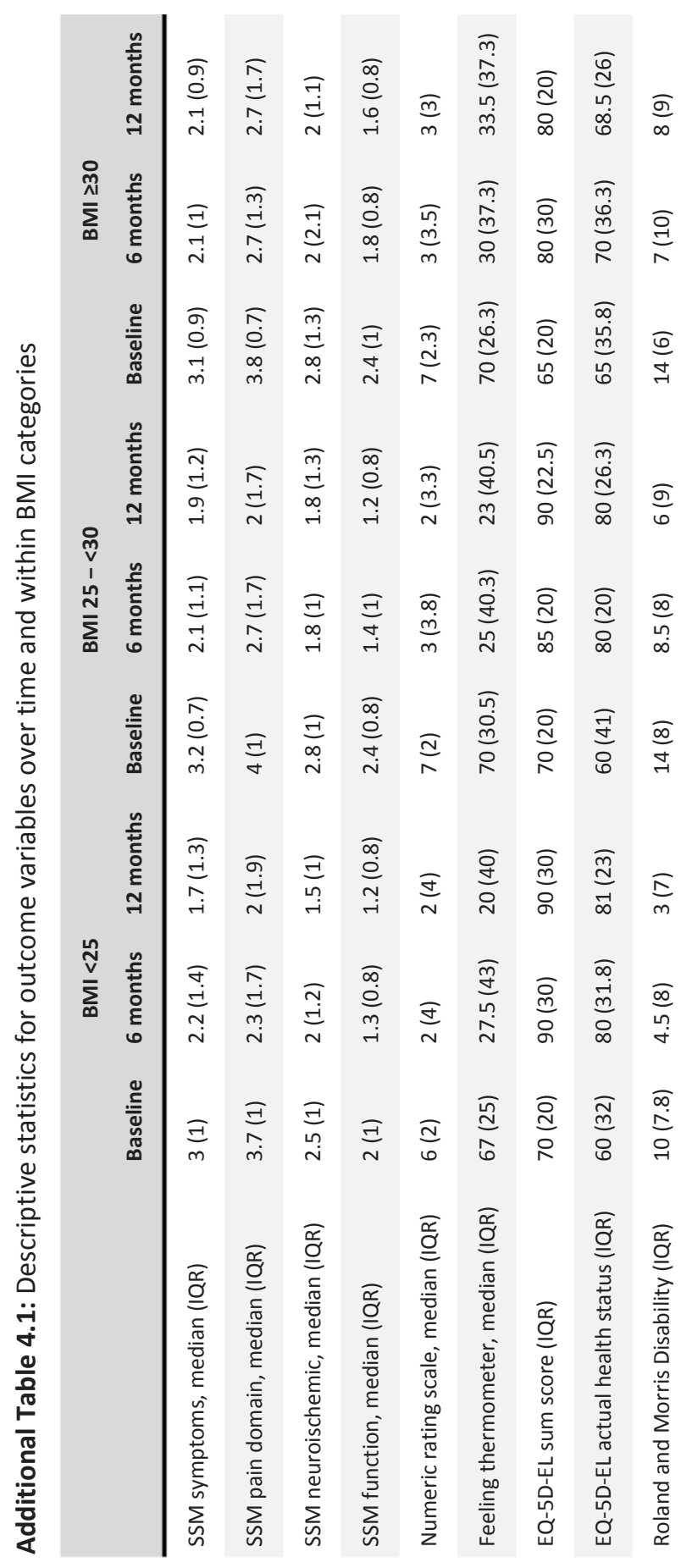






\section{Chapter 5}

\section{The Influence of Catastrophizing on}

Treatment Outcome in Patients with Non-Specific Low Back Pain A Systematic Review

Maria M. Wertli, M.D. Jakob M. Burgstaller, M.D., D.M.D. Sherri Weiser, Ph.D. Johann Steurer, M.D. Reto Kofmehl, BSc. Ulrike Held, Ph.D. 


\section{Abstract}

Study design: Systematic review

Objective: The aim of the current study was to assess the effect of catastrophizing on treatment efficacy and outcome in patients treated for low back pain.

Summary of Background Data: Psychological factors including catastrophizing thoughts are believed to increase the risk for chronic low back pain. The influence of catastrophizing is debated.

Methods: In September 2012 the following databases were searched: BIOSIS, CINAHL, Cochrane Library, Embase, OTSeeker, PeDRO, Psyclnfo, Medline, Scopus, and Web of Science. For 50 of 706 references full text was assessed. Results based on 11 studies were included in this analysis.

Results: In 11 studies, a total of 2,269 patients were included. Seven studies were of good and four of moderate methodological quality. Heterogeneity in study settings, treatments, outcomes, and patient populations impeded meta-analysis. Catastrophizing at baseline was predictive for disability at follow-up in four studies and for pain in two studies. Three studies found no predictive effect of catastrophizing. A mediating effect was found in all studies $(n=5)$ assessing the impact of a decrease in catastrophizing during treatment. A greater decrease was associated with better outcome. Most studies that investigated the moderating effects on treatment efficacy found no effect $(n=5)$. However, most studies did not look for a direct interaction between the treatment and catastrophizing thoughts. No study investigated the influence of catastrophizing on work-related outcomes including return to work.

Conclusion: Catastrophizing predicted degree of pain and disability and mediated treatment efficacy in most studies. The presence of catastrophizing should be considered in patients with persisting back pain. Limited evidence was found for the moderating effects on treatment efficacy. Future research should aim to clarify the role of catastrophizing as a moderator of outcome and investigate its importance for work-related outcomes. 


\section{Introduction}

Patients' attitudes and coping mechanisms have been shown to play a causal role in the chronification of low back pain (LBP). Almost all adults once in their lifetime complain about LBP, but only 10-15 percent develop chronic LBP [1]. This small percentage of patients accounts for three-quarters of the costs of medical care and lost productivity associated with LBP $[2,3]$. There is consensus among experts to avoid unnecessary investigation and overtreatment of patients with acute LBP by treating symptomatically with encouragement to return to normal activity [4]. Persisting pain for several weeks strongly predicts the development of chronic low back pain, a condition where complete recovery and return to full physical function are often difficult to achieve [5]. Current research aims to identify risk indicators for delayed recovery in patients with sub-acute LBP in order to optimize treatment and avoid chronification. Targeted and timely interventions in patients at risk for chronic pain facilitate recovery and may reduce health care costs [6].

The Fear Avoidance Model (FAM) is a theoretical model that describes how psychological factors affect the experience of pain and the development of chronic pain and disability [7]. Within this theoretical model, the presence of catastrophizing thoughts or behavior is a prerequisite for poor outcome and is defined as "an exaggerated negative mental set brought to bear during actual or anticipated painful experience." [8] It is theorized that negative beliefs about pain and/or negative illness information leads to a catastrophizing response in which patients imagine the worst possible outcome. This leads to fear of activity and avoidance that in turn causes disuse and resultant distress, reinforcing the original negative appraisal in a deleterious cycle [7]. In chronic cases, catastrophizing may become a cognitive coping strategy based on the patient's characteristic coping style or because catastrophizing is believed to have prevented severe pain or other aversive outcomes in the past [9]. The FAM suggests that patients without catastrophizing and fear avoidance beliefs (FAB) are more likely to confront pain problems and are more active in the coping process. This type of "good" coping has been used to develop interventions for those high in catastrophizing and FAB. 
Although there is some empirical support for the FAM, it is a matter of debate as to how and when to best assess catastrophizing in clinical practice. Current treatment guidelines for LBP recommend the timely identification and initiation of multidisciplinary treatment for other psychological factors (e.g. depression, distress, job dissatisfaction) associated with increased risk for delayed recovery $[4,10,11]$. Whether catastrophizing influences treatment outcome in patients with low back pain remains unclear.

To date, the role of catastrophizing on treatment efficacy in LBP has not been reviewed systematically. The aim of this review is to assess the influence of catastrophizing on treatment response in randomized controlled trials (RCTs) in patients with LBP.

\section{Materials and methods}

This systematic review follows the recommendation of the Preferred Reporting Items for Systematic Reviews and Meta-Analyses (PRISMA) statement (Figure 5.1) on conducting systematic reviews of RCTs [12].

\section{Literature Search}

We identified all RCTs meeting our eligibility criteria published between January 1980 and September 2012. The following databases were search by an experienced librarian (MG): BIOSIS, CINAHL, Cochrane Library, Embase, OTSeeker, PeDRO, Psyclnfo, Medline, Scopus, and Web of Science. Search terms for catastrophizing were identified in the literature (e.g. catastrophising, catastrophization, catastrophisation). Two detailed search strategies are depicted in Appendix 5.1. To ensure the completeness of the literature search, one reviewer (JB) conducted an electronic hand search of the six most often retrieved journals and added all potentially eligible references not retrieved by the systematic search. In addition, bibliographies of included studies relevant to the research question were searched and potential eligible references included in the full text review (inclusion and exclusion criteria applied). 


\section{Eligibility Criteria}

All RCTs were considered eligible that met the following criteria: they reported results concerning patients seeking care for LBP, they assessed the influence of catastrophizing on treatment outcome, and they were published between January 1980 and September 2012. We focused on RCTs with at least 30 patients per group because of a concern about sample size. Assuming a reduction in perceived disability that was one-third greater in the treatment group when compared to the reference group, a sample size of 37 patients per group would be sufficient to detect the difference in allowing a drop-out rate of $15 \%$ (alpha 0.80 , significance level 0.05 ). No limits for the study setting or language of the publication were applied. Excluded were reports from conference proceedings.

\section{Study Selection, Data Extraction and Synthesis}

The bibliographic details of all retrieved articles were stored. Two reviewers (MW and JB) independently screened all references by title and abstract and reviewed full texts in all studies that met the pre-defined eligibility criteria. Disagreements were discussed and resolved by consensus or by third-party arbitration (SW). Alternative researchers with specific language proficiencies were approached for non-English language references.

\section{Outcome Definition}

All investigated outcomes were extracted and categorized into work-related (e.g. sick days, employment) and non-work-related outcomes (e.g. pain, perceived disability). Each method of outcome measurement was appraised with regards to their validity and reliability and was operationalized [e.g. perceived disability measured by Oswestry Disability Index (ODI)].

\section{Quality Assessment}

The internal validity of each study was assessed using the Scottish Intercollegiate Guidelines Network (SIGN) Methodology checklist for RCTs by the two reviewers independently (MW and JB) [13]. 
Quality was rated as follows:

- $\square$ High (++): most of the criteria have been fulfilled. If not fulfilled, the conclusions of the study are very unlikely to alter.

- $\square$ Moderate (+): some criteria fulfilled. Criteria not adequately described are unlikely to alter the conclusions.

- $\square$ Low (-): few or no criteria fulfilled. The conclusions are likely to alter.

As recommended by SIGN, studies rated by both reviewers as low quality were excluded from further analysis.

\section{Operationalization of Catastrophizing as Predictor, Mediator, and Moderator}

The definitions for predictor, mediator, and moderator were adopted from Pincus and colleagues [14]:

- $\square$ Predictor: baseline catastrophizing affects outcome but does not interact with the allocated treatment intervention.

- $\square$ Mediator: change in catastrophizing during treatment impacts outcome, with or without interacting with allocated treatment.

- $\square$ Moderator: catastrophizing at baseline interacts with treatment.

The quality of the moderator analysis was assessed for each study by two reviewers (MW and JB) and discussed with an experienced statistician (UH). The following factors were considered: 1) Was the analysis a priori defined; 2) Was the selection of factors for the analysis clinically plausible; 3 ) Were moderators measured prior to randomization; and 4) Was there an adequate quality of measurement of baseline factors, that contains an explicit test of the interaction between moderator and treatment?

\section{Psychometric Properties and Description of the Questionnaires}

The Pain Catastrophizing Scale (PCS) consists of 13 questions $[15,16]$. The score is a sum of all 13 items (each item on a scale of $0-4$, range $0-52$ ). The higher the score, the more catastrophizing thoughts are present. The internal consistency is high (Cronbach's alpha 
0.87 to 0.95 ) [16-18]. The three catastrophizing subscales are: rumination (sum of item 8 , $9,10,11$; range $0-16$ ), magnification (sum of items $6,7,13$; range $0-12$ ), and helplessness (sum of items $1,2,3,4,5,12$; range $0-24$ ). The internal consistency is moderate to high (Cronbach's alpha: rumination $0.87-0.95$, magnification $0.66-0.88$, helplessness $0.78-0.91)[16,18]$.

The Coping Strategies Questionnaire (CSQ) consists of a 48-item checklist assessing six cognitive and two behavioral coping strategies [9]. Six questions assess catastrophizing (item $5,12,14,28,38,42$ ). The score is computed by summing responses to the six items (each item is scored $0-6$ points, range 0 to 36 ). Internal consistency and reliability in a low back pain population was good in all sub-scales (Cronbach's alpha between 0.71 and 0.85 [9]). The Cronbach's alpha of the catastrophizing subscale was between 0.78 [9] and 0.84 [19].

The Pain-Related Self-Statements Scale (PRSS) is intended to assess situation-specific cognitions that either promote or hinder attempts to cope with pain [20]. Catastrophizing is assessed with the items $2,4,7,9,10,13,15,16$ and has been shown to be reliable and valid (Cronbach's alpha 0.83) [20]. Items are scored on a Likert scale (0 to 5 points); the score is the average of all items (range 0 to 5 ). Higher values indicate more catastrophizing.

The Pain Cognition List (PCL) is a 50 item scale that measures a verbal-cognitive response system of chronic pain [21]. Catastrophizing is measured by 17 items (each item scored on a five-point Likert scale; 1 : highly disagree to 5 : totally agree). A sum score is obtained per subscale for each patient. The catastrophizing subscale (range $17-85$ ) has been shown to be reliable and valid (Cronbach's alpha 0.88) [21, 22].

The Pain Coping and Cognition List (PCCL) is a 42-item self-report questionnaire, developed on the basis of the PCL, CSQ, and MPLC (Multidimensional Pain Locus of Control Questionnaire) covering attributions, expectancies, and cognitive coping strategies. Each item is scored on a six-point Likert scale (1: totally disagree to 6: totally agree). Catastrophizing is covered by one of the four subscales ( 12 items). The internal consistencies of the Catastrophizing subscale proved to be good (Cronbach's alpha 0.85) [23, 24]. 
The PCS and the CSQ are considered to be equally reliable and valid for the measurement of catastrophizing thoughts $[25,26]$. It has therefore been proposed to use the PCS in research that aims to explore catastrophizing [25]. The PRSS is considered to be more pain-specific when compared to the CSQ. A direct comparison of the PRSS and the CSQ showed a moderately strong linear relationship between the two scales ( $r=0.56)$ [20]. The correlation between the catastrophizing subscale of the PCL and the CSQ or PCS was high $(r=0.70)[22]$.

\section{Statistical analysis}

Due to heterogeneous study populations, measurements, and scales used as well as outcomes investigated, only descriptive statistics were used to summarize findings across all cohort studies. Forest plots were generated based on values reported using $R$ statistical software for Windows [27].

\section{Results}

\section{Study Selection}

The search and inclusion process is summarized in Figure 5.1. Out of 1,473 records, 50 were reviewed in full text. The full text assessment utilizing the inclusion and exclusion criteria resulted in the exclusion of 37 studies. The main reasons for exclusion were are summarized in Figure 5.1. In total, 13 publications based on 11 RCTs were included in the analysis.

\section{Study Characteristics}

RCTs conducted in a general practitioner setting (GP, $n=3)$, in rehabilitation clinics $(n=3)$, hospitals / specialists ( $n=3)$, and physical therapy outpatient clinics $(n=2)$ (baseline characteristics in Table 5.1). The study quality was good in seven and moderate in six studies (Appendix 5.2). The primary outcome in most RCTs was self-report measurements (i.e. pain, disability, change in pain or disability). No RCT investigated return to work or other 
Figure 5.1: Study flow

\begin{tabular}{|c|c|}
\hline \multicolumn{2}{|c|}{$\begin{array}{l}\text { Number of records identified } \\
\text { through database search: } \\
\text { Total } \mathbf{n}=\mathbf{1 4 7 3}\end{array}$} \\
\hline \multicolumn{2}{|l|}{$\nabla$} \\
\hline \multicolumn{2}{|c|}{$\begin{array}{l}\text { Number of records after removal } \\
\text { of duplicates: }\end{array}$} \\
\hline BIOSIS & $n=2$ \\
\hline CINHAHL & $\mathrm{n}=8$ \\
\hline Chochrane Library & $n=3$ \\
\hline Embase & $\mathrm{n}=51$ \\
\hline OT Seeker & $\mathrm{n}=2$ \\
\hline PeDRO & $n=2$ \\
\hline Psclnfo & $\mathrm{n}=35$ \\
\hline PubMed/Medline & $n=174$ \\
\hline Scopus & $n=8$ \\
\hline Web of Science & $n=366$ \\
\hline Total $n=651$ & \\
\hline
\end{tabular}
Hand search/screen of:
Journals most often
$\mathrm{n}=35$
publishing about the topic
Bibliographies
$\mathrm{n}=20$

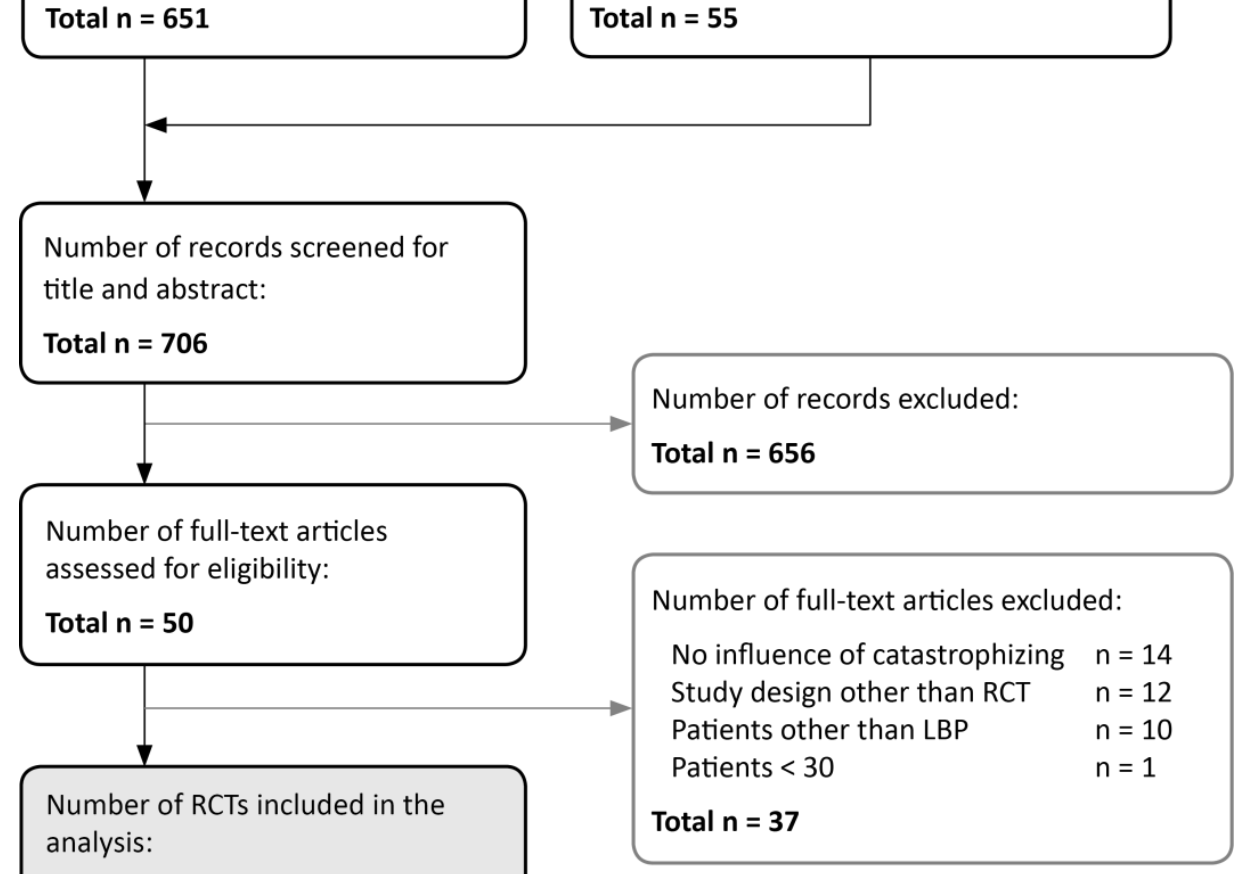

Total $\mathbf{n}=\mathbf{1 1}$

13 publications based on 11 RCTs 
work-related outcomes. Five publications (four RCTs) used the CSQ for assessing catastrophizing [28-32], three the PCS (two RCTs) [33-35], two the PCL [36, 37], two the PRSS catastrophizing subscale $[38,39]$, and one the PCCL [24]. Cut-off values were only applied once (median split $>11, \leq 11$ ) [30].

Table 5.1: Baseline characteristics of studies investigating Low Back Pain

\begin{tabular}{|c|c|c|c|c|c|c|c|}
\hline \multicolumn{8}{|c|}{ Less than six months } \\
\hline Study & Setting & $\begin{array}{l}\text { Diagnostic } \\
\text { criteria }\end{array}$ & $\begin{array}{l}\text { DD: days } \\
\text { mean (SD) }\end{array}$ & $\begin{array}{l}\text { Age } \\
\text { mean } \\
\text { (SD) }\end{array}$ & Treatment & $n(f)$ & FU \\
\hline $\begin{array}{l}\text { Jellema, } \\
\text { Vlaeyen, } \\
2006 \text { [29] }\end{array}$ & $\begin{array}{l}\text { Randomization } \\
\text { on level GP } \\
\text { practice. Partici- } \\
\text { pating GPs } \\
\text { selected } 10 \\
\text { consecutive } \\
\text { patients, Nether- } \\
\text { lands }\end{array}$ & $\begin{array}{l}\text { NSLBP, } 14.6 \\
\text { \% radiating } \\
\text { below the } \\
\text { knee }\end{array}$ & $\begin{array}{l}\text { UC median } \\
14 \text { IQR (7- } \\
21) \\
\text { MIC } 11 \text { (5- } \\
21)\end{array}$ & $\begin{array}{l}\text { UC } 42.0 \\
(12) ; \\
\text { MIC } \\
43.4 \\
(11.1)\end{array}$ & $\begin{array}{l}\text { UC }(n=171) \\
\text { vs. } \\
\operatorname{MIC}(n=143)\end{array}$ & $\begin{array}{l}314 \\
(149)\end{array}$ & 6 weeks \\
\hline $\begin{array}{l}\text { Jellema, } \\
2005 \text { [30] }\end{array}$ & $\begin{array}{l}\text { Same study as } \\
\text { Jellema, Vlaeyen, } \\
2006\end{array}$ & & & & & & $\begin{array}{l}52 \\
\text { weeks }\end{array}$ \\
\hline $\begin{array}{l}\text { Hancock, } \\
\text { Davies, } \\
2009 \text { [39] }\end{array}$ & $\begin{array}{l}\text { Patient present- } \\
\text { ing in } 40 \text { general } \\
\text { practitioners } \\
\text { working in } \\
\text { primary practice } \\
\text { across Sydney, } \\
\text { Australia }\end{array}$ & $\begin{array}{l}\text { NSLBP: } 12 \text { th } \\
\text { rib to but- } \\
\text { tock crease } \\
\text { with moder- } \\
\text { ate pain and } \\
\text { moderate } \\
\text { disability } \\
\text { (SF-36, item } \\
7 / 8 \text { ) }\end{array}$ & $9.13(9.31)$ & $\begin{array}{l}40.7 \\
(15.6)\end{array}$ & $\begin{array}{l}\text { Spinal mani- } \\
\text { pulation + } \\
\text { Diclofenac / } \\
\text { Placebo ( } \mathrm{n}= \\
\text { 119) vs. Place- } \\
\text { bo Spinal } \\
\text { manipulation } \\
+ \text { Diclofenac / } \\
\text { Placebo ( } \mathrm{n}= \\
\text { 120) }\end{array}$ & $\begin{array}{l}239 \\
(105)\end{array}$ & $\begin{array}{l}\text { Time to } \\
\text { recovery }\end{array}$ \\
\hline $\begin{array}{l}\text { Smeets, } \\
2009 \text { [38] }\end{array}$ & $\begin{array}{l}\text { Recruitment by } \\
\text { clinician referral, } \\
\text { advertisement, } \\
\text { waiting list PT } \\
\text { clinics, treatment } \\
\text { in } 7 \text { physiothera- } \\
\text { py clinics in } \\
\text { Australia and } \\
\text { New Zealand }\end{array}$ & $\begin{array}{l}\text { NSLBP } \geq 6 \\
\text { weeks but } \\
\leq 12 \text { weeks }\end{array}$ & $\begin{array}{l}42-56(48 \%), \\
63-77(37 \%), \\
>84(15 \%)\end{array}$ & $\begin{array}{l}49.9 \\
(15.8)\end{array}$ & $\begin{array}{l}\text { EA }(n=63) \text { vs } \\
\text { SEA }(n=63) \text { vs } \\
\text { ESA }(n=65) \text { vs } \\
\text { SESA }(n=68)\end{array}$ & $\begin{array}{l}259 \\
(124)\end{array}$ & 1 year \\
\hline
\end{tabular}


Table 5.1 continued

\begin{tabular}{|c|c|c|c|c|c|c|}
\hline $\begin{array}{l}\text { George, } \\
\text { Zeppieri, } \\
2008 \text { [34] }\end{array}$ & $\begin{array}{l}\text { Patients referred } \\
\text { for rehabilitation } \\
\text { to three partici- } \\
\text { pating University } \\
\text { of Florida affili- } \\
\text { ated clinics, } \\
\text { U.S.A. }\end{array}$ & $\begin{array}{l}\text { NSLBP + } \\
\text { SLBP Quebec } \\
\text { Task Force } \\
\text { on Spinal } \\
\text { Disorders } \\
\text { (QTFSD). Leg } \\
\text { pain TBC } \\
38 \%, \text { GA } \\
49 \%, \text { GX } 42 \%\end{array}$ & $\begin{array}{l}\text { TBC 47 (34), } \\
\text { TBC + GA } 41 \\
(39), \\
\text { TBC + GX } 69 \\
(49)\end{array}$ & $\begin{array}{l}37.5 \\
(14.9)\end{array}$ & $\begin{array}{l}\text { Treatment- } \\
\text { based classifi- } \\
\text { cation (TBC) } \\
\text { physical } \\
\text { therapy vs. } \\
\text { TBC + graded } \\
\text { activity (GA) } \\
\text { vs. } \\
\text { TBC + graded } \\
\text { exposure (GX) }\end{array}$ & $108(74)$ \\
\hline
\end{tabular}

\begin{tabular}{|c|c|c|c|}
\hline $\begin{array}{l}\text { Beneciuk, } \\
2012 \text { [35] }\end{array}$ & $\begin{array}{l}\text { Same study as } \\
\text { George, Zeppieri } \\
2008\end{array}$ & & \\
\hline $\begin{array}{l}\text { Hill, } \\
2008 \text { [32] }\end{array}$ & $\begin{array}{l}\text { Patient recruited } \\
\text { from } 28 \text { general } \\
\text { practices, treat- } \\
\text { ed by trial phys- } \\
\text { io-therapists, } \\
\text { North Stafford- } \\
\text { shire, UK }\end{array}$ & $\begin{array}{l}\text { NSLBP } \leq 12 \\
\text { weeks for } \\
\text { the first or } \\
\text { second time }\end{array}$ & $\leq 12$ weeks \\
\hline $\begin{array}{l}\text { Wessels, } \\
2007 \text { [28] }\end{array}$ & $\begin{array}{l}\text { Patients recruit- } \\
\text { ed from several } \\
\text { hospitals, treat- } \\
\text { ment setting n.r., } \\
\text { Germany }\end{array}$ & $\begin{array}{l}\text { NSLBP. At } \\
\text { least } 1 \text { LBP } \\
\text { episode in } \\
\text { the last } 2 \\
\text { years }\end{array}$ & n.r. \\
\hline
\end{tabular}

$\begin{array}{llll}40.65 & \text { Pain manage- } & 402 & 1 \text { year } \\ (11.8) & \text { ment program } & (210) & \\ & \text { or PT + ma- } \\ & \text { nipulation }\end{array}$

More than 6 months

\begin{tabular}{|c|c|c|c|c|c|c|c|}
\hline Study & Setting & $\begin{array}{l}\text { Diagnostic } \\
\text { criteria }\end{array}$ & DD & $\begin{array}{l}\text { Age } \\
\text { mean } \\
\text { (SD) }\end{array}$ & Treatment & $n(f)$ & FU \\
\hline $\begin{array}{l}\text { Leeuw, } \\
2008 \text { [33] }\end{array}$ & $\begin{array}{l}\text { Patients recruit- } \\
\text { ed via } 9 \text { various } \\
\text { outpatient } \\
\text { facilities or } \\
\text { newspaper-ad, } \\
\text { treated in } 4 \\
\text { outpatient } \\
\text { rehabilitation } \\
\text { centers, Nether- } \\
\text { lands }\end{array}$ & $\begin{array}{l}\text { NSLBP } \geq 3 \\
\text { months, } \\
\text { RDQ }>3, \text { TSK } \\
>33\end{array}$ & $\begin{array}{l}9.0 \text { years } \\
(9.4)\end{array}$ & $\begin{array}{l}45.3 \\
(9.45)\end{array}$ & $\begin{array}{l}\text { Exposure in } \\
\text { vivo }(n=42) \\
\text { vs } \\
\text { GA }(n=43)\end{array}$ & $85(41)$ & $\begin{array}{l}6 \\
\text { months }\end{array}$ \\
\hline $\begin{array}{l}\text { Oosterhof, } \\
2008 \text { [36] }\end{array}$ & $\begin{array}{l}\text { Patients referred } \\
\text { by family doctor } \\
\text { or medical } \\
\text { specialist to the } \\
\text { Pain Centre of } \\
\text { Radboud Univer- }\end{array}$ & $\begin{array}{l}\text { NSLBP } \geq 6 \\
\text { months }\end{array}$ & $\begin{array}{l}6.4 \text { years } \\
(0.6)\end{array}$ & $\begin{array}{l}50.2 \\
(1.1)\end{array}$ & $\begin{array}{l}\text { TENS }(n=81) \\
\text { vs } \\
\text { sham TENS }(n= \\
82)\end{array}$ & 165 (97) & 10 days \\
\hline
\end{tabular}


sity Medical
Centre Nijme-
gen, Netherlands

Table 5.1 continued

\begin{tabular}{|c|c|c|c|c|c|c|c|}
\hline Study & Setting & $\begin{array}{l}\text { Diagnostic } \\
\text { criteria }\end{array}$ & DD & $\begin{array}{l}\text { Age } \\
\text { mean } \\
\text { (SD) }\end{array}$ & Treatment & $n(f)$ & FU \\
\hline $\begin{array}{l}\text { Smeets, } \\
2006 \text { [37] }\end{array}$ & $\begin{array}{l}\text { Patients referred } \\
\text { by GPs and } \\
\text { medical special- } \\
\text { ists to } 3 \text { Dutch } \\
\text { outpatient } \\
\text { rehabilitation } \\
\text { centers, the } \\
\text { Netherlands }\end{array}$ & $\begin{array}{l}\text { NSLBP } \geq 3 \\
\text { months, } \\
\text { ability to } \\
\text { walk at least } \\
100 m \text { with- } \\
\text { out interrup- } \\
\text { tion }\end{array}$ & $\begin{array}{l}4.8 \text { years } \\
(6.1)\end{array}$ & $\begin{array}{l}41.81 \\
(9.92)\end{array}$ & $\begin{array}{l}\text { APT }(n=52) \text { vs } \\
\text { CBT }(n=55) \text { vs } \\
\text { CT }(n=55) \text { vs } \\
\text { WL }(n=49)\end{array}$ & $\begin{array}{l}227 \\
(105)\end{array}$ & 70 days \\
\hline $\begin{array}{l}\text { Mannion, } \\
1999 \text { [31] }\end{array}$ & $\begin{array}{l}\text { Hospital based } \\
\text { outpatient } \\
\text { treatment (PT), } \\
\text { recruitment by } \\
\text { advertisement, } \\
\text { Switzerland }\end{array}$ & $\begin{array}{l}\text { NSLBP } \pm \\
\text { referred } \\
\text { pain (non- } \\
\text { radicular), } \\
\text { continual or } \\
\text { recurrent, } \\
\geq 3 \text { months, } \\
\text { causing } \\
\text { absence } \\
\text { from work } \\
\text { or solicita- } \\
\text { tion of } \\
\text { medical } \\
\text { attention }\end{array}$ & $\begin{array}{l}10.9 \text { years } \\
(9.4)\end{array}$ & $\begin{array}{l}45.1 \\
(10.0)\end{array}$ & $\begin{array}{l}\text { Modern active } \\
\text { PT ( } n=49 \text { ) vs. } \\
\text { muscle condi- } \\
\text { tioning on } \\
\text { training devic- } \\
\text { es ( } n=49 \text { ) vs. } \\
\text { low-impact } \\
\text { aerobics ( } n= \\
50 \text { ) }\end{array}$ & $148(84)$ & $\begin{array}{l}6 \\
\text { months }\end{array}$ \\
\hline $\begin{array}{l}\text { Spinho- } \\
\text { ven, } 2004 \\
{[24]}\end{array}$ & $\begin{array}{l}\text { Patients referred } \\
\text { by GPs and } \\
\text { medical special- } \\
\text { ists to Hoens- } \\
\text { broeck Rehabili- }\end{array}$ & $\begin{array}{l}\text { NSLBP } \geq 6 \\
\text { months }\end{array}$ & $\begin{array}{l}10.1 \text { months } \\
\text { (8.7) }\end{array}$ & $\begin{array}{l}40.0 \\
(9.2)\end{array}$ & $\begin{array}{l}\text { OPCO }(n=59) \\
\text { vs } \\
\text { OPDI }(n=58) \\
\text { vs } \\
\text { WLC }(n=31)\end{array}$ & 159 (94) & 1 year \\
\hline
\end{tabular}

LBP: low back pain; NSLBP, non-specific low back pain; SLBP, specific low back pain; PF, prognostic factor reporting of the total of 16 possible domains; SIGN, SIGN quality rating: ++ high quality, + moderate quality; DD, Disease Duration; FU, Follow-up; TBC, treatment-based classification; GA: graded activity; GX, graded exposure; PT, physical therapy; UC, usual care; MIS, minimal intervention strategy; $A M$, active management; $C B T$, cognitive behavioral therapy; $A P T$, active physical therapy; $C T$, combined therapy; WL, waiting list; GivE, Graded in vivo exposure; QA, Questionnaire used; FAB, Fear Avoidance Beliefs; FABQ, fear avo idance questionnaire; FABQ-P, FABQ physical activity sub-scale; FABQ-W: FABQ work sub-scale; TSK: Tampa Scale of Kinesiophobia; $\mathrm{OR}$, odds ratio; MA, multiple regression analysis; IQR: interquartile range; CMID, clinical meaningful important difference; Log. Reg., logistic regression; U.L., univariante logistic regression; L.R., linear regression; ODI, Oswestry Disability Index: higher score indicates more disability: CMID $=\geq 12$ points reduction; RTW, return to work; $C P G$, chronic pain grade (von Korff) questionnaire: higher score indicates more pain; GCP, graded chronic pain scale; PDI, pain disability index (Pollard, 1984): higher score indicates more disability; RMQ, Roland Morris Questionnaire: higher score indicates more disability: CMID = $\geq 2-3$ point reduction, $\geq 30 \%$ change; SF-36D, physical health sub-score: higher score indicates higher level of functioning; SF-36M, mental health sub-score: higher score indicates higher level of functioning; EA, exercise + advice; SEA, sham exercise + advice; ESA, exercise + sham advice; SESA, sham exercise + sham advice; OPCO, operant behavioral treatment and cognitive coping skills training; OPDI, operant behavioral treatment and group discussion; WLC, waiting-list control condition; SIGN, Scottish Intercollegiate Guidelines Network; GP, general practitioner; TENS, transcutaneous electrical nerve stimulation; SD, standard deviation; n.r., not reported 


\section{The Influence of Catastrophizing on Treatment Efficacy and Outcome}

A summary of the predictor-, mediator-, and moderator-analyses is provided in Table 5.2. Catastrophizing at baseline predicted treatment outcome without interacting with the treatment in four RCTs $[28,33,35,37]$, but was not predictive in two other RCTs [24, 32, 36]. High catastrophizing was associated with more disability at follow-up in four RCTs [28, $33,35,37]$ and with more pain in two RCTs $[35,37]$. Only one RCT failed to find an association between high catastrophizing scores and disability [32]. In this RCT, baseline catastrophizing was very low (mean CSQ 8.4 on a 0 to 36 points scale). Catastrophizing was not predictive for treatment satisfaction [36].

In all five RCTs that investigated the mediating effects of a change in catastrophizing from baseline to follow-up, a decrease in catastrophizing was found to be associated more daily activity [28], more internal pain control [24], a greater decrease in highest level of pain (not for average pain or disability) in one RCT [31], and more decrease in pain [34] and disability in another [33] (Table 5.3).

Catastrophizing moderated treatment efficacy in two publications based on one RCT $[29,30]$ but not in five other RCTs $[28,33,36,38,39]$. One RCT found high catastrophizing scores to reduce treatment efficacy for usual care (UC) but not in the minimal intervention study (MIS) targeted to reduce pain-related fear and activity avoidance [29, 30]. No moderating effect was found in three RCTs that compared exercise to cognitive behavioral approaches (CBT) $[28,33,38]$. A detailed description of the study results is given in Appendix 5.3. 
Table 5.2: Summary of the effect of catastrophizing as predictor, mediator and moderator Less than six months

\begin{tabular}{|c|c|c|c|c|}
\hline $\begin{array}{l}\text { Study } \\
\text { Year }\end{array}$ & $\begin{array}{c}\text { Scale: } \\
\text { mean } \\
(\mathrm{SD})\end{array}$ & Predictor & Mediator & Moderator \\
\hline $\begin{array}{l}\text { Jellema, } \\
\text { Vlaeyen, } \\
2006 \text { [29] }\end{array}$ & $\begin{array}{l}\mathrm{CSQ} \\
11.8 \\
(6.7)\end{array}$ & $\varnothing$ & $\varnothing$ & $\begin{array}{cc}+ & - \\
\text { Moderator in } & \text { No moderator } \\
\text { UC (OR 0.94, } & \text { in MIS (OR n.r.) } \\
95 \% \mathrm{Cl}, 0.89- & \\
0.99) & \end{array}$ \\
\hline $\begin{array}{l}\text { Jellema, } \\
2005 \text { [30] }\end{array}$ & $\begin{array}{l}\mathrm{CSQ} \\
11.8 \\
(6.7)\end{array}$ & $\varnothing$ & $\varnothing$ & $\begin{array}{c}+ \\
\text { High catastrophizing }(>11) \text { in MIS } \\
\text { more recovery than in UC } \\
\text { (OR } 0.72,95 \% \mathrm{Cl}, 0.29-1.80) \\
\text { Low catastrophizing }(\leq 11) \text { in MIS } \\
\text { less recovery than in UC } \\
\text { (OR } 1.84,95 \% \mathrm{Cl}, 0.80-4.22 \text { ) }\end{array}$ \\
\hline $\begin{array}{l}\text { Hancock, } \\
\text { Davies, } \\
2009 \text { [39] }\end{array}$ & $\begin{array}{l}\text { PRSS } \\
1.85 \\
\text { (scale } \\
0-5 \text { ) }\end{array}$ & $\varnothing$ & $\varnothing$ & $\begin{array}{l}\text { No interaction of catastrophizing } \\
\text { with treatment (NSAID vs. pla- } \\
\text { cebo) on pain and recovery }\end{array}$ \\
\hline $\begin{array}{l}\text { Smeets, } \\
2009 \text { [38] }\end{array}$ & $\begin{array}{l}\text { PRSS } \\
18(9)\end{array}$ & $\varnothing$ & $\varnothing$ & $\begin{array}{l}\text { - } \\
\text { No significant influence of } \\
\text { catastrophizing on exercise or } \\
\text { advice for pain and disability }\end{array}$ \\
\hline $\begin{array}{l}\text { George, } \\
\text { Zeppieri, } \\
2008 \text { [34] }\end{array}$ & $\begin{array}{c}\text { PCS } \\
\text { range } \\
12.6- \\
20.7\end{array}$ & $\varnothing$ & $\begin{array}{c}+ \\
\text { Decrease in catastrophiz- } \\
\text { ing associated with more } \\
\text { pain decrease } \\
(\beta 0.38,95 \% \mathrm{Cl}, 0.09- \\
0.67)\end{array}$ & $\varnothing$ \\
\hline $\begin{array}{l}\text { Beneciuk, } \\
2012 \text { [35] }\end{array}$ & $\begin{array}{c}\text { PCS } \\
16.3 \\
(11.2)\end{array}$ & $\begin{array}{l}\qquad \\
\text { High catastrophizing with } \\
\text { high fear avoidance } \\
\text { beliefs associated with } \\
\text { more pain and disability in } \\
\text { all treatment groups } \\
\qquad(p<0.05)\end{array}$ & $\varnothing$ & $\varnothing$ \\
\hline $\begin{array}{l}\text { Hill, } \\
2008 \text { [32] }\end{array}$ & $\begin{array}{c}\mathrm{CSQ} \\
8.4 \\
(6.7)\end{array}$ & $\begin{array}{c}- \\
\text { Catastrophizing not } \\
\text { associated with disability } \\
\text { after } 12 \text { months } \\
\text { (univariante OR } 1.77,95 \% \\
\mathrm{Cl}, 1.13-2.75 ; \text { multivari- } \\
\text { ante n.r.) }\end{array}$ & $\varnothing$ & $\varnothing$ \\
\hline
\end{tabular}


Table 5.2 continued

\begin{tabular}{|c|c|c|c|c|}
\hline $\begin{array}{l}\text { Wessels, } \\
2007 \text { [28] }\end{array}$ & $\varnothing$ & $\begin{array}{c}+ \\
\text { Catastrophizing interferes } \\
\text { with daily activity at } 3 \\
\text { months } \\
(\beta 0.25,95 \% \mathrm{Cl}, 0.12 \text { - } \\
0.35)\end{array}$ & $\begin{array}{c}+ \\
\text { Decrease in catastrophiz- } \\
\text { ing explains } 2.5 \% \text { of total } \\
\text { variability in outcome } \\
\text { (MPI-D) }(\beta 0.236,95 \% \mathrm{Cl} \text {, } \\
0.12-0.35)\end{array}$ & $\begin{array}{l}- \\
\text { No significant interaction be- } \\
\text { tween catastrophizing and } \\
\text { treatment } \\
(p=0.06)\end{array}$ \\
\hline \multicolumn{5}{|c|}{ More than 6 months } \\
\hline $\begin{array}{l}\text { Study } \\
\text { Year }\end{array}$ & $\begin{array}{l}\text { Scale: } \\
\text { mean } \\
\text { (SD) }\end{array}$ & Predictor & Mediator & Moderator \\
\hline $\begin{array}{l}\text { Leeuw, } \\
2008 \text { [33] }\end{array}$ & $\begin{array}{c}\text { PCS } \\
22.9 \\
(10.4)\end{array}$ & $\begin{array}{c}+ \\
\text { More catastrophizing is } \\
\text { associated with more } \\
\text { disability at } 6 \text { months } \\
\text { (QPDBS } \beta 0.43,95 \% \mathrm{Cl} \text {, } \\
0.25-0.61 \text {; PSC } \beta 0.70 \text {, } \\
95 \% \mathrm{Cl}, 0.41-0.99 \text { ) }\end{array}$ & $\begin{array}{c}\mathbf{+} \\
\text { Decrease in catastrophiz- } \\
\text { ing significantly mediated } \\
\text { the effect of EXP relative } \\
\text { to GA on disability and } \\
\text { main complaint. Results } \\
\text { n.r. }\end{array}$ & $\begin{array}{l}\text { - } \\
\text { No significant interaction be- } \\
\text { tween catastrophizing and } \\
\text { treatment (criteria for inclusion } \\
\qquad \mathrm{p}<0.10)\end{array}$ \\
\hline $\begin{array}{l}\text { Ooster- } \\
\text { hof, } \\
2008 \text { [36] }\end{array}$ & $\begin{array}{l}\mathrm{PCL} \\
43.9 \\
(\mathrm{SE} \\
1.2)\end{array}$ & $\begin{array}{l}\text { Catastrophizing no influ- } \\
\text { ence on treatment satis- } \\
\text { faction after } 10 \text { days }\end{array}$ & $\varnothing$ & $\begin{array}{l}\text { Catastrophizing no influence on } \\
\text { treatment satisfaction (values } \\
\text { n.r.) }\end{array}$ \\
\hline $\begin{array}{l}\text { Smeets, } \\
2006 \text { [37] }\end{array}$ & $\begin{array}{c}\text { PCL } 39 \\
(12)\end{array}$ & $\begin{array}{c}\mathbf{+} \\
\text { Catastrophizing associat- } \\
\text { ed with more pain and } \\
\text { disability in all treatment } \\
\text { groups (APT, CBT and CT) } \\
\text { after } 2 \text { months }\end{array}$ & $\varnothing$ & $\varnothing$ \\
\hline
\end{tabular}

\begin{tabular}{|c|c|c|c|c|}
\hline $\begin{array}{l}\text { Mannion, } \\
1999 \text { [31] }\end{array}$ & $\varnothing$ & $\varnothing$ & $\begin{array}{l}+ \\
\text { Decrease in catastrophiz- } \\
\text { ing explains } 23 \% \text { decrease } \\
\text { in greatest pain but not } \\
\text { decrease in average pain } \\
\text { and disability }\end{array}$ & $\varnothing$ \\
\hline $\begin{array}{l}\text { Spinho- } \\
\text { ven, } \\
2004 \text { [24] }\end{array}$ & $\begin{array}{c}\text { PCCL } \\
40.5 \\
(9)\end{array}$ & $\varnothing$ & $\begin{array}{c}+ \\
\text { Decrease in catastrophiz- } \\
\text { ing increases internal pain } \\
\text { control } \\
(\beta 0.20, p<0.05)\end{array}$ & $\varnothing$ \\
\hline
\end{tabular}

Scale ranges: PCS 0 - 52, CSQ 0 - 36, PRSS 0 - 45, PCL 17 - 85, PCCL 12 - 72; $\varnothing$, not investigated; UC, usual care; MIS, minimal intervention strategy; $\mathrm{CBT}$, cognitive behavioral therapy; APT, active physical therapy; $\mathrm{CT}$, combined therapy; FAB, Fear Avoidance Beliefs; MPI-D, German version of the West Haven Multidimensional Pain Inventory; PCCL, pain coping and cognition list; $\mathrm{PCL}$, pain cognition list; $\mathrm{CSQ}$, coping strategies questionnaire; SD, standard deviation; OR, odds ratio; $\mathrm{Cl}$, confidence interval; PRSS, pain-related self-statements scale; NSAID, nonsteroidal anti-inflammatory drugs; PCS, pain catastrophizing scale; EXP, exposure in vivo treatment; n.r., not reported 
Table 5.3: Moderating effect of catastrophizing on treatments

\begin{tabular}{|c|c|c|c|c|c|c|}
\hline $\begin{array}{l}\text { Study } \\
\text { Year }\end{array}$ & Moderating effect on Treatment & $\begin{array}{c}\text { Test of } \\
\text { interaction }\end{array}$ & $\begin{array}{c}\text { Disease } \\
\text { Dura- } \\
\text { tion }\end{array}$ & $\mathbf{n}$ & $\begin{array}{c}\text { FU } \\
\text { (weeks) }\end{array}$ & Outcome \\
\hline $\begin{array}{l}\text { Jellema, } \\
2006[29] \\
+ \\
2005[30]\end{array}$ & $\begin{array}{l}\text { Catastrophizing reduces treatment } \\
\text { effect in Group 1: UC: guideline GP } \\
\text { based care; but not in Group } 2 \text { MIS: GP } \\
\text { provided information and advice for } \\
\text { self-care + Back Book }\end{array}$ & no & $\begin{array}{c}\text { acute - } \\
\text { sub- } \\
\text { acute }\end{array}$ & 314 & 52 & $\begin{array}{l}\text { Non-work } \\
\text { related: } \\
\text { RMQ }\end{array}$ \\
\hline $\begin{array}{l}\text { Hancock, } \\
\text { Davies, } \\
2009 \text { [39] }\end{array}$ & $\begin{array}{l}\text { No effect on NSAID vs. Placebo } \\
\text { Group 1: Placebo + placebo manipula- } \\
\text { tion } \\
\text { Group 2: Diclofenac + placebo manipula- } \\
\text { tion } \\
\text { Group 3. Placebo + spinal manipulation } \\
\text { Group 4: Diclofenac + manipulation }\end{array}$ & yes & acute & 240 & 12 & $\begin{array}{l}\text { Non-work } \\
\text { related: } \\
\text { Number of } \\
\text { days to } \\
\text { recovery }\end{array}$ \\
\hline $\begin{array}{l}\text { Smeets, } \\
2009 \text { [38] }\end{array}$ & $\begin{array}{l}\text { No effect on all treatment groups: } \\
\text { Group 1: CBT informed progressive } \\
\text { exercise and PT advice stay active and } \\
\text { addressing helpful beliefs } \\
\text { Group 2: CBT informed exercise + sham } \\
\text { advice } \\
\text { Group 3: Sham exercise + advice } \\
\text { Group 4: Sham exercise + sham advice }\end{array}$ & no & $\begin{array}{l}\text { sub- } \\
\text { acute }\end{array}$ & 259 & 52 & $\begin{array}{l}\text { Non-work } \\
\text { related: } \\
\Delta \text { pain (NRS) } \\
+ \\
\Delta \text { disability } \\
\text { (PSFS) }\end{array}$ \\
\hline $\begin{array}{l}\text { Wessels, } \\
2007 \text { [28] }\end{array}$ & $\begin{array}{l}\text { No interaction between catastrophizing } \\
\text { and treatment: } \\
\text { Group 1: Exercise } \\
\text { Group 2: multidisciplinary prevention } \\
\text { program including CBT, work hardening, } \\
\text { back school }\end{array}$ & no & $\begin{array}{c}\text { sub- } \\
\text { acute - } \\
\text { chronic }\end{array}$ & 162 & 13 & $\begin{array}{l}\text { Non-work } \\
\text { related: } \\
\text { MPI-D }\end{array}$ \\
\hline $\begin{array}{l}\text { Leeuw, } \\
2008[33]\end{array}$ & $\begin{array}{l}\text { No interaction between catastrophizing } \\
\text { and treatment: } \\
\text { Group 1: operant behavioral GA: func- } \\
\text { tional treatment goals, } 2 \text { psychological } \\
\text { sessions } \\
\text { Group 2: EXP: CBT techniques by using } \\
\text { PHODA to identify fear hierarchy }\end{array}$ & yes & chronic & 85 & 26 & $\begin{array}{l}\text { Non-work } \\
\text { related: } \\
\text { QBPDS } \\
\text { PSC }\end{array}$ \\
\hline $\begin{array}{l}\text { Ooster- } \\
\text { hof, } 2008 \\
{[36]}\end{array}$ & $\begin{array}{l}\text { No influence on Group } 1 \text { TENS, and } \\
\text { Group 2: Sham TENS }\end{array}$ & yes & chronic & 165 & 10 & $\begin{array}{l}\text { Non-work } \\
\text { related: } \\
\text { treatment } \\
\text { satisfaction }\end{array}$ \\
\hline
\end{tabular}

TENS, transcutaneous electrical nerve stimulation; UC, usual care; MIS, minimal intervention strategy; $C B T$, cognitive behavioral therapy; APT, active physical therapy; CT, combined therapy; PT, physical treatment; PHODA, Photograph Series of Daily Activities; FAB, Fear Avoidance Beliefs; MPI-D, German version of the West Haven Multidimensional Pain Inventory; RMQ, Roland and Morris Disability Questionnaire; QBPDS, Quebec Back Pain Disability Scale; PSC, Patient Specific Complaints; NRS, Numeric Rating Scale; PSFS, Patient-Specific Functional Scale; GP, general practitioner; NSAID, nonsteroidal anti-inflammatory drugs; GA: graded activity; PT, physical therapy; EXP, exposure in vivo treatment 


\section{Discussion}

\section{Main Findings}

In this systematic review of 11 randomized controlled trials (RCTs) on the effect of catastrophizing in patients with low back pain, we found catastrophizing to predict outcome for pain and disability in four RCTs. The RCTs that investigated mediating effects showed an association between a decrease in catastrophizing and an increase in daily activities and a decrease in pain. There was limited and conflicting evidence for the moderating effect of catastrophizing on treatment efficacy. No RCT assessed work-related outcomes.

The analysis of a moderator effect was inadequate in most RCTs and a final conclusion would be premature. All RCTs showing no moderating effect of catastrophizing included too few patients to detect a difference between the treatment arms. Therefore, any moderating effects could have been easily missed. Further, low catastrophizing at baseline could explain non-predictive findings. However, baseline values were not consistently associated with outcomes. Most RCTs did not look for a direct interaction test between the treatment and catastrophizing.

\section{Results in Light of Existing Literature}

The effect of catastrophizing on the outcome of treatment has received increasing attention $[40,41]$. To our knowledge this is the first systematic review that assessed the predictive, mediating, and moderating effect of catastrophizing in patients with low back pain. In surgical patients, catastrophizing has been associated with more post-surgical pain and poorer quality of life [42]. The influence of catastrophizing on outcome in patients undergoing non-surgical treatments has not been reviewed systematically. In a recent analysis of subgroups that might benefit from self-management programs in musculoskeletal pain, catastrophizing was identified as a moderator in one study [43]. The current analysis further expands the knowledge about the influence of catastrophizing in patients with low back pain on treatment efficacy and outcome. While there was a consistent association 
between higher catastrophizing and more disability and pain at follow-up, there is insufficient data available to analyze the influence of catastrophizing on work-related outcomes including return to work and sick days. Pain catastrophizing conceptually belongs to the fear avoidance model. It is believed that catastrophizing is a precursor of pain-related fear [44]. Fear avoidance beliefs decrease the treatment efficacy of treatments based on biomedical concepts (e.g. physical therapy) and increase treatment efficacy in treatments that aim to reduce fear avoidance beliefs (Wertli et al. submitted). However, it is possible to have fear avoidance beliefs without catastrophizing [45]. To date it is not known if one can also have high catastrophizing and low fear avoidance beliefs.

\section{Limitations}

The main limitation is small sample sizes in most RCTs. None of the RCTs provided a power analysis for moderator effect and most RCTs did not conduct a direct test for any interaction between catastrophizing and treatment. The heterogeneity of studies and the methodological limitations impeded the authors from conducting a meta-analysis. We have tried to balance these limitations by providing a comprehensive comparative description of all the RCTs included.

\section{Implications for Research}

Future research should aim at identifying the importance of catastrophizing in relation to fear avoidance beliefs and other psychological factors. Further, the influence of catastrophizing on treatment response in currently used treatment strategies in low back pain should be investigated. The current analysis suggests that any catastrophizing can be associated with worse outcome. It is unknown whether or not cut-off values can be applied to detect patients at high risk.

\section{Implications for Practice}

The findings of this review suggest that high catastrophizing scores are associated with more pain and disability at follow-up. It has been shown that catastrophizing may be mod- 
ified with treatment and that a decrease during treatment is associated with better outcome $[24,37,46]$. Therefore, measures that assess catastrophizing might be helpful in clinical practice to identify patients at risk for delayed recovery. Questionnaires used in the analyzed RCTs consisted of at least six items. In a busy back pain patient clinic shorter screening tools are warranted. Stratified primary care management by using screening tools that incorporate catastrophizing among other psychological domain, e.g. the STarT Back Tool or the Orebro Questionnaire [47], have been shown to be effective and reduce costs $[6,48]$.

\section{Conclusion}

Catastrophizing thoughts were associated with more pain and disability at follow-up in patients with low back pain. A decrease in catastrophizing during treatment is associated with better outcome. Insufficient evidence was available for the assessment of moderating effects and no RCT investigated work-related outcomes. 


\section{References}

1. Balague F, Mannion AF, Pellise F, et al. Non-specific low back pain. Lancet 2012;379:482-91.

2. Vos T, Flaxman AD, Naghavi M, et al. Years lived with disability (YLDs) for 1160 sequelae of 289 diseases and injuries 1990-2010: a systematic analysis for the Global Burden of Disease Study 2010. Lancet 2012;380:2163-96.

3. Fourney DR, Andersson G, Arnold PM, et al. Chronic low back pain: a heterogeneous condition with challenges for an evidence-based approach. Spine (Phila Pa 1976) 2011;36:S1-9.

4. van Tulder M, Becker A, Bekkering T, et al. Chapter 3. European guidelines for the management of acute nonspecific low back pain in primary care. European Spine Journal 2006;15 Suppl 2:S169-91.

5. Krismer M, van Tulder M. Strategies for prevention and management of musculoskeletal conditions. Low back pain (non-specific). Best Pract Res Clin Rheumatol 2007;21:77-91.

6. Hill JC, Whitehurst DG, Lewis M, et al. Comparison of stratified primary care management for low back pain with current best practice (STarT Back): a randomised controlled trial. Lancet 2011;378:1560-71.

7. Linton SJ, Shaw WS. Impact of Psychological Factors in the Experience of Pain. Phys Ther 2011;91:700-11.

8. Sullivan MIL, Thorn B, Haythornthwaite JA, et al. Theoretical perspectives on the relation between catastrophizing and pain. Clinical Journal of Pain 2001;17:52-64.

9. Rosenstiel AK, Keefe FJ. The use of coping strategies in chronic low back pain patients: relationship to patient characteristics and current adjustment. Pain 1983;17:33-44.

10. Chou R, Huffman L. Nonpharmacologic therapies for acute and chronic low back pain: a review of the evidence for an American Pain Society/American College of Physicians clinical practice guideline. Ann Intern Med 2007;147:492-504.

11. Airaksinen O, Brox J, Cedraschi C, et al. Chapter 4 European guidelines for the management of chronic nonspecific low back pain. Eur Spine J 2006;15:s192-s300.

12. Moher D, Liberati A, Tetzlaff J, et al. Preferred reporting items for systematic reviews and meta-analyses: the PRISMA statement. PLoS Med 2009;6:e1000097.

13. Harbour R, Lowe G, Twaddle S. Scottish Intercollegiate Guidelines Network: the first 15 years (1993-2008). J R Coll Physicians Edinb 2011;41:163-8.

14. Pincus T, Miles C, Froud R, et al. Methodological criteria for the assessment of moderators in systematic reviews of randomised controlled trials: a consensus study. BMC Med Res Methodol 2011;11:14.

15. Sullivan MJL, Bishop SR, Pivik J. The Pain Catastrophizing Scale: Development and validation. Psychological Assessment 1995;7:524-32.

16. Sullivan MJL. The Pain Catastrophizing Scale - User Manual [Sullivan, M.J.L.], 2009. Available from: http://sullivan-painresearch.mcgill.ca/pcs1.php.

17. Osman A, Barrios FX, Kopper BA, et al. Factor structure, reliability, and validity of the Pain Catastrophizing Scale. Journal of Behavioral Medicine 1997;20:589-605.

18. Osman A, Barrios FX, Gutierrez PM, et al. The Pain Catastrophizing Scale: further psychometric evaluation with adult samples. Journal of Behavioral Medicine 2000;23:351-65.

19. Robinson ME, Riley JL, 3rd, Myers CD, et al. The Coping Strategies Questionnaire: a large sample, item level factor analysis. Clinical Journal of Pain 1997;13:43-9.

20. Flor H, Behle DJ, Birbaumer N. Assessment of pain-related cognitions in chronic pain patients. Behaviour Research and Therapy 1993;31:63-73.

21. Vlaeyen JWS, Geurts SM, Kole-Snijders AMJ, et al. What do chronic pain patients think of their pain? Towards a pain cognition questionnaire. British Journal of Clinical Psychology 1990;29:383-94.

22. Van Breukelen GJ, Vlaeyen JW. Norming clinical questionnaires with multiple regression: the Pain Cognition List. Psychol Assess 2005;17:336-44.

23. Stomp-van der Berg S, Vlaeyen J, Ter Kuile M, et al. Meetinstrumenten chronische pijn deel 2 Pijn Coping en Cognitie Lijst (PCCL). Maastricht: Pijn Kennis Centrum Academisch Ziekenhuis Maastricht 2001. 
24. Spinhoven P, Ter Kuile M, Kole-Snijders AMJ, et al. Catastrophizing and internal pain control as mediators of outcome in the multidisciplinary treatment of chronic low back pain. European Journal of Pain 2004;8:211-9.

25. Hirsh AT, George SZ, Riley JL, et al. An evaluation of the measurement of pain catastrophizing by the coping strategies questionnaire. European Journal of Pain 2007;11:75-81.

26. Hirsh AT, George SZ, Bialosky JE, et al. Fear of pain, pain catastrophizing, and acute pain perception: relative prediction and timing of assessment. Journal of Pain 2008;9:806-12.

27. R Core Team. R: A language and environment for statistical computing [R Foundation for Statistical Computing], 2013. Available from: http://www.R-project.org/.

28. Wessels T, Ewert T, Limm H, et al. Change factors explaining reductions of "interference" in a multidisciplinary and an exercise prevention program for low back pain. Clinical Journal of Pain 2007;23:629-34.

29. Jellema P, van der Horst HE, Vlaeyen JWS, et al. Predictors of outcome in patients with (sub)acute low back pain differ across treatment groups. Spine 2006;31:1699-705.

30. Jellema $P$, van der Windt DAWM, van der Horst HE, et al. Should treatment of (sub)acute low back pain be aimed at psychosocial prognostic factors? Cluster randomised clinical trial in general practice. BMJ (Clinical research ed) 2005;331:84.

31. Mannion AF, Muntener M, Taimela S, et al. A randomized clinical trial of three active therapies for chronic low back pain. Spine 1999;24:2435-48.

32. Hill JC, Dunn KM, Lewis M, et al. A primary care back pain screening tool: identifying patient subgroups for initial treatment. Arthritis \& Rheumatism 2008;59:632-41.

33. Leeuw M, Goossens MEJB, van Breukelen GJP, et al. Exposure in vivo versus operant graded activity in chronic low back pain patients: results of a randomized controlled trial. Pain 2008;138:192-207.

34. George SZ, Zeppieri G, Jr., Cere AL, et al. A randomized trial of behavioral physical therapy interventions for acute and sub-acute low back pain (NCT00373867). Pain 2008;140:145-57.

35. Beneciuk JM, Robinson ME, George SZ. Low back pain subgroups using fear-avoidance model measures: results of a cluster analysis. Clinical Journal of Pain 2012;28:658-66.

36. Oosterhof J, Samwel HJA, de Boo TM, et al. Predicting outcome of TENS in chronic pain: A prospective, randomized, placebo controlled trial. Pain 2008;136:11-20.

37. Smeets RJEM, Vlaeyen JWS, Kester ADM, et al. Reduction of pain catastrophizing mediates the outcome of both physical and cognitive-behavioral treatment in chronic low back pain. Journal of Pain 2006;7:261-71.

38. Smeets RJEM, Maher CG, Nicholas MK, et al. Do psychological characteristics predict response to exercise and advice for subacute low back pain? Arthritis \& Rheumatism 2009;61:1202-9.

39. Hancock MJ, Maher CG, Latimer J, et al. Can predictors of response to NSAIDs be identified in patients with acute low back pain? Clinical Journal of Pain 2009;25:659-65.

40. Pinto Pc, Mclntyre T, Almeida A, et al. The mediating role of pain catastrophizing in the relationship between presurgical anxiety and acute postsurgical pain after hysterectomy. Pain 2012;153:218-26.

41. Vissers M, Bussmann J, Verhaar JAN, et al. Psychological factors affecting the outcome of total hip and knee arthroplasty: a systematic review. Seminars in arthritis and rheumatism 2012;41:576-88.

42. Khan R, Ahmed K, Blakeway E, et al. Catastrophizing: a predictive factor for postoperative pain. The American journal of surgery 2011;201:122-31.

43. Miles $C L$, Pincus $T$, Carnes $D$, et al. Can we identify how programmes aimed at promoting self-management in musculoskeletal pain work and who benefits? A systematic review of sub-group analysis within RCTs. European Journal of Pain 2011;15.

44. Leeuw M, Goossens ME, Linton SJ, et al. The fear-avoidance model of musculoskeletal pain: current state of scientific evidence. Journal of Behavioral Medicine 2007;30:77-94.

45. Pincus T, Smeets RJ, Simmonds MJ, et al. The fear avoidance model disentangled: improving the clinical utility of the fear avoidance model. Clinical Journal of Pain 2010;26:739-46.

46. Jensen MP, Turner JA, Romano JM. Changes in beliefs, catastrophizing, and coping are associated with improvement in multidisciplinary pain treatment. Journal of Consulting and Clinical Psychology 2001;69:655-62. 
Chapter 5

47. Linton S, Nicholas M, MacDonald S. Development of a short form of the Orebro Musculoskeletal Pain Screening Questionnaire. Spine (Philadelphia, Pa. 1976) 2011;36:1891-5.

48. Hill JC, Dunn KM, Main CJ, et al. Subgrouping low back pain: a comparison of the STarT Back Tool with the Orebro Musculoskeletal Pain Screening Questionnaire. European Journal of Pain 2010;14:83-9. 
Appendix 5.1: Search History for PubMed, CINAHL, PsychINFO October Week 22012 Ovid MEDLINE(R), Ovid MEDLINE(R) In-Process \& Other Non-Indexed Citations, Ovid MEDLINE(R) Daily and Ovid OLDMEDLINE(R) 1946 to Present

\begin{tabular}{|c|c|c|}
\hline \# & Query & Results \\
\hline 1 & exp Low Back Pain/ & 12474 \\
\hline 2 & $\begin{array}{l}\text { ((low or lower) adj3 ("back pain" or "back pains" or "back ache" or "back aches" or } \\
\text { backache*)).ti,ab. }\end{array}$ & 16245 \\
\hline 3 & ((lowback or lumbal or lumbar or lumbosacral) adj3 (pain* or ache* or syndrome)).ti,ab. & 3488 \\
\hline 4 & (lumbago or lumbalgia or lumbalgesia or (lumbosacroiliac adj3 strain)).ti,ab. & 1221 \\
\hline 5 & or/1-4 & 23882 \\
\hline 6 & exp Catastrophization/ & 183 \\
\hline 7 & $\begin{array}{l}\text { (catastrophizing or catastrophising or catastrophization or catastrophisation).mp. } \\
\text { [mp=title, abstract, original title, name of substance word, subject heading word, } \\
\text { protocol supplementary concept, rare disease supplementary concept, unique identifi- } \\
\text { er] }\end{array}$ & 1111 \\
\hline 8 & (catastrophic adj3 (thinking or thought*)).ti,ab. & 131 \\
\hline 9 & (pain adj3 (catastrophizer* or catastrophiser*)).ti,ab. & 20 \\
\hline 10 & or/6-9 & 1185 \\
\hline 11 & 5 and 10 & 179 \\
\hline 12 & limit 11 to $y r=" 1980$-Current" & 179 \\
\hline 13 & limit 12 to animals & 0 \\
\hline
\end{tabular}

\section{PsycINFO 1806 to October Week 22012 (Ovid)}

\begin{tabular}{lll}
$\#$ & Searches & Results \\
\hline 1 & back pain/ and (low or lower).ti,ab. & 1870 \\
2 & $\begin{array}{l}\text { ((low or lower) adj3 ("back pain" or "back pains" or "back ache" or "back aches" or } \\
\text { backache*)).ti,ab. }\end{array}$ & 2206 \\
3 & ((lowback or lumbal or lumbar or lumbosacral) adj3 (pain* or ache* or syndrome)).ti,ab. & 176 \\
4 & (lumbago or lumbalgia or lumbalgesia or (lumbosacroiliac adj3 strain)).ti,ab. & 26 \\
5 & or/1-4 & 2534 \\
6 & (catastrophizing or catastrophising or catastrophization or catastrophisation).mp. & 1144 \\
& [mp=title, abstract, heading word, table of contents, key concepts, original title, tests \& \\
7 & measures] & 150 \\
8 & (catastrophic adj3 (thinking or thought*)).ti,ab. & 25 \\
9 & (pain adj3 (catastrophizer* or catastrophiser*)).ti,ab. & 1222 \\
10 & 5 and 9 & 129 \\
11 & limit 10 to yr="1980 -Current"
\end{tabular}




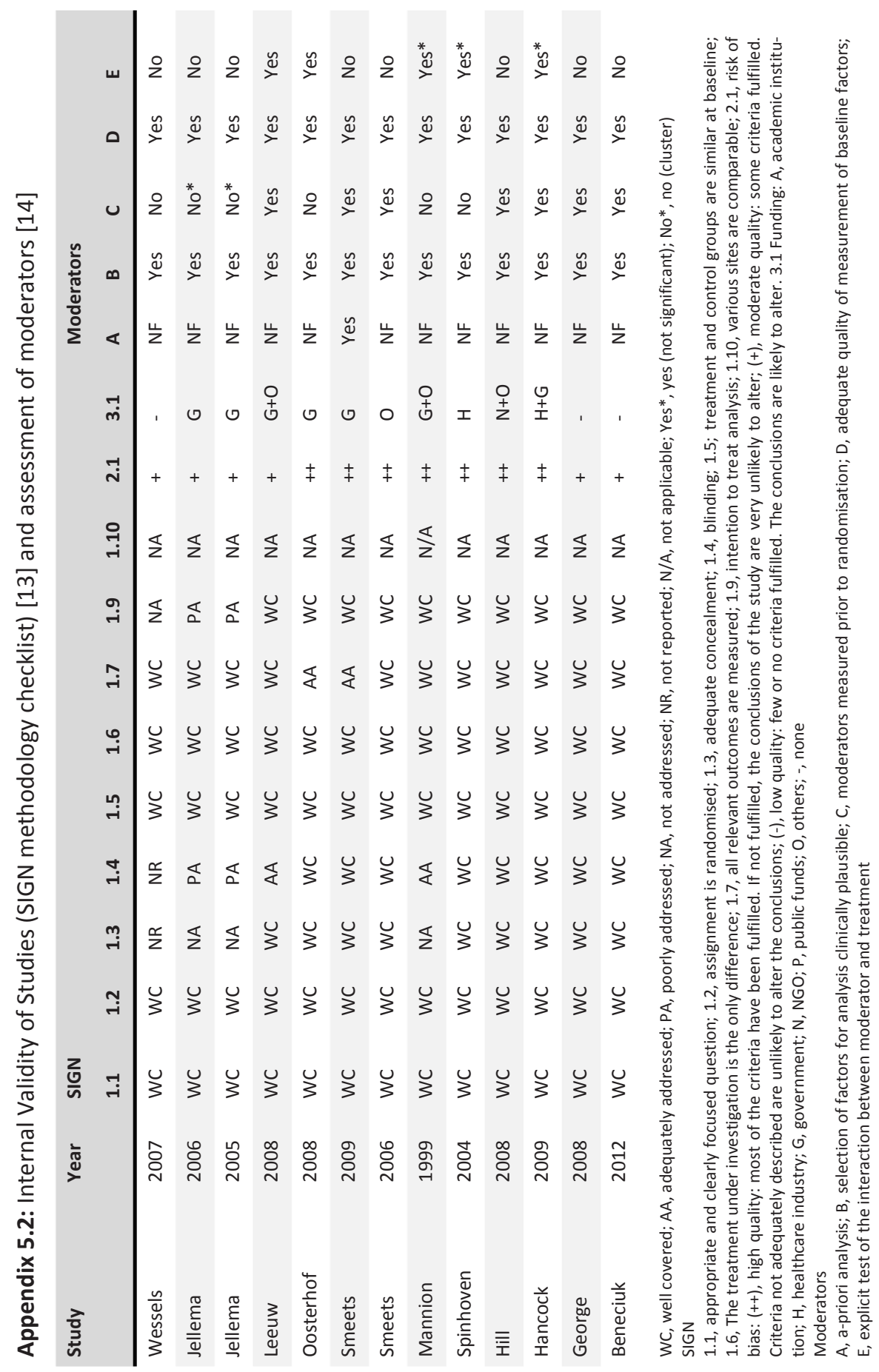




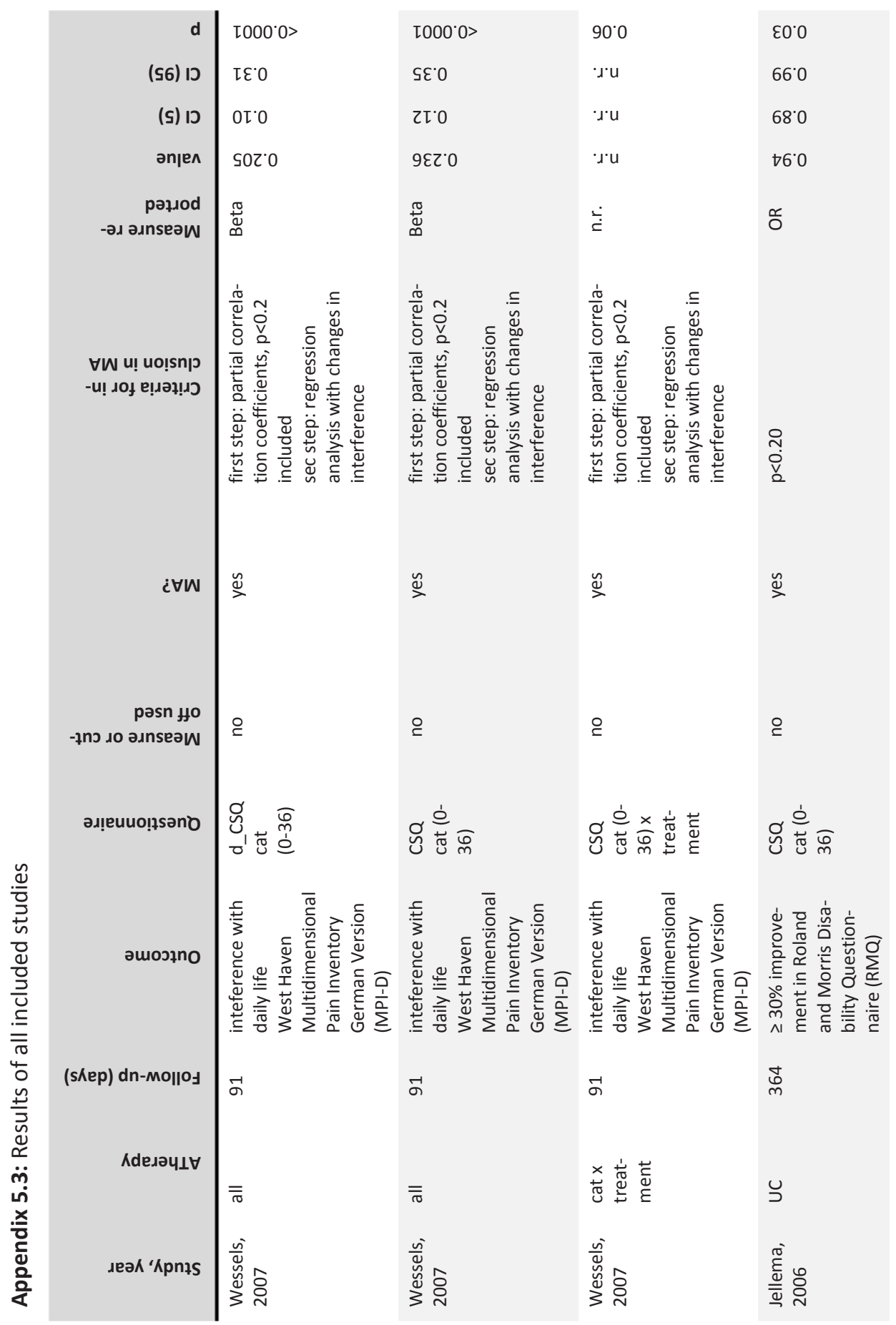




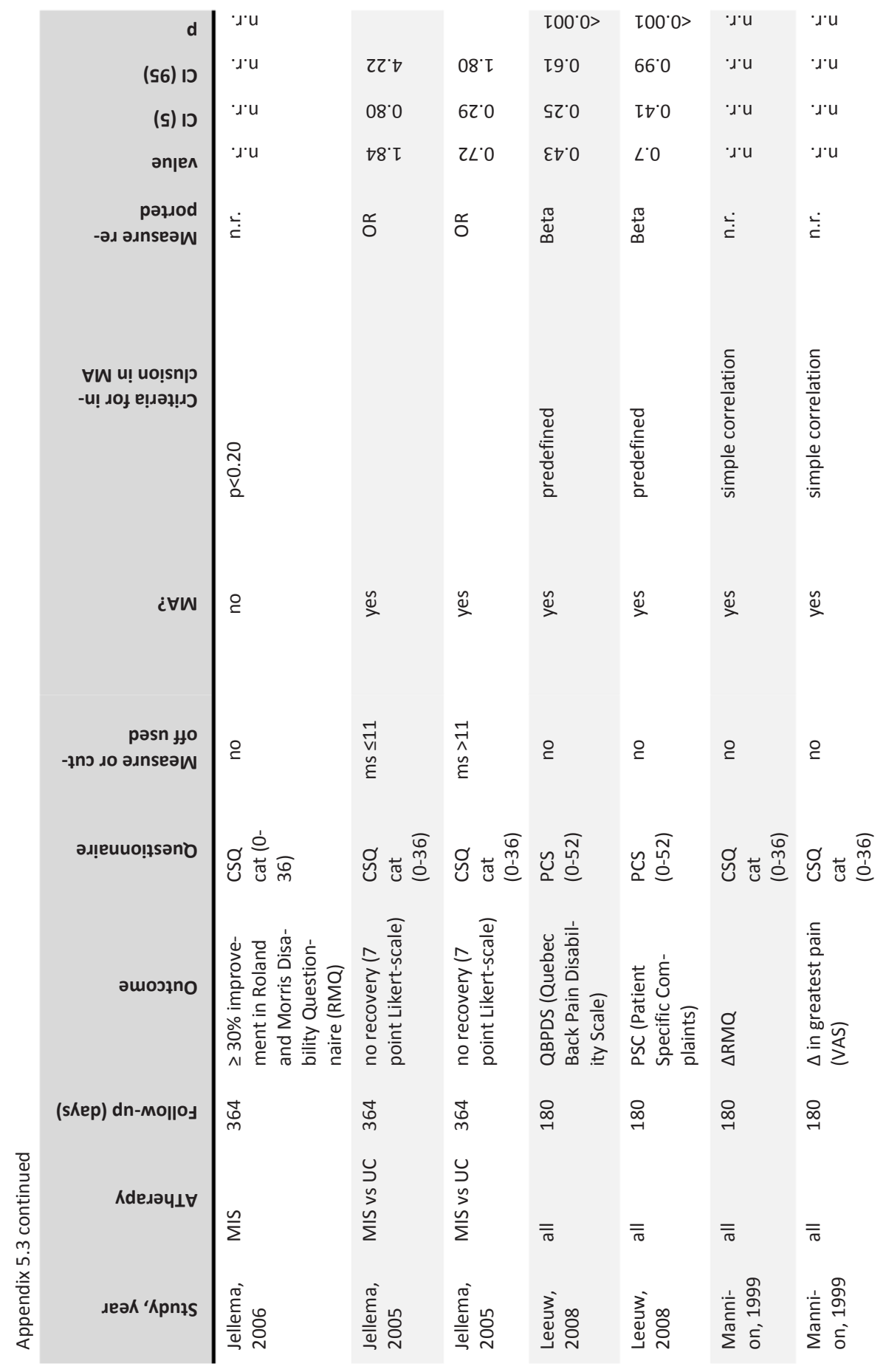




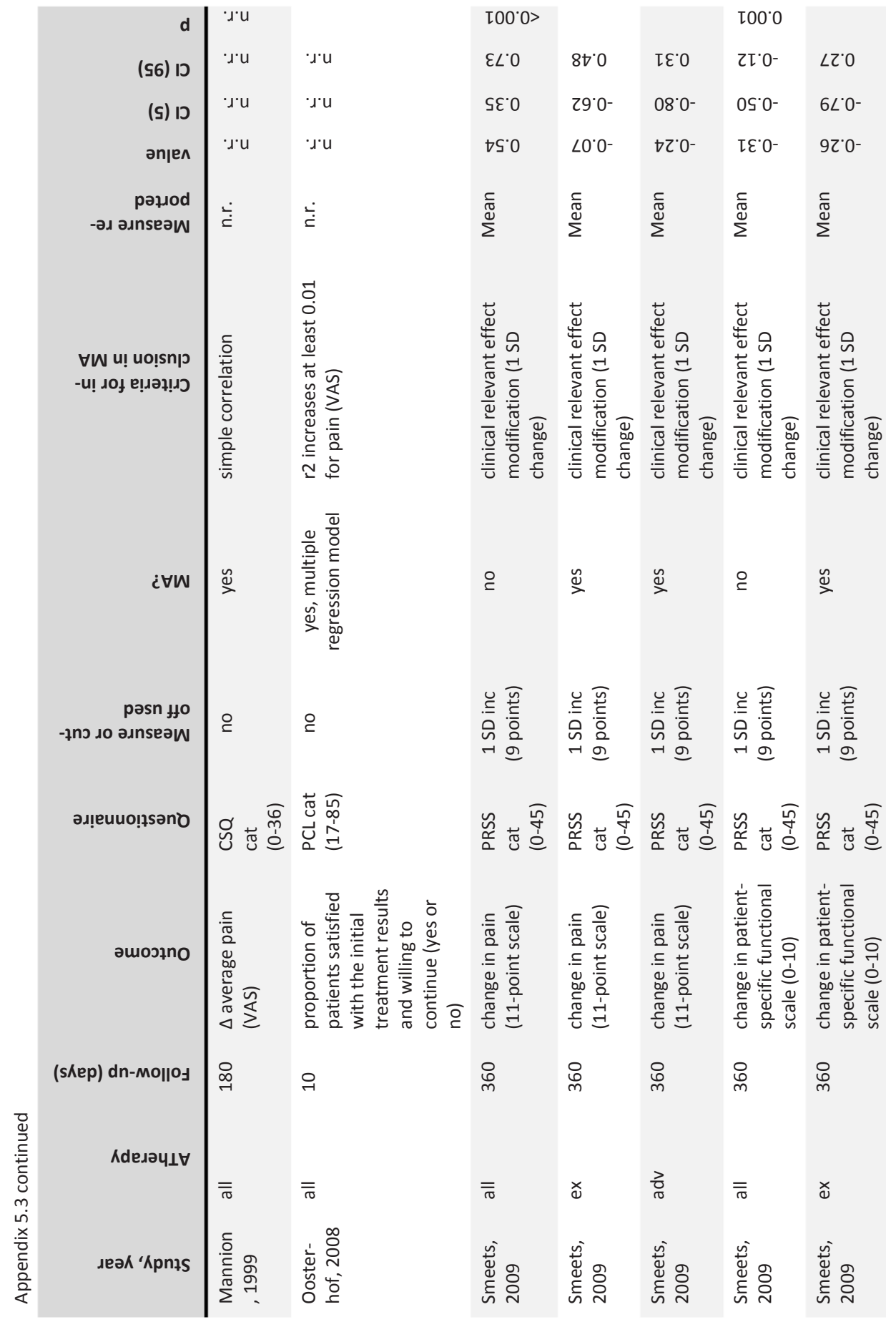




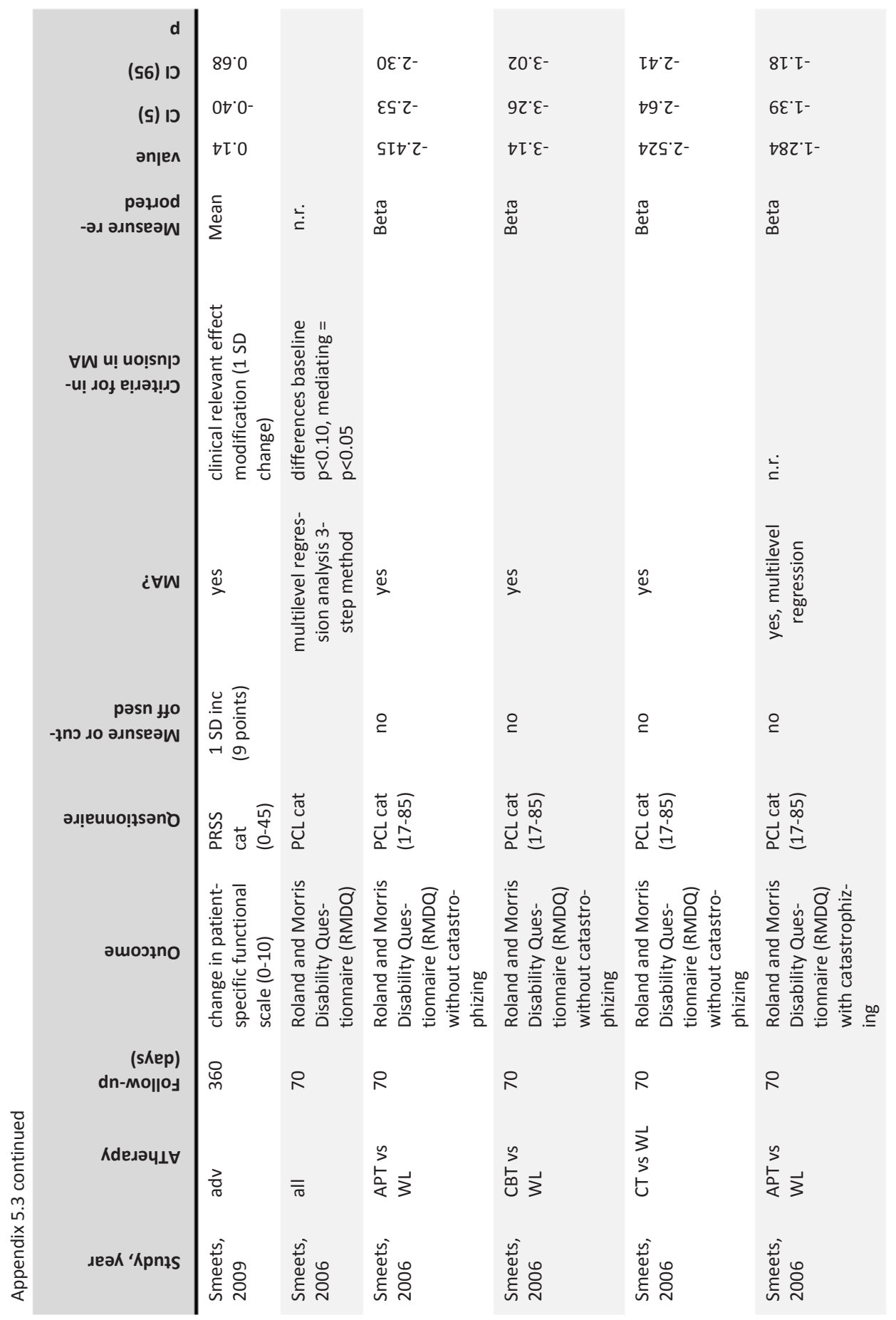




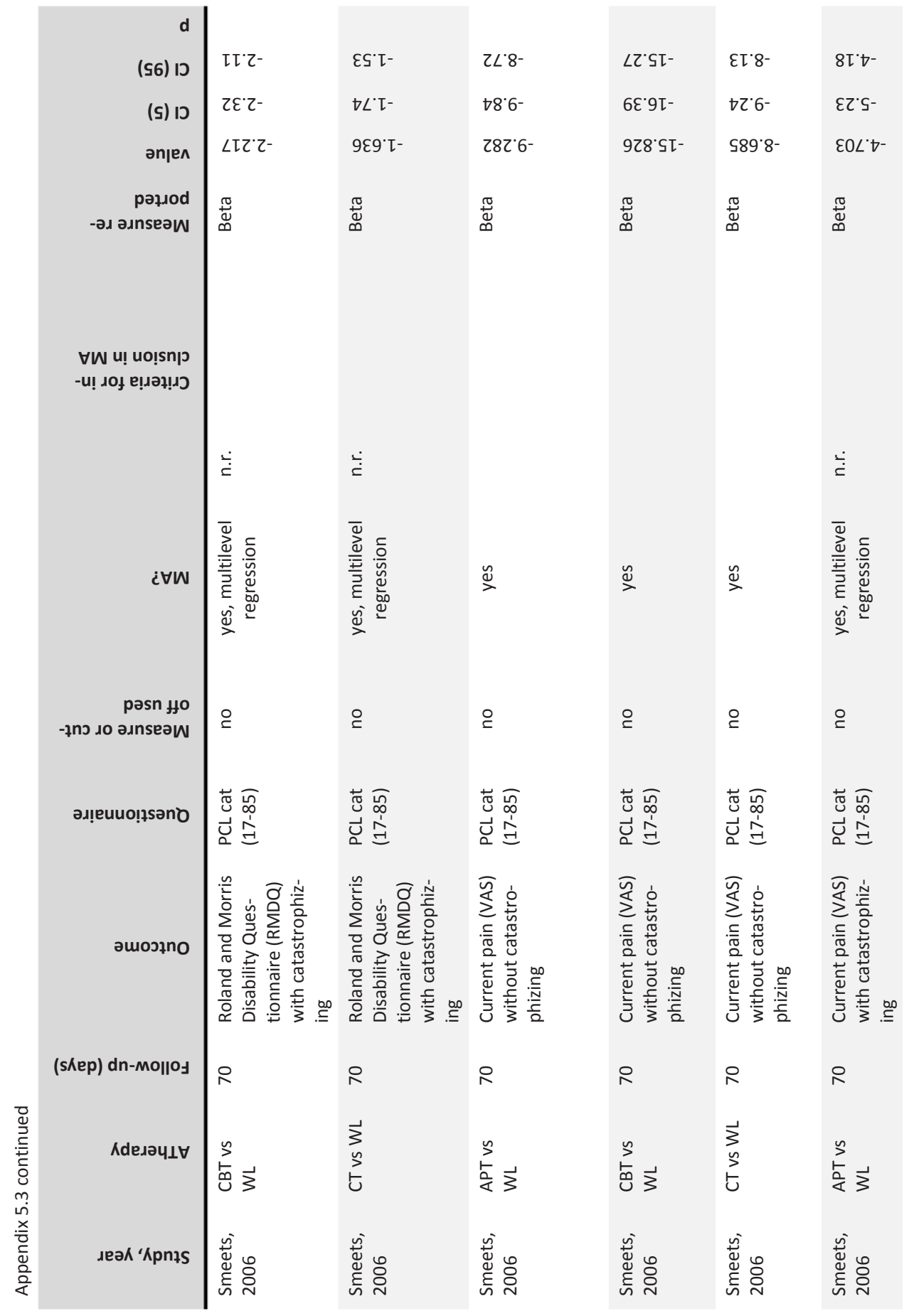




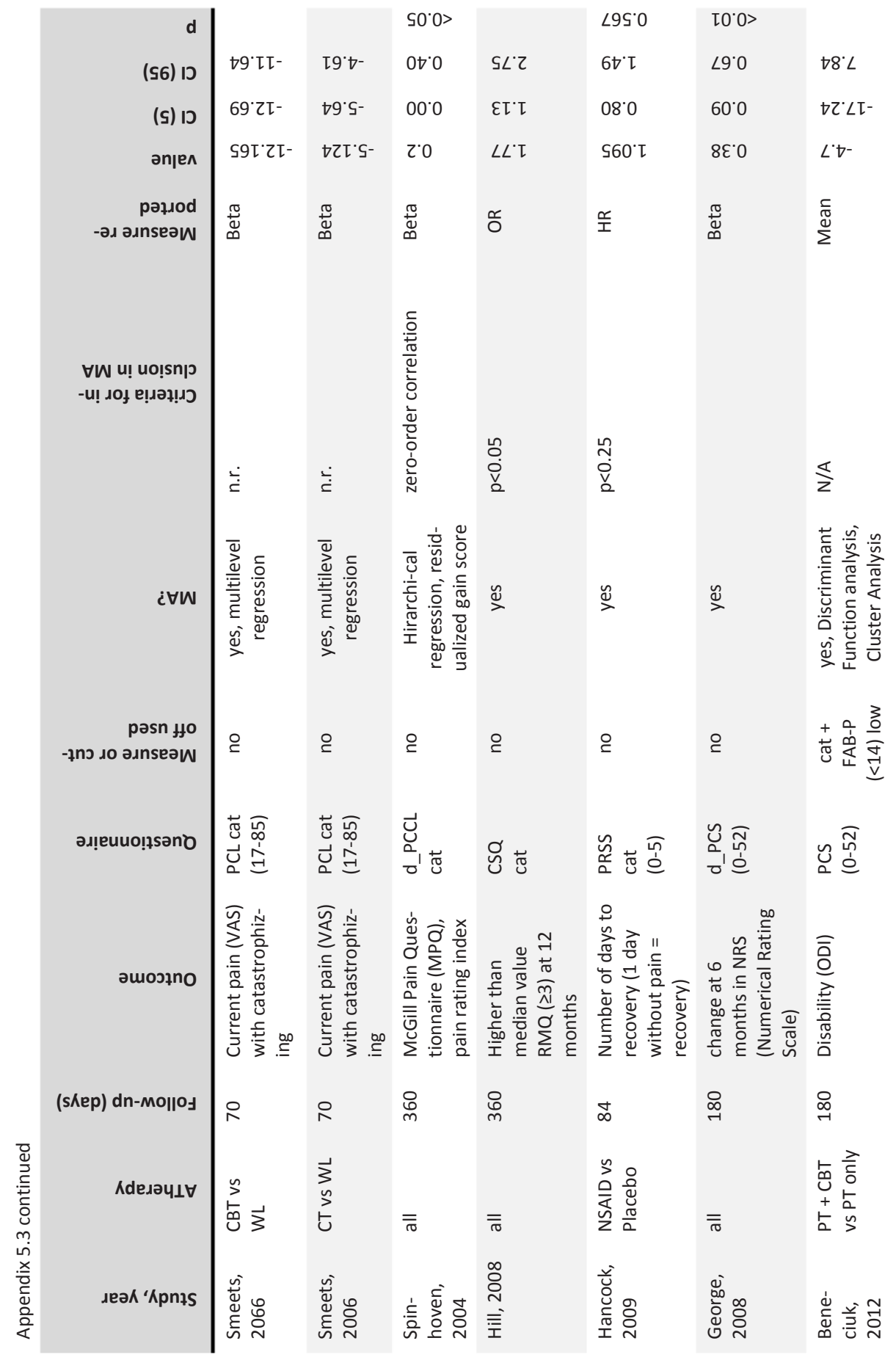




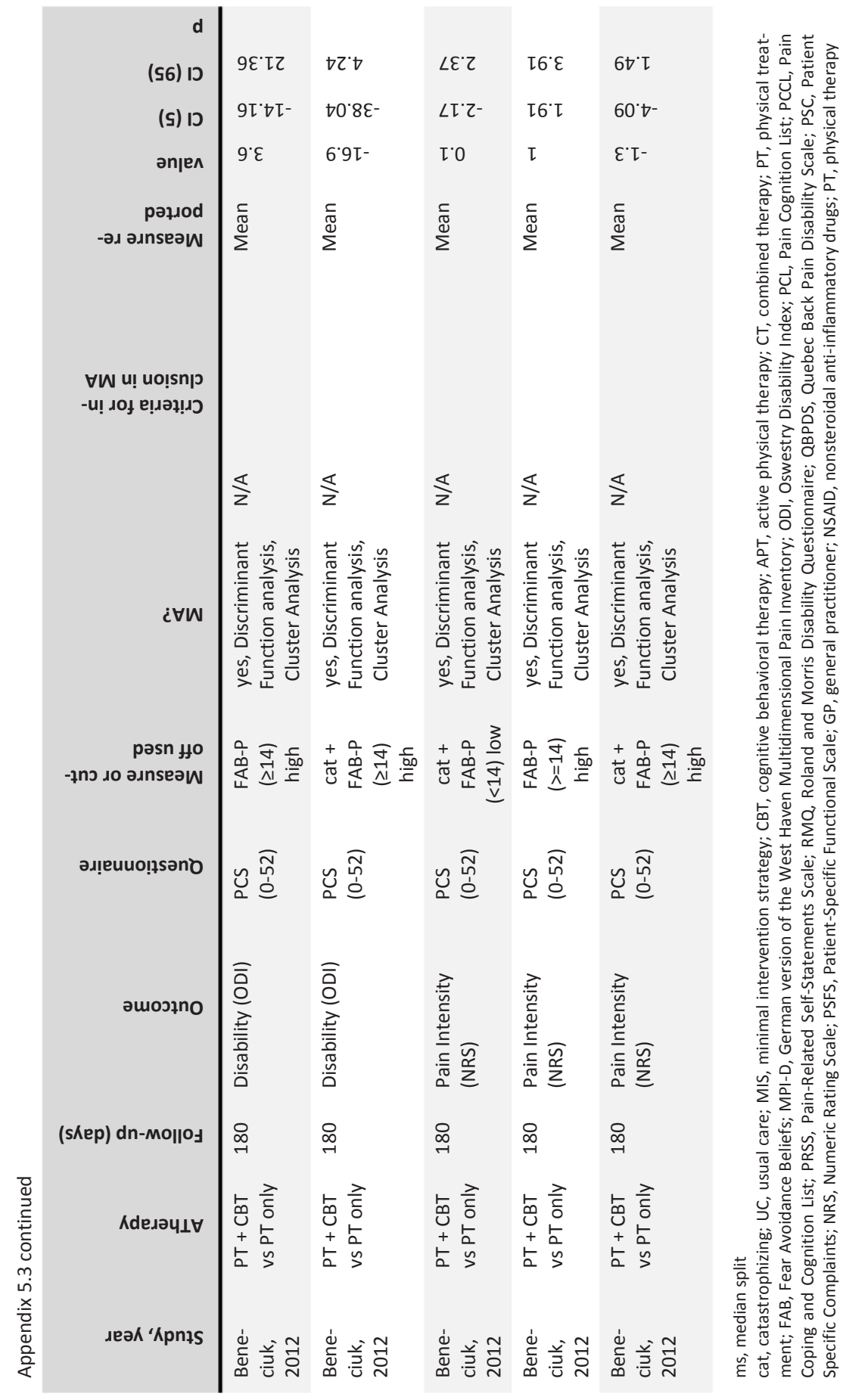





\section{Chapter 6}

\section{The influence of pre- and post-}

operative fear avoidance beliefs on postoperative pain and disability in patients with lumbar spinal stenosis: Analysis of the Lumbar Spinal
Outcome Study (LSOS) data

Jakob M. Burgstaller, M.D., D.M.D.

Maria M. Wertli, M.D., Ph.D. Johann Steurer, M.D.

Alfons G.H. Kessels, M.D., MSc. Ulrike Held, Ph.D.

Hans-Fritz Gramke, M.D., Ph.D. on behalf of the LSOS Study Group 


\section{Abstract}

Study design: Prospective multi-center cohort study.

Objective: To evaluate the effect of pre- and postoperatively assessed fear avoidance beliefs (FAB) on pain and disability in patients with degenerative lumbar spinal stenosis (LSS) after decompression surgery.

Summary of Background Data: To the present, the influence of pre- and postoperative FAB on the prognosis after surgery for LLS is still unclear.

Methods: Patients of the Swiss Lumbar Stenosis Outcome Study (LSOS) with confirmed LSS undergoing first-time decompression without fusion were enrolled in this study. The main outcome of this study was minimal clinically important difference (MCID) in SSM symptoms (pain) and function (disability) after twelve months. To analyze the influence of pre- and postoperatively assessed FAB on pain and disability we built simple and multiple logistic regression models.

Results: In this analysis of 234 patients undergoing decompression surgery for symptomatic degenerative LSS we found baseline FAB measured by the FAB physical activity subscale (FABQ-P) not to be associated with pain (OR 0.95; 95\% Cl: $0.55-1.67$ ) and disability (OR 1.11; 95\% Cl: 0.64-1.92) at twelve months' follow-up. In the final multiple logistic regression models patients with high $\mathrm{FABQ}-\mathrm{P}$ at six months (OR 0.46; 95\% Cl: 0.24-0.91) and high persistent FABQ-P at baseline and six months (OR 0.34, 95\% Cl: 0.16-0.73) were less likely to report a MCID for SSM symptoms at twelve months. Our analysis found a similar trend for disability, however, the results were not statistically significant.

Conclusions: In elderly patients undergoing decompression surgery for symptomatic degenerative LSS preoperative fear avoidance beliefs were not a prognostic indicator for the outcome. Patients with FAB at six months and persistent FAB were less likely to experience clinically relevant improvement in pain at twelve months. Studies should address the importance of persistent postoperative FAB. 


\section{Introduction}

Low back pain (LBP) with its global prevalence of $9.4 \%$ constitutes a high health and economic burden on individuals [1]. Lumbar spinal stenosis (LSS) is an important subgroup of LBP patients. In the United States, LSS is the most frequent indication for spine surgery in patients older than 65 years [2]. However, there is a wide variation in rates of improvement in patients after surgery $[3,4]$. Various factors may influence chronic postsurgical complaints being a major concern because it can affect patient recovery and quality of life after surgery $[5,6]$. Preoperatively assessed psychological factors including fear and pain catastrophizing were associated with more postoperative pain [7]. On the other hand, high postoperative fear was also associated with poorer outcomes as postoperative pain intensity and disability [8]. How fear and catastrophizing influence the postoperative course in patients with LSS has not yet fully understood.

The fear-avoidance model is a widely used theoretical model to explain psychological factors in the experience of pain and the development of chronic pain and disability [9]. Negative beliefs about pain and / or negative illness information may lead to an exaggerated negative mental response where the worst possible outcome is imagined (pain catastrophizing). This catastrophizing response to a painful experience leads to painrelated fear and avoidance behaviors. Avoidance behavior results in disuse, disability and depression, and maintains the original negative appraisal in a deleterious cycle [9]. On the other hand it is assumed that patients without catastrophizing thoughts and fear avoidance beliefs are more likely to confront pain and are more active in the coping process [9]. While in non-specific low back pain the importance of fear avoidance beliefs and catastrophizing thoughts on the prognosis and treatment efficacy has been shown [10-13], their influence in patients with LSS has not been investigated. How surgery influences postoperative fear avoidance beliefs is not well understood. One study showed a postoperative reduction in fear avoidance beliefs in patients undergoing surgery for degenerative spinal conditions [8]. To date no study investigated the influence of pre- and postoperative fear avoidance beliefs on the prognosis after surgery for LLS. 
The aim of this study is to evaluate the effect of high pre- and postoperative fear avoidance beliefs on pain and disability in patients with degenerative lumbar spinal stenosis after decompression surgery.

\section{Materials and Methods}

\section{Patient Selection}

We used data from the Lumbar Stenosis Outcome Study (LSOS) [14], a multi-center prospective cohort study, to explore this issue. Patients with a history of neurogenic claudication were recruited from outpatient clinics at all participating centers. Eligible patients had no evidence of stenosis caused by tumor, fracture, infection, or significant deformity $\left(>15^{\circ}\right.$ lumbar scoliosis), and were aged 50 years or more. Magnetic Resonance Imaging (MRI) verified lumbar spinal canal stenosis. None of the patients had prior lumbar spine surgery. Furthermore, patients had no clinical peripheral artery occlusive disease (confirmed by a vascular specialist in patients without palpable pulses in the lower limb).

\section{Surgical Procedure}

Surgery consisted of a standard open or microscopic posterior lumbar decompression at the affected level or levels without instrumentation.

\section{Questionnaires}

Fear Avoidance Beliefs Questionnaire (FABQ): The FABQ [15] is a 16-item questionnaire. High values indicate increased levels of fear avoidance beliefs. Two subscales exist: a seven-item work subscale (FABQ-W; range 0-42) and a four-item physical activity subscale (FABQ-P; range 0-24). The FABQ and the two subscales have been shown to be reliable and valid for the measurement of fear avoidance beliefs. The Cronbach $\alpha$ value for the FABQ-P was 0.75 (test-retest reliability, $r=0.64$ ) and for the FABQ-W 0.82 (test-retest $r=0.80$ ) [16]. In this study we did not use the FABQ-W because most patients were retired. 
Spinal Stenosis Measure (SSM): The SSM, an instrument specifically developed for spinal stenosis patients by Stucki et al. [17], targets to measure severity of symptoms and quantifies disability of the lumbar spinal stenosis population. This instrument is recommended by the North American Spine Society (NASS) and used in different studies on lumbar spinal stenosis [18-21]. It consists of three different subscales; the symptom severity subscale (score range 1-5, best-worst), the physical function subscale (1-4) and the satisfaction subscale (1-4).

$E Q-5 D-3 L$ : The EQ-5D-3L is an assessment tool to quantify health-related quality of life. It quantifies general non-disease specific health-related quality of life, including physical, mental and social dimensions [22]. It can be calculated as a sum score (score range 0-100, worst-best) [22]. The second part of the questionnaire estimates patient's actual health status (score range 0-100, worst-best).

Hospital Anxiety and Depression Scale (HADS): The HADS was originally developed to measure anxiety (score range 0-21, best-worst) and depression (0-21) in a hospital setting [23], however, it is nowadays common to use it in all settings [24].

\section{Data Collection and Follow-up}

Parts of the basic data sheet were interview-administered and recorded by a study coordinator. All other questionnaires were self-administered and filled in by the patients themselves. All data were collected at baseline, six and twelve months.

\section{Prognostic indicator}

We defined $F A B Q-P$ to qualify as a prognostic indicator if the score of $F A B Q-P$ influenced the course of the disease after adjustment for potential confounders.

\section{Cutoff value for high FABQ-P}

We used a cutoff value for high FABQ-P of $>16$ points based on the 75 th percentile at six months according to Grotle et al. [25]. 


\section{Outcomes}

The main outcome of this study was clinically meaningful improvement in SSM symptoms and function, which is denoted as MCID (minimal clinically important difference), after twelve months.

The MCID is defined as "the smallest difference in a score that is considered to be worthwhile or important" [26]. Thus, the MCID is a threshold for a relevant change in an outcome measure. Patients who reached or even exceed this threshold consider this change as meaningful and worthwhile. According to Stucki et al. [17] MCID for SSM is reached when "Symptom Severity scale" improve at least 0.48 points and "Physical Function scale" at least 0.52 points at the 6 - or 12 -month follow-up.

\section{Statistical analyses}

Analysis of data consisted of descriptive statistics of patient demographics and outcomes. Continuous and ordinal scaled variables were shown as median and interquartile ranges, and categorical variables were shown as numbers and percentages of total.

To analyze the influence of pre- and postoperatively assessed fear avoidance beliefs (FAB) on pain and disability we built different models for MCID in SSM symptoms and SSM function, respectively. First, continuous FABQ-P at baseline and continuous FABQ-P at six months, respectively, were the potential prognostic indicators in the models la and Ib. Dichotomous FABQ-P $>16$ at baseline (high FABQ-P-0) and FABQ-P $>16$ at six months (high FABQ-P-6), respectively, were entered in the models Ila and IIb. Persistent high FABQP >16 at baseline and at six months (high FABQ-P-persistent) entered in model III. In the models la and Ib, we first fitted a non-linear effect within the generalized additive model framework in order to verify or falsify the linearity assumption of the continuous prognostic indicator.

Potential confounders were selected a priori in an interdisciplinary consensus (JB, MW, $\mathrm{JS}, \mathrm{AF}, \mathrm{UH}, \mathrm{HG}$ ) and based on the current literature $[27,28]$. Demographic variables were age and gender (entered as continuous and categorical variable in the model, respectively), socio-economic variables were education (low education defined as compulsory edu- 
cation), and civil status (single, divorced, and widowed as risk factor), general health (presence of comorbidities (including osteoarthritis of the hip or knee, chronic lung disease, cardiac disease, and neurologic diseases) and body mass index (BMI, continuous variable), psychological health (anxiety (HADS anxiety score $\geq 8$ ), depression (HADS depression score $\geq 8$ ), and fear avoidance beliefs (FABQ-P $>16$ ), and current episode (duration of

complaints <3 months, 3-6 months, 6-12 months, >12 months), baseline SSM symptoms, SSM function, and EQ-5D sum score.

To reduce the number of confounders included in the multiple regression model simultaneously, we used an approach based on change in the specific estimated effect of FABQ$\mathrm{P}$ on each of the dichotomous outcomes. We considered those variables to be confounders that changed this effect by more than $\pm 10 \%$ [29].

Some of the potential confounders had a small percentage of missing values (ranging from $0.4 \%$ to $4.7 \%$ ). We used multiple imputation based on chained equations (with five replications) to obtain data sets without missing values [30]. The multiple imputation was based on the above described set of confounders, FABQ-P, and SSM symptoms and function. Pooled effect estimates were obtained with Rubin's formula [31].

All analyses were conducted with R for Windows [32].

\section{Ethics}

This multi-center cohort study was conducted in compliance with all international laws and regulations as well as any applicable guidelines. The study was approved by the independent Ethics Committee of the Canton Zurich (KEK-ZH-NR: 2010-0395/0).

\section{Results}

\section{Patient characteristics}

Between December 2010 and August 20151537 patients were potentially eligible, and 800 patients agreed to participate (Figure 6.1, study flow). Decompression surgery was performed in 331 patients. For this study, 234 patients (71\%) completed the twelve 
months follow-up until the end of August 2015 and were included in the analysis.

In Table 6.1 we present the patients baseline characteristics for all patients and patients with low FABQ-P (194 patients with FABQ-P $\leq 16$ at baseline and/or at six months follow-up) and patients in group high FABQ-P-persistent (40 patients with FABQ-P $>16$ at baseline and six months follow-up).

Continuous FABQ-P at baseline and at six months as prognostic indicator - model la and Ib In the model la we found that the effect of cont. FABQ-P-O was not linear on MCID in SSM symptoms and disability, respectively, at twelve months. Therefore, the linearity assumption was falsified and we restrained from further analysis.

In the model Ib, the effect of FABQ-P was linear on MCID in SSM symptoms and disability. The estimated OR for a one unit change in FABQ-P-6 was 0.95 (95\% Cl: 0.92-0.99) and 0.96 (95\% Cl: 0.93-1.00) for MCID in SSM symptoms and disability, respectively, at twelve months.

\section{High FABQ-P-0 (at baseline) as prognostic indicator - model Ila}

We found in the simple logistic regression analysis almost no effect of high FABQ-P-O for MCID in SSM symptoms at twelve months (OR 0.95; 95\% Cl: 0.55-1.67) and for MCID in SSM function at twelve months (OR 1.11; 95\% Cl: 0.64-1.92). The minimal effect of $F A B Q-$ P-0 on all outcomes might have resulted in an overestimated effect of confounders. Therefore, we restrained from further confounder analysis.

\section{High FABQ-P-6 (at six months) as prognostic indicator - model IIb}

In the model Ilb we found in the simple logistic regression analysis an effect of high FABQP-6 for MCID in SSM symptoms at twelve months (OR 0.58; 95\% Cl: 0.31-1.09). In the high FABQ-P-6 group patients were less likely to report a MCID than patients in the low FABQP-6 group (58.9\% vs. $72.5 \%$ ). In the final multiple logistic regression model we found that patients with high FABQ-P-6 were less likely to report MCID in SSM symptoms scale at twelve months (OR 0.46; 95\% Cl: 0.24-0.91) after adjustment for confounding (Table 6.2). 
Figure 6.1: Study flow

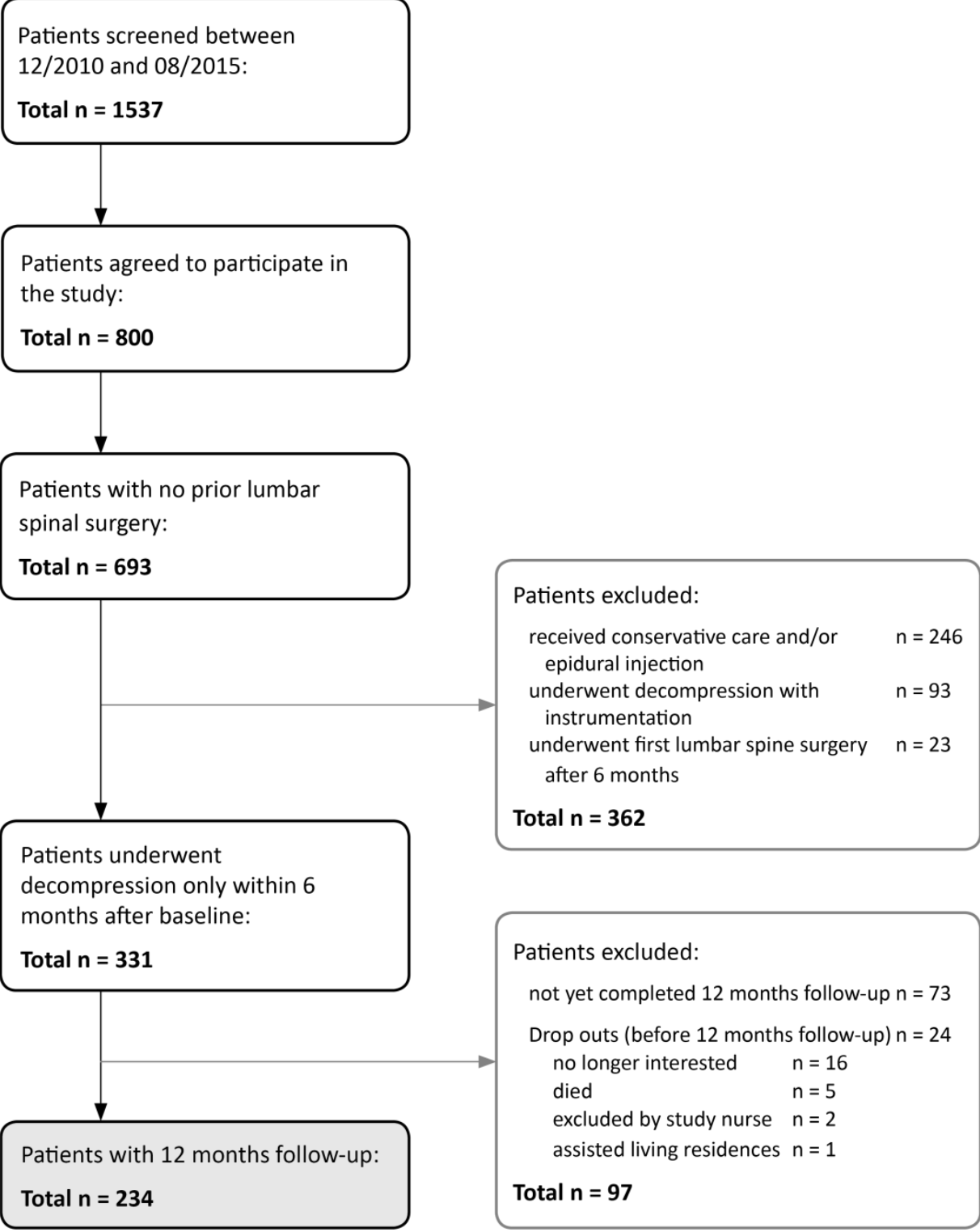


Table 6.1: Descriptive statistics of patients with low FABQ-P and high FABQ-P-persistent

\begin{tabular}{|c|c|c|c|c|}
\hline & All & Low FABQ-P* & $\begin{array}{l}\text { High FABQ-P- } \\
\text { persistent** }\end{array}$ & $\begin{array}{l}p- \\
\text { value }\end{array}$ \\
\hline$n$ & 234 & 194 & 40 & \\
\hline Age, years, median [IQR] & $75.0[68,80]$ & $75.0[68,80]$ & $74.5[68,81]$ & 0.9 \\
\hline Female, n (\%) & $120(51.3)$ & $99(51)$ & $21(52.5)$ & 0.99 \\
\hline BMI, kg/m2, median [IQR] & $26.9[24.3,30.4]$ & $26.8[24.4,30.3]$ & $27.4[23.8,30.5]$ & 0.97 \\
\hline Diabetes, n (\%) & $34(14.5)$ & $26(13.4)$ & $8(20)$ & 0.41 \\
\hline Education, n (\%) & & & & 0.08 \\
\hline Compulsory school & $58(24.8)$ & $53(27.3)$ & $5(12.5)$ & \\
\hline High school, college, university & $176(75.2)$ & $141(72.7)$ & $35(87.5)$ & \\
\hline Civil status, n (\%) & & & & 0.88 \\
\hline Single, divorced, widowed & $94(40.2)$ & 77 (39.7) & $17(42.5)$ & \\
\hline Married, registered partnership & $140(59.8)$ & $117(60.3)$ & $23(57.5)$ & \\
\hline Duration of complaints, $\mathrm{n}(\%)$ & & & & 0.58 \\
\hline$<3$ months & $25(10.8)$ & $19(9.9)$ & $6(15.4)$ & \\
\hline 3-6 months & $42(18.2)$ & $36(18.8)$ & $6(15.4)$ & \\
\hline $6-12$ months & $32(13.9)$ & $25(13.0)$ & 7 (17.9) & \\
\hline$>12$ months & $132(57.1)$ & $112(58.3)$ & $20(51.3)$ & \\
\hline \multicolumn{5}{|l|}{ Comorbidities, n (\%) } \\
\hline Coxarthrosis & $32(14.0)$ & $25(13.2)$ & 7 (17.9) & 0.6 \\
\hline Gonarthrosis & $37(16.2)$ & $30(15.9)$ & 7 (17.9) & 0.93 \\
\hline $\begin{array}{l}\text { Chronic lung disease } \\
\text { (COPD, asthma, fibrosis, others) }\end{array}$ & $13(5.7)$ & $7(3.7)$ & $6(15)$ & 0.02 \\
\hline Heart failure & $14(6.1)$ & $10(5.3)$ & $4(10)$ & 0.44 \\
\hline Coronary disease & $17(7.4)$ & $11(5.8)$ & $6(15)$ & 0.09 \\
\hline Neuropathy & $21(9.2)$ & $15(7.9)$ & $6(15.4)$ & 0.25 \\
\hline Parkinson's disease & $5(2.2)$ & $5(2.6)$ & $0(0)$ & 0.66 \\
\hline SSM symptoms, median [IQR] & $3.1[2.7,3.6]$ & $3.1[2.7,3.4]$ & $3.4[3.0,3.7]$ & 0.01 \\
\hline SSM function, median [IQR] & $2.4[1.8,2.8]$ & $2.3[1.8,2.8]$ & $2.7[2,3]$ & 0.05 \\
\hline EQ5D sum score, median [IQR] & $70[60,80]$ & $70[60,80]$ & $60[50,80]$ & 0.08 \\
\hline HADS anxiety, n (\%) & & & & 0.44 \\
\hline $0-7$ & $194(82.9)$ & $163(84)$ & $31(77.5)$ & \\
\hline $8-21$ & $40(17.1)$ & $31(16)$ & $9(22.5)$ & \\
\hline HADS depression, n (\%) & & & & 0.3 \\
\hline $0-7$ & $192(82)$ & $162(83.4)$ & $30(75)$ & \\
\hline $8-21$ & $42(18)$ & $32(16.6)$ & $10(25)$ & \\
\hline FABQ-P-0 (at baseline), median [IQR] & $16[12,20]$ & $15[10.8,18]$ & $22[19.8,24]$ & $<0.01$ \\
\hline FABQ-P-6 (at 6 months), median [IQR] & $12[4,16.5]$ & $8[1.5,14]$ & $21[19,23]$ & $<0.01$ \\
\hline
\end{tabular}


For disability, the simple logistic regression analysis showed an effect of high FABQ-P-6 for MCID in SSM function at twelve months (OR 0.82; 95\% Cl: 0.43-1.55). Patients in the high FAB-P-6 group reported similar MCID rates compared to the low FABQ-P-6 group (64.3\% vs. $68.9 \%)$. In the final multiple logistic regression model patients with high FABQP-6 showed a trend towards less MCID in SSM function at twelve months (OR 0.64; $95 \% \mathrm{Cl}$ : 0.31-1.32) after adjustment for confounding, however, the results were not statistically significant (Table 6.2).

Table 6.2: Multiple logistic regression model for SSM symptoms and function for MCID reached at 12 months in patients with high FABQ-P-6 (at six months) (model Ilb)

\begin{tabular}{llcc} 
& & $\begin{array}{c}\text { Patients MCID } \\
\text { reached, } \mathbf{n}(\%)^{* *}\end{array}$ & $\begin{array}{c}\text { MCID at 12 months: } \\
\text { OR (95\% CI) }\end{array}$ \\
\hline $\begin{array}{l}\text { Pain* } \\
\text { (SSM symptoms) }\end{array}$ & FABQ-P-6 $>16$ & $33(58.9)$ & $0.46(0.24-0.91)$ \\
& FABQ-P-6 $\leq 16$ & $121(72.5)$ & $2.8(1.57-4.99)$ \\
\hline & FSM symptoms & & $0.64(0.31-1.32)$ \\
& FABQ-P-6 $>16$ & $36(64.3)$ & \\
& BMI & $115(68.9)$ & $0.9(0.84-0.96)$ \\
Disability* & Duration 3-6mo & & $1.6(0.43-6)$ \\
(SSM function) & Duration 6-12mo & & $1.84(0.45-7.48)$ \\
& Duration $>12$ mo & & $0.97(0.31-3.05)$ \\
& Neuropathy Yes & & $0.5(0.18-1.4)$ \\
& HADS Depression $\geq 8$ & & $0.53(0.23-1.25)$ \\
& EQ5D sum score & $1.01(0.99-1.04)$ \\
& SSM symptoms & & $0.8(0.44-1.46)$ \\
& SSM function & $7.04(2.36-8.63)$
\end{tabular}

BMI, body mass index; $\mathrm{Cl}$, confidence interval; Duration, duration of symptoms FABQ-P, Fear Avoidance Beliefs Physical Activity Subscale; HADS, Hospital Anxiety and Depression Scale; SSM, Spinal Stenosis Measure

*Confounders included when a variable changed the effect between FAB and each outcome by $>+/-10 \%$ from the preselected potential confounders: age, gender, low education, civil status, presence of comorbidities, BMI, HADS anxiety score $\geq 8$, HADS depression score $\geq 8$, duration of complaints $<3$ months, 3-6 months, 6-12 months, or $>12$ months, baseline SSM symptoms, baseline SSM function, and baseline EQ-5D sum score.

**: raw data 
Table 6.3: Multiple logistic regression model for SSM symptoms and function for MCID reached at 12 months in patients with high FABQ-P-persistent (at baseline and at six months) (model III)

\begin{tabular}{|c|c|c|c|}
\hline & & $\begin{array}{l}\text { Patients MCID } \\
\text { reached, } \mathrm{n}(\%)^{* *}\end{array}$ & $\begin{array}{l}\text { MCID at } 12 \text { months: } \\
\text { OR }(95 \% \mathrm{CI})\end{array}$ \\
\hline \multirow{3}{*}{$\begin{array}{l}\text { Pain* } \\
\text { (SSM symptoms) }\end{array}$} & FABQ-P-persistent $>16$ & $22(55)$ & $0.34(0.16-0.73)$ \\
\hline & FABQ-P-persistent $\leq 16$ & $136(72.3)$ & \\
\hline & SSM symptoms & & $2.75(1.63-4.64)$ \\
\hline \multirow{8}{*}{$\begin{array}{l}\text { Disability* } \\
\text { (SSM function) }\end{array}$} & FABQ-P-persistent $>16$ & $24(60)$ & $0.53(0.25-1.15)$ \\
\hline & FABQ-P-persistent $\leq 16$ & $129(68.6)$ & \\
\hline & Duration 3-6mo & & $1.45(0.41-5.12)$ \\
\hline & Duration 6-12mo & & $1.94(0.5-7.44)$ \\
\hline & Duration $>12 \mathrm{mo}$ & & $0.92(0.31-2.76)$ \\
\hline & EQ5D sum score & & 1.02 (0.99-1.04) \\
\hline & SSM symptoms & & $0.81(0.45-1.46)$ \\
\hline & SSM function & & 4.05 (2.19-7.48) \\
\hline \multicolumn{4}{|c|}{$\begin{array}{l}* \text { * measured at baseline; } \mathrm{Cl} \text {, confidence interval; Duration, duration of symptoms; FABQ-P, Fear Avoidance Beliefs Physical } \\
\text { Activity Subscale; SSM, Spinal Stenosis Measure } \\
\text { *Confounders included when a variable changed the effect between FAB and each outcome by }>+/-10 \% \text { from the preselected } \\
\text { potential confounders: age, gender, low education, civil status, presence of comorbidities, BMI, HADS anxiety score } \geq 8 \text {, HADS } \\
\text { depression score } \geq 8 \text {, duration of complaints }<3 \text { months, } 3-6 \text { months, } 6-12 \text { months, or }>12 \text { months, baseline SSM symptoms, } \\
\text { baseline SSM function, and baseline EQ-5D sum score. } \\
\text { **: raw data }\end{array}$} \\
\hline
\end{tabular}

High FABQ-P-persistent (at baseline and six months) as prognostic indicator - model III In the model III we found in the simple logistic regression analysis an effect of high FABQP-persistent for MCID in SSM symptoms at twelve months (OR 0.49; 95\% Cl: 0.24-0.98). The percentage of patients who reached MCID was smaller than in the low FABQ-Ppersistent group (55\% and $72.3 \%$, respectively). In the multiple logistic regression model patients with high FABQ-P-persistent were less likely to report MCID in SSM symptoms at twelve months (OR 0.34, 95\% Cl: 0.16-0.73) after adjustment for confounding (Table 6.3).

For disability, the effect of high FABQ-P-persistent showed in the simple logistic regression analysis an effect for MCID in SSM function at twelve months (OR 0.69; 95\% Cl: 0.34-1.4). The percentage of patients who reached MCID was similar between the high 
and low FABQ-P-persistent groups (60\% and 68.6\%, respectively). In the multiple logistic regression model patients with high FABQ-P-persistent were again less likely to experience MCID at twelve months (OR 0.53, 95\% $\mathrm{Cl}$ : 0.25-1.15) after adjustment for confounding. While the effect was relevant, the wide $95 \% \mathrm{Cl}$ crossed one and therefore, the effect was not statistically significant (Table 6.3).

\section{Discussion}

In this analysis of 234 patients undergoing decompression surgery for symptomatic degenerative lumbar spinal stenosis (LSS) we found baseline high fear avoidance beliefs (FAB) measured by FABQ-P not to be associated with pain of symptoms and disability at twelve months' follow-up. For continuous FABQ-P-0 we found no linear association and for FABQ-P-6 there was an effect of about 5 percent reduced chance for MCID on SSM symptoms and function per one unit change at twelve months. Patients with high FABQ-P6 and high FABQ-P-persistent were less likely to report a MCID for SSM symptoms at twelve months. Our analysis found a similar trend for disability. However, the confidence intervals were wide indicating heterogeneity in the patient population and the effect statistically not significant.

\section{Results compared to the literature}

To date, the influence of FAB in patients with symptomatic lumbar spinal stenosis on pain and disability is hardly investigated. The influence of psychological factors on the individual experience of pain and disability is increasingly recognized [9]. Studies in patients with low back pain (LBP) support the conceptual framework of the fear-avoidance model which implies that fear of pain may lead to avoidance behavior [9]. Avoidance behavior results in disuse, disability and depression, and maintains the original negative appraisal in a deleterious cycle. In low back pain high FAB were indicators for poor outcome in the subacute phase and influenced the treatment response in conservative treatments $[12,13]$. In patients undergoing surgery for spinal disorders one study showed a postoperative reduc- 
tion in fear avoidance beliefs [8]. Similar to our study, they found that preoperative fear of movement (measured by the Tampa Scale of kinesiophobia) was not a prognostic factor for poor outcome. Archer et al. [8] found in their study that postoperative high scores in the Tampa Scale at six weeks and three months were associated with more pain and disability.

Wood et al. [33] compared the influence of fear of movement (measured by the Tampa Scale of kinesiophobia) in patients with lumbar spinal stenosis with neurogenic claudication to patients with claudication due to peripheral arterial disease and asymptomatic patients. In this cross-sectional study they found that persons with neurogenic claudication reported higher fear avoidance beliefs than patients with claudication due to other illnesses.

A study including 159 patients with lumbar spinal stenosis or disc herniation that underwent decompression surgery showed in a prediction model that preoperative $F A B$ of physical activity was the only predictor for postoperative outcome (measured by using a global outcome measure) after one year [34]. In the study by Havakeshian et al. [34], FABQ-P were used on a continuous scale. Our study aimed to investigate the impact of high FABQ-P beliefs using a cutoff and therefore, increasing the clinical applicability. In our study in elderly patients with symptomatic degenerative lumbar spinal stenosis undergoing decompressive surgery high pre-operative FABQ-P were not a prognostic indicator for MCID at six or twelve months for patient reported outcomes pain and disability. High FABQ-P-6 and high FABQ-P-persistent were associated with less MCID for pain at twelve months but not for disability. One explanation could be that the FABQ-P was originally validated for low back pain patients. The wording focuses on pain and the back. In LSS patients the complaints are frequently not primarily back related or the pain itself but rather the neurogenic complaints or gait impairment. Hence, we found an association between postoperative FABQ-P and pain outcomes but not on disability. Therefore, the wording of the FABQ-P may need to be adjusted and the scale validated for this specific population. One other explanation could be that preoperative fear (fear of the pending surgery) might influence the reporting in FABQ-P. The FABQ-P does not specifically assess 
surgical fear and therefore, we were not able to distinguish between surgical fear and FABQ-P as negative coping strategy [6].

Preoperative fear has been shown in patients undergoing elective surgery to be associated with acute postoperative as well as long-term pain [35]. Our findings indicated that high FABQ-P-6 or high FABQ-P-persistent were a relevant factor for pain at twelve months but not disability. It can be hypothesized that in patients with high FABQ-P-persistent fear persists over a longer time period and so the impact will be more relevant on their ability to cope with the pain. One may also hypothesize that high fear avoidance beliefs are the result and not the cause of a worse treatment outcome. The correlations between FABQP-0 with symptoms and disability at baseline and the FABQ-P-6 with symptoms and disability at 6 months, respectively, were weak (data not shown). This indicates that high FABQ-P-persistent after surgery is independent from symptoms and disability a relevant prognostic indicator that may be modified by specific treatment approaches. This has to be addressed specifically in future studies.

\section{Strength and limitations}

A limitation of this study was that it was not possible to distinguish how strongly $F A B Q-P-0$ was influenced by specifically assessed surgical fear. Furthermore, our cutoff value for FABQ-P was derived based on the 75th percentile according to a previously published study, however, a variety of other cutoff values have been proposed but none of them has been established yet. Additionally, we did not evaluate catastrophizing, and thus we were unable to assess the influence of catastrophizing on the interaction between FABQ-P and catastrophizing.

Our study has several strengths. These include the multi-center setting and prospective collection of data as well as the use of established questionnaires on degenerative lumbar spinal stenosis. Furthermore, we had a homogenous patient sample regarding the treatment since only first-time decompression surgeries without fusions were included. Additionally, we used multiple imputation techniques to avoid potentially biased results as compared to a complete case analysis. 


\section{Implications for research}

Our finding was unexpected considering that high preoperative $F A B$ has been shown in a previous study to be a predictor of poor outcome [34]. Future studies should further investigate the importance of fear of surgery and its difference to FAB as a negative coping. In future studies on patients undergoing surgical treatment it is advisable to use additionally a specific questionnaire assessing surgical fear, such as the Surgical Fear Questionnaire (SFQ) [35]. Furthermore, it is unclear whether patients with persistent fear avoidance beliefs after surgery may benefit from specific cognitive and behavioral intervention that have been shown in other setting to modify the impact of FAB.

\section{Implications for clinical practice}

In patients undergoing surgery for degenerative lumbar spinal stenosis high FABQ-P-0 were not associated with poor prognosis. Similar to previous studies we showed that FABQ-P-6 and FABQ-P-persistent maybe important factors to consider in patients with persistent complaints.

\section{Conclusions}

In elderly patients undergoing decompression surgery for symptomatic degenerative lumbar spinal stenosis preoperative fear avoidance beliefs were not a prognostic indicator for the outcome. Patients with fear avoidance beliefs at six months and persistent fear avoidance beliefs were less likely to experience clinically relevant improvement in pain at twelve months. Studies should address the importance of persistent postoperative fear avoidance beliefs. 


\section{References}

1. Hoy D, March L, Brooks P, Blyth F, Woolf A, Bain C, Williams G, Smith E, Vos T, Barendregt J et al: The global burden of low back pain: estimates from the Global Burden of Disease 2010 study. Ann Rheum Dis 2014, 73(6):968-974.

2. Deyo RA: Treatment of lumbar spinal stenosis: a balancing act. The spine journal : official journal of the North American Spine Society 2010, 10(7):625-627.

3. Atlas SJ, Keller RB, Wu YA, Deyo RA, Singer DE: Long-term outcomes of surgical and nonsurgical management of lumbar spinal stenosis: 8 to 10 year results from the maine lumbar spine study. Spine (Phila Pa 1976) 2005, 30(8):936-943.

4. Weinstein JN, Tosteson TD, Lurie JD, Tosteson A, Blood E, Herkowitz H, Cammisa F, Albert T, Boden SD, Hilibrand A et al: Surgical versus nonoperative treatment for lumbar spinal stenosis four-year results of the Spine Patient Outcomes Research Trial. Spine (Phila Pa 1976) 2010, 35(14):1329-1338.

5. Brodner G, Mertes N, Buerkle H, Marcus MA, Van Aken H: Acute pain management: analysis, implications and consequences after prospective experience with 6349 surgical patients. Eur J Anaesthesiol 2000, 17(9):566575.

6. Theunissen M, Peters ML, Bruce J, Gramke HF, Marcus MA: Preoperative anxiety and catastrophizing: a systematic review and meta-analysis of the association with chronic postsurgical pain. Clin J Pain 2012, 28(9):819-841.

7. Sommer M, de Rijke JM, van Kleef M, Kessels AG, Peters ML, Geurts JW, Patijn J, Gramke HF, Marcus MA: Predictors of acute postoperative pain after elective surgery. Clin J Pain 2010, 26(2):87-94.

8. Archer KR, Wegener ST, Seebach C, Song Y, Skolasky RL, Thornton C, Khanna AJ, Riley LH, 3rd: The effect of fear of movement beliefs on pain and disability after surgery for lumbar and cervical degenerative conditions. Spine (Phila Pa 1976) 2011, 36(19):1554-1562.

9. Linton SJ, Shaw WS: Impact of psychological factors in the experience of pain. Phys Ther 2011, 91(5):700711.

10. Wertli MM, Burgstaller JM, Weiser S, Steurer J, Kofmehl R, Held U: Influence of catastrophizing on treatment outcome in patients with nonspecific low back pain: a systematic review. Spine (Phila Pa 1976) 2014, 39(3):263273.

11. Wertli MM, Eugster R, Held U, Steurer J, Kofmehl R, Weiser S: Catastrophizing-a prognostic factor for outcome in patients with low back pain: a systematic review. The spine journal : official journal of the North American Spine Society 2014, 14(11):2639-2657.

12. Wertli MM, Rasmussen-Barr E, Held U, Weiser S, Bachmann LM, Brunner F: Fear-avoidance beliefs-a moderator of treatment efficacy in patients with low back pain: a systematic review. The spine journal : official journal of the North American Spine Society 2014, 14(11):2658-2678.

13. Wertli MM, Rasmussen-Barr E, Weiser S, Bachmann LM, Brunner F: The role of fear avoidance beliefs as a prognostic factor for outcome in patients with nonspecific low back pain: a systematic review. The spine journal : official journal of the North American Spine Society 2014, 14(5):816-836 e814.

14. Steurer J, Nydegger A, Held U, Brunner F, Hodler J, Porchet F, Min K, Mannion AF, Michel B, LumbSten Research C: LumbSten: the lumbar spinal stenosis outcome study. BMC Musculoskelet Disord 2010, 11:254.

15. Waddell G, Newton M, Henderson I, Somerville D, Main CJ: A Fear-Avoidance Beliefs Questionnaire (FABQ) and the role of fear-avoidance beliefs in chronic low back pain and disability. Pain 1993, 52(2):157-168.

16. Swinkels-Meewisse EJ, Swinkels RA, Verbeek AL, Vlaeyen JW, Oostendorp RA: Psychometric properties of the Tampa Scale for kinesiophobia and the fear-avoidance beliefs questionnaire in acute low back pain. Man Ther 2003, 8(1):29-36.

17. Stucki G, Liang $\mathrm{MH}$, Fossel $\mathrm{AH}$, Katz JN: Relative responsiveness of condition-specific and generic health status measures in degenerative lumbar spinal stenosis. J Clin Epidemiol 1995, 48(11):1369-1378.

18. Tuli SK, Yerby SA, Katz JN: Methodological approaches to developing criteria for improvement in lumbar spinal stenosis surgery. Spine (Phila Pa 1976) 2006, 31(11):1276-1280. 
19. Zucherman JF, Hsu KY, Hartjen CA, Mehalic TF, Implicito DA, Martin MJ, Johnson DR, 2nd, Skidmore GA, Vessa PP, Dwyer JW et al: A multicenter, prospective, randomized trial evaluating the X STOP interspinous process decompression system for the treatment of neurogenic intermittent claudication: two-year follow-up results. Spine (Phila Pa 1976) 2005, 30(12):1351-1358.

20. Hansraj KK, O'Leary PF, Cammisa FP, Jr., Hall JC, Fras Cl, Cohen MS, Dorey FJ: Decompression, fusion, and instrumentation surgery for complex lumbar spinal stenosis. Clin Orthop Relat Res 2001(384):18-25.

21. Fokter SK, Yerby SA: Patient-based outcomes for the operative treatment of degenerative lumbar spinal stenosis. Eur Spine J 2006, 15(11):1661-1669.

22. Hinz A, Klaiberg A, Brahler E, Konig HH: [The Quality of Life Questionnaire EQ-5D: modelling and norm values for the general population]. Psychother Psychosom Med Psychol 2006, 56(2):42-48.

23. Zigmond AS, Snaith RP: The Hospital Anxiety and Depression Scale. Acta Psychiatrica Scandinavica 1983, 67(6):361-370.

24. Crawford JR, Henry JD, Crombie C, Taylor EP: Normative data for the HADS from a large non-clinical sample. British Journal of Clinical Psychology 2001, 40:429-434.

25. Grotle M, Brox JI, Glornsrod B, Lonn JH, Vollestad NK: Prognostic factors in first-time care seekers due to acute low back pain. Eur J Pain 2007, 11(3):290-298.

26. Beaton DE, Boers M, Wells GA: Many faces of the minimal clinically important difference (MCID): a literature review and directions for future research. Curr Opin Rheumatol 2002, 14(2):109-114.

27. Pincus T, Santos R, Breen A, Burton AK, Underwood M, Multinational Musculoskeletal Inception Cohort Study C: A review and proposal for a core set of factors for prospective cohorts in low back pain: a consensus statement. Arthritis Rheum 2008, 59(1):14-24.

28. Deyo RA, Dworkin SF, Amtmann D, Andersson G, Borenstein D, Carragee E, Carrino J, Chou R, Cook K, DeLitto A et al: Report of the NIH Task Force on research standards for chronic low back pain. Pain Med 2014, 15(8):1249-1267.

29. Rothman KJ, Greenland S, Lash TL: Introduction to Stratified Analysis. In: Modern epidemiology. Third Edition edn.: Lippincott Williams \& Wilkins; 2008: 258-282.

30. van Buuren S, Groothuis-Oudshoorn K: mice: Multivariate Imputation by Chained Equations in R. 20112011 , 45(3):67.

31. Rubin DB: Multiple imputation for nonresponse in surveys, vol. 81: John Wiley \& Sons; 2004.

32. R Core Team: R: A Language and Environment for Statistical Computing. In. Vienna, Austria: R Foundation for Statistical Computing; 2015: http://www.R-project.org/.

33. Wood DW, Haig AJ, Yamakawa KSJ: Fear of movement/(re)injury and activity avoidance in persons with neurogenic versus vascular claudication. Spine Journal 2012, 12(4):292-300.

34. Havakeshian S, Mannion AF: Negative beliefs and psychological disturbance in spine surgery patients: a cause or consequence of a poor treatment outcome? European Spine Journal 2013, 22(12):2827-2835.

35. Theunissen M, Peters ML, Schouten EG, Fiddelers AA, Willemsen MG, Pinto PR, Gramke HF, Marcus MA: Validation of the surgical fear questionnaire in adult patients waiting for elective surgery. PLoS One 2014, 9(6):e100225. 




\section{Chapter 7}

\section{General Discussion}



The research presented in this doctoral thesis examined a series of potential prognostic indicators in patients with symptomatic lumbar spinal stenosis (LSS). The work presented in this thesis highlights the need for future studies to establish / identify prognostic indicators that may help to identify patients that will benefit from specific treatment strategies. The findings presented in this thesis are an important step in this direction and may inspire future research in LSS.

\section{Results in light of existing literature}

MRI parameters associated with pain in patients with lumbar spinal stenosis (Chapter 2) Magnetic resonance imaging (MRI) is recommended as the most appropriate non-invasive tool to establish the diagnosis of LSS according to the guidelines of the North American Spine Society [1]. Nevertheless, our review showed that studies investigating the association between MRI parameters and pain were rare and yielded in controversial results [25]. Sigmundsson et al. [5] found a weak correlation between the size of the dural sac area and reported leg/back pain (Visual Analogue Scale, VAS). Whereas Lavelle et al. [4] found an association between the degree of stenosis, assessed by spine surgeons in the MRI, and leg pain (quantified by a VAS), Geisser et al. [2] found no association between osseous antero-posterior spinal canal diameter and disability (McGill Pain Questionnaire (MPQ)) and Kim et al. [3] no association between the grading of canal stenosis (method by Schizas) and VAS. As part of the Lumbar Stenosis Outcome Study (LSOS), a systematic literature review and a Delphi survey was conducted to identify the best MRI parameters that need to be considered when quantifying a LSS on MRI studies. In the Delphi survey renowned international experts participated and in a consensus conference a core set of five MRI parameters were defined: "compromise of central zone", "relation of fluid to nerve roots in the central canal", "nerve root compression in the lateral recess (right/left)", "compromise of the foraminal zone (right/left)", and "foraminal nerve root impingement (right/left)" [6]. In the LSOS study all MRIs were reanalyzed by two independent radiologists ( $\mathrm{k}$ values for the core image parameters ranged between 0.42 and 0.77 for inter- 
reader agreement and between 0.59 and 0.80 for intra-reader agreement [7]). This is the first study that analyzed the agreement between this core set parameters and patient reported outcome measure for pain (measured by using the pain subscale of the Spinal Stenosis Measure (SSM) [8]). The pain subscale of the SSM assesses pain and neuroischemic complaints. Despite the use of up-to-date methods, we were unable to identify a correlation between MRI parameters and pain. Several reasons could be responsible for these findings. First, complaints on pain severity are extremely subjective and depend on the individual processing of nociceptive information $[9,10]$. Second, the spinal canal is a dynamic structure and the diameters vary by changing posture and by bodily activities [3]. Up to date, standard MRI procedure of a patient with LSS comprises static images of the lumbar spinal canal in the supine. However, the dimensions of the spinal canal are different while standing or walking and consequently may not represent the real circumstances. Third, all of the four above cited papers including our own analysis used standard statistical approaches which seem not to be sufficient enough to analyze accurately the association between MRI parameters and pain. Consequently, future research should apply innovative methods or techniques like machine learning approaches as well as new imaging modalities.

\section{Arguments of surgeons when choosing a specific type of surgical treatment for a patient (Chapter 3)}

Surgical treatment for LSS is the last option when symptoms are moderate to severe and conservative treatment has failed [1]. Nonetheless, our systematic appraisal of randomized controlled trials (RCTs) showed that surgeons disagree when it comes to the choice what specific type of surgical procedure should be performed. The main controversy identified was whether in an anticipated postoperative instability (instrumented) fusion procedures should be used or not [11]. Two recently in the New England Journal of Medicine published RCTs from 2016 emphasize this dissent: the authors came to opposite conclusions. While one RCT found a significant difference between decompression surgery plus fusion and decompression surgery alone in patients with degenerative spondylolisthesis 
the other RCT found no difference $[12,13]$. There could be several reasons for these opposite results: Ghogawala et al. [12] reported an improvement only in the physicalcomponent summary of the Medical Outcomes Study 36-Item Short-Form Health Survey (SF-36). The SF-36 is a generic outcome measure that does not measure specific neuroischemic features of LSS which may be the dominant symptoms [14]. Furthermore, more patients were lost to follow-up and more patients underwent reoperation in the decompression alone group which could have had a negative effect on the physical-component summary score of SF-36 during recovery. However, fusion surgery is associated with increased risk of major complications (i.e. pneumonia, respiratory failure, and stroke) and wound complications [15]. Furthermore, the longer operating times of fusion compared to decompression surgery alone increase the risks of anesthesia and their consequences in the typical elderly lumbar spinal stenosis patient population. On the one hand fusion surgery results in higher fusion rates and more stability with an increased perioperative risk. On the other hand, decompression alone may lead to increased vertebral instability which results in a progression of degenerative changes and compression of nerve roots and therefore require reoperation. However, by reading the original papers in our appraisal we noticed that the key term instability is ambiguously and not clearly defined. Authors of different studies used various definitions, and the meaning is different for clinicians, radiologists and bioengineers [16]. An example for a clinical definition was "The loss of the spine's ability to maintain its pattern of displacement under physiologic loads so there is no initial or additional neurologic deficit, no major deformity, and no incapacitating pain." $[17,18]$ A radiological definition was "Increased angulatory or translatory motion noted on active flexion-extension lateral or anteroposterior bending radiographs that exceeds 4 $\mathrm{mm}$ or $10^{\circ}$ angulation [...]." [19] Recently, an international and interdisciplinary panel consisting of 14 experts concluded: "Although the term instability is in common use and is felt to be important by some, no commonly agreed definition of the concept could be found by the expert panel“ [20]. To facilitate the meaningful interpretation of study results, it is crucial that researchers and clinicians agree on definitions for important key concepts such as instability. 


\section{Clinical improvement in obese patients after surgery for symptomatic degenerative lumbar spinal stenosis compared to non-obese patients (Chapter 4)}

Prognostic indicators are factors associated with the future course of an illness. In low back pain, obesity has been shown to be associated with reduced quality of life for physical function and co-morbid disability [21]. The impact of surgical treatment in obese patients with LSS is inconsistent. It is intuitive to assume that in morbidly obese patients poor fitness and gait instability due to the body weight may lead to worse treatment outcome. However, our results in patients with LSS undergoing decompression surgery did not demonstrate this association and the findings are in line with other studies that found no influence of obesity on clinical outcome. In an analysis of the Spine Patient Outcomes Research Trial (SPORT), a multicenter study across the United States, Rihn et al. [22] showed that obesity did not affect the clinical outcome in patients with lumbar stenosis without degenerative spondylolisthesis after undergoing operative treatment. Gepstein et al. [23] reported a similar reduction in overall improvement as well as in pain in decompressed obese and non-obese patients. In addition, obese patients undergoing lumbar fusion procedures showed no significant differences in back- and leg-pain and in ODI score at two-year follow-up [24]. Furthermore, Rosen et al. [25] reported no significant differences between obese and non-obese patients after lumbar spine fusion surgery in terms of self-reported outcome measures, operative time and length of hospital stay. In contrast to these results two studies showed in obese patients more peri- and postoperative complications, and increased transfusion requirements [26, 27]. Ou et al. [28] reported in their retrospective study of 190 patients undergoing lumbar fusion for degenerative spine diseases that BMI is a risk factor for adjacent segment disease. In our study the obese patient population had a slightly worse comorbidity score measured by using Cumulative Illness Rating Scale (CIRS) than the non-obese population reflecting some differences at baseline and in the perioperative situation, similar to the studies of Rihn [22] and Gepstein [23]. Whereas Gepstein et al. reported significant differences in perioperative complications in obese patients, Rhin et al. found no significant differences in intra- and postoperative complications. We did not analyze intra- and postoperative complications in this analysis. 
This should be addressed in a future study. The proportion of patients with very high BMI ( $\geq 35 \mathrm{~kg} / \mathrm{m} 2$ ) was small (our study $4.2 \%$, Gepstein $4 \%$, Rihn no information). Therefore, the findings may be different in populations that are severely obese where gait instability and severe deconditioning can be expected.

\section{The influence of catastrophizing on the treatment response in patients with low back pain (Chapter 5)}

The effect of catastrophizing on the outcome of treatment has received increasing attention $[29,30]$. A systematic review on the relevance of preoperative catastrophizing in patients undergoing surgery, catastrophizing thoughts were associated with more postsurgical pain and poorer quality of life [31]. However, the importance of catastrophizing in spine surgery has not been reviewed. Therefore, our systematic review in low back pain patients closes an important gap and broadens the knowledge about the influence of catastrophizing on treatment efficacy and outcome. In 11 RCTs we found a consistent association between higher catastrophizing scores and more disability and pain at followup but there was insufficient data to analyze the influence of catastrophizing on workrelated outcomes including return to work and sick days. While the findings were in line with the fear avoidance model, we need to acknowledge the methodological limitations of the included RCTs (small sample size, no power analysis for subgroup analyses, no direct test for interaction between catastrophizing and treatment). Pain catastrophizing which conceptually belongs to the fear avoidance model is believed to be a precursor of painrelated fear [32]. Fear avoidance beliefs (FAB) decrease the treatment efficacy of treatments based on biomedical concepts (e.g. physical therapy) and increase treatment efficacy in treatments that aim to reduce fear avoidance beliefs [33]. However, it is possible to have fear avoidance beliefs without catastrophizing [34]. Further, fear is a more common reaction to pain than catastrophizing thoughts. Future research should aim at identifying the importance of catastrophizing in relation to fear avoidance beliefs and other psychological factors. 
The influence of preoperatively assessed fear avoidance beliefs on pain and disability in patients with degenerative lumbar spinal stenosis after decompression surgery (Chapter 6)

To date, the influence of FAB in patients with symptomatic lumbar spinal stenosis on pain and disability is hardly investigated although the influence of psychological factors on the individual experience of pain and disability is more and more accepted [35]. In patients undergoing surgery for spinal disorders Archer et al. [36] found that preoperative fear of movement (measured by the Tampa Scale of kinesiophobia) was no prognostic factor for poor outcome. Furthermore, they reported that postoperative high scores in the Tampa Scale at six weeks and three months were associated with more pain and disability. These results were in line with our study. Wood et al. [37] compared in a cross-sectional study the influence of fear of movement (measured by the Tampa Scale of kinesiophobia) in patients with lumbar spinal stenosis with neurogenic claudication to patients with claudication due to peripheral arterial disease and asymptomatic patients. The authors found in patients with neurogenic claudication higher fear avoidance beliefs than in patients with claudication due to other illnesses. Havakeshian et al. [38] identified preoperative FAB of physical activity (FABQ-P) as the only predictor for postoperative outcome (measured by using a global outcome measure) after one year in patients undergoing decompression surgery for lumbar spinal stenosis or disc herniation. In contrast to our study, FABQ-P was measured on a continuous scale. In our study we used a cutoff for high fear avoidance beliefs to increase the clinical applicability. We found that high pre-operative FABQ-P were not a prognostic indicator for minimal clinically important difference (MCID) at six or twelve months for patient reported outcomes pain and disability measured by Spinal Stenosis Measure (SSM) symptoms and function, respectively. While we found no linear association between FABQ-P and pain or disability at baseline, we found a linear association at six months. In the multivariate analysis high FABQ-P at baseline that persisted at six months were associated with less MCID for pain at twelve months but not for disability. One explanation could be that the FABQ-P was originally validated for low back pain patients where the wording focuses on pain and the back and not on neurogenic complaints 
which LSS patients mainly complain about. Hence, we found an association between postoperative $F A B Q-P$ and pain outcomes but not on disability. One other explanation could be that preoperative fear (fear of the pending surgery) might influence the reporting in FABQ-P. The FABQ-P does not specifically assess surgical fear and therefore, we were not able to distinguish between surgical fear and FABQ-P as negative coping strategy [39]. Surgical fear has to be addressed specifically in future studies.

\section{Strength and limitation}

The strength of this thesis is that we used different methods to identify important prognostic indicators in patients with degenerative lumbar spinal stenosis: systematic literature review, analysis of primary studies included in systematic reviews, and analyses of data from an ongoing cohort study (the LSOS). Inspired from findings in low back pain patients we applied concepts and research question on an important subgroup of patients that may need other treatment strategies than patients with non-specific low back pain.

This thesis has also some limitations. The LSOS study started patient collection in December 2010 and stopped collection in December 2015. Consequently, the 2- and 3-years follow-ups are missing in many patients that could not be considered in this thesis. We may have further insights at the end of the follow-up of LSOS. Another limitation is that we were not able to conduct meta-analyses in both systematic reviews in this thesis due to the heterogeneity in the study settings and differences in outcome assessment.

\section{Implication for research}

We suggest the following implications for future research based on the various aspects discussed above: It is crucial to understand the causal associations between clinical symptoms and radiologic findings. This is particularly important for primary care physicians that need to recommend patients a specific treatment and decide on whether to refer a patient to a spine surgeon. Further, it is also very important for spine surgeons in planning 
the type of surgery. Therefore, sophisticated statistical methods like machine learning approaches, that have been already successfully used in glioma diagnostics $[40,41]$, or model averaging should be applied in future studies. Furthermore, the more sophisticated and less invasive surgical procedures could improve patient outcome and decrease the risk for adverse events. Decompression surgery is still the gold standard for surgical treatment of LSS, even though the procedure is somewhat bone-destructive $[42,43]$. New developments of less destructive surgical interventions such as minimally invasive lumbar decompression (MILD) or interspinous process devices (IPD) have become popular in recent years. The MILD procedure is an image guided minimally invasive procedure used in central canal LSS patients with ligamentum flavum hypertrophy. The procedure "involves limited percutaneous laminotomy and thinning of the ligamentum flavum" [44]. However, before those newer techniques can be applied in clinical practice the scientific evidence should support the benefit of the procedures compared to the "gold standard". A recent systematic review revealed that current evidence is of low quality and, therefore, impeded a meta-analysis [45]. While the MILD procedure is shown to be relatively safe, there is a need for more high-quality studies without industry funding to confirm these findings. The IPD is another alternative minimal invasive technique that was developed "to stabilize and increase the interspinous distance with indirect decompression of the dural sac and nerve roots" [46]. Two recently published RCTs compared interspinous spacers with standard decompression alone and found no advantage of IPDs in the outcomes between the groups $[47,48]$. Moreover, the reoperation rate was in both studies higher in the IPD groups while the complication rate was lower in the spacer group [47, 48]. Due to the reason that IPDs are a relatively new technology, there is a need for a more comprehensive evaluation of their indications as well as of their design.

While psychological factors (e.g. fear avoidance beliefs, depression, bothersomeness) have been shown to influence the outcome in low back pain patients, the impact in LSS needs further high quality studies. The unexpected finding that pre-operative fear avoidance beliefs were no prognostic indicator in our study raises the question about the impact of pre-surgical fear and its relevance in LSS patients. One way to approach this could 
be to use compare the FABQ with a questionnaire that measures surgical fear, such as the Surgical Fear Questionnaire (SFQ) [49].

\section{Implication for practice}

Our findings may have a substantial impact on health care costs. Firstly, MRIs are routinely performed in every patient in whom LSS is suspected and each MRI costs between 600 and 1'000 USD. However, our findings could not show a relevant association between MRI parameters and pain, despite the use of up-to-date methods and radiological evaluation procedures. Therefore, it is a debatable whether patients with mild and typically specific stenosis symptoms who will be first treated conservatively should undergo a MRI study. Secondly, spine care is quite preference sensitive [50]. Preference sensitive interventions are interventions for a disease where more than one treatment option exists. The choice for a conservative or surgical intervention is based on the clinical judgment of the treating physician and depends on personal beliefs, preferences and experiences. Conservative treatment is cheaper than surgical procedures and decompression plus fusion is at least twice as expensive as decompression alone surgery. Although fusion surgery is associated with increased risk of major complications and despite the lack of convincing evidence surgeons use more and more fusion procedures. Therefore, it is crucial that the surgeon discusses the pros and cons of the different treatment options together with the patient and that both together decide what is the best treatment.

\section{Conclusion}

With our research activities we expect to have made a sustained contribution to the arising recognition of the importance of prognostic indicators in degenerative lumbar spinal stenosis. We hope that patients suffering from degenerative lumbar spinal stenosis, their relatives, clinicians, and researchers can benefit from our findings. The results presented in this thesis demonstrate that many questions need to be addressed until we have the 
Chapter 7

knowledge that we need to inform our patients on their personal best treatment strategy. Prognostic indicators may help to identify the patients that benefit from a specific treatment method and great effort should be undertaken to understand their importance. Future clinical trials should apply the latest innovative methods, use new imaging modalities, investigate in new surgery techniques, assess and report important prognostic information, and use of standardized, reliable, valid, and comparable outcome measures. 


\section{References}

1. Kreiner DS, Shaffer WO, Baisden JL, Gilbert TJ, Summers JT, Toton JF, et al. An evidence-based clinical guideline for the diagnosis and treatment of degenerative lumbar spinal stenosis (update). Spine Journal. 2013;13(7):734-43.

2. Geisser ME, Haig AJ, Tong HC, Yamakawa KS, Quint DJ, Hoff JT, et al. Spinal canal size and clinical symptoms among persons diagnosed with lumbar spinal stenosis. Clin J Pain. 2007 Nov-Dec;23(9):780-5. PubMed PMID: 18075405. English.

3. Kim HJ, Suh BG, Lee DB, Lee GW, Kim DW, Kang KT, et al. The influence of pain sensitivity on the symptom severity in patients with lumbar spinal stenosis. Pain Physician. 2013;16(2):135-44.

4. Lavelle WF, Tallarico R, Madom IA, Palumbo MA, Metkar US, Marawar S, et al. Comparison of surgeon assessed stenosis and validated patient functional outcome scores. Spine Journal. 2012;12(9):117S-8S.

5. Sigmundsson FG, Kang XP, Jonsson B, Stromqvist B. Correlation between disability and MRI findings in lumbar spinal stenosis: a prospective study of 109 patients operated on by decompression. Acta Orthop. 2011 Apr;82(2):204-10. PubMed PMID: 21434811. Pubmed Central PMCID: PMC3235292. English.

6. Andreisek G, Deyo RA, Jarvik JG, Porchet F, Winklhofer SFX, Steurer J, et al. Consensus conference on core radiological parameters to describe lumbar stenosis - an initiative for structured reporting. European Radiology. 2014 Dec;24(12):3224-32. PubMed PMID: WOS:000345141300027. English.

7. Winklhofer S, Held U, Burgstaller JM, Finkenstaedt T, Bolog N, Ulrich N, et al. Degenerative lumbar spinal canal stenosis: intra- and inter-reader agreement for magnetic resonance imaging parameters. Eur Spine J. 2016 Jun 22. PubMed PMID: 27334492.

8. Stucki G, Liang MH, Fossel AH, Katz JN. Relative responsiveness of condition-specific and generic health status measures in degenerative lumbar spinal stenosis. J Clin Epidemiol. 1995 Nov;48(11):1369-78. PubMed PMID: 7490600. Epub 1995/11/01. eng.

9. Edwards RR, Sarlani E, Wesselmann U, Fillingim RB. Quantitative assessment of experimental pain perception: multiple domains of clinical relevance. Pain. 2005 Apr;114(3):315-9. PubMed PMID: 15777856.

10. Ruscheweyh R, Verneuer B, Dany K, Marziniak M, Wolowski A, Colak-Ekici R, et al. Validation of the pain sensitivity questionnaire in chronic pain patients. Pain. 2012 Jun;153(6):1210-8. PubMed PMID: 22541722.

11. Burgstaller JM, Porchet F, Steurer J, Wertli MM. Arguments for the choice of surgical treatments in patients with lumbar spinal stenosis - a systematic appraisal of randomized controlled trials. BMC Musculoskelet Disord. 2015;16:96. PubMed PMID: 25896506. Pubmed Central PMCID: 4409719.

12. Ghogawala Z, Dziura J, Butler WE, Dai F, Terrin N, Magge SN, et al. Laminectomy plus Fusion versus Laminectomy Alone for Lumbar Spondylolisthesis. N Engl J Med. 2016 Apr 14;374(15):1424-34. PubMed PMID: 27074067.

13. Forsth $P$, Olafsson G, Carlsson T, Frost A, Borgstrom F, Fritzell P, et al. A Randomized, Controlled Trial of Fusion Surgery for Lumbar Spinal Stenosis. N Engl J Med. 2016 Apr 14;374(15):1413-23. PubMed PMID: 27074066

14. Pratt RK, Fairbank JCT, Virr A. The reliability of the Shuttle Walking Test, the Swiss Spinal Stenosis Questionnaire, the Oxford Spinal Stenosis Score, and the Oswestry Disability Index in the assessment of patients with lumbar spinal stenosis. Spine. 2002 Jan 1;27(1):84-91. PubMed PMID: WOS:000173218200018. English.

15. Deyo RA, Mirza SK, Martin BI, Kreuter W, Goodman DC, Jarvik JG. Trends, major medical complications, and charges associated with surgery for lumbar spinal stenosis in older adults. JAMA. 2010 Apr 7;303(13):1259-65. PubMed PMID: 20371784. Pubmed Central PMCID: 2885954.

16. Leone A, Guglielmi G, Cassar-Pullicino VN, Bonomo L. Lumbar intervertebral instability: a review. Radiology. 2007 Oct;245(1):62-77. PubMed PMID: 17885181.

17. Panjabi MM. Clinical spinal instability and low back pain. Journal of electromyography and kinesiology : official journal of the International Society of Electrophysiological Kinesiology. 2003 Aug;13(4):371-9. PubMed PMID: 12832167.

18. White AA, PANJABI MMA. Clinical Biomechanics of the Spine. 2nd ed. Philadelphia: Lippincott Williams \& Wilkins; $1990.1 \mathrm{p}$. 
19. Sonntag VK, Marciano FF. Is fusion indicated for lumbar spinal disorders? Spine (Phila Pa 1976). 1995 Dec 15;20(24 Suppl):138S-42S. PubMed PMID: 8747268. Epub 1995/12/15. eng.

20. Mannion AF, Pittet V, Steiger F, Vader JP, Becker HJ, Porchet F, et al. Development of appropriateness criteria for the surgical treatment of symptomatic lumbar degenerative spondylolisthesis (LDS). Eur Spine J. 2014 Apr 24. PubMed PMID: 24760463.

21. Marcus DA. Obesity and the impact of chronic pain. Clin J Pain. 2004 May-Jun;20(3):186-91. PubMed PMID: 15100595. Epub 2004/04/22. eng.

22. Rihn JA, Radcliff K, Hilibrand AS, Anderson DT, Zhao W, Lurie J, et al. Does obesity affect outcomes of treatment for lumbar stenosis and degenerative spondylolisthesis? Analysis of the Spine Patient Outcomes Research Trial (SPORT). Spine (Phila Pa 1976). 2012 Nov 1;37(23):1933-46. PubMed PMID: 22614793. Pubmed Central PMCID: 3757558. Epub 2012/05/23. eng.

23. Gepstein R, Shabat S, Arinzon ZH, Berner Y, Catz A, Folman Y. Does obesity affect the results of lumbar decompressive spinal surgery in the elderly? Clin Orthop Relat R. 2004 Sep(426):138-44. PubMed PMID: WOS:000223708600023. English.

24. Djurasovic M, Bratcher KR, Glassman SD, Dimar JR, Carreon LY. The effect of obesity on clinical outcomes after lumbar fusion. Spine (Phila Pa 1976). 2008 Jul 15;33(16):1789-92. PubMed PMID: 18628712. Epub 2008/07/17. eng.

25. Rosen DS, Ferguson SD, Ogden AT, Huo D, Fessler RG. Obesity and self-reported outcome after minimally invasive lumbar spinal fusion surgery. Neurosurgery. 2008 Nov;63(5):956-60; discussion 60. PubMed PMID: 19005386. Epub 2008/11/14. eng.

26. Patel N, Bagan B, Vadera S, Maltenfort MG, Deutsch H, Vaccaro AR, et al. Obesity and spine surgery: relation to perioperative complications. J Neurosurg Spine. 2007 Apr;6(4):291-7. PubMed PMID: 17436915. Epub 2007/04/18. eng.

27. Shamji MF, Parker S, Cook C, Pietrobon R, Brown C, Isaacs RE. Impact of body habitus on perioperative morbidity associated with fusion of the thoracolumbar and lumbar spine. Neurosurgery. 2009 Sep;65(3):490-8; discussion 8. PubMed PMID: 19687694.

28. Ou CY, Lee TC, Lee TH, Huang YH. Impact of Body Mass Index on Adjacent Segment Disease After Lumbar Fusion for Degenerative Spine Disease. Neurosurgery. 2015 Apr;76(4):396-401. PubMed PMID: WOS:000351613000022. English.

29. Pinto Pc, Mclntyre T, Almeida A, AraÃojo Soares V. The mediating role of pain catastrophizing in the relationship between presurgical anxiety and acute postsurgical pain after hysterectomy. Pain. 2012;153(1):218-26.

30. Vissers M, Bussmann J, Verhaar JAN, Busschbach JJV, Bierma-Zeinstra SMA, Reijman M. Psychological factors affecting the outcome of total hip and knee arthroplasty: a systematic review. Seminars in arthritis and rheumatism. 2012;41(4):576-88.

31. Khan R, Ahmed K, Blakeway E, Skapinakis P, Nihoyannopoulos L, Macleod K, et al. Catastrophizing: a predictive factor for postoperative pain. The American journal of surgery. 2011;201(1):122-31.

32. Leeuw M, Goossens MEJB, Linton SJ, Crombez G, Boersma K, Vlaeyen JWS. The fear-avoidance model of musculoskeletal pain: current state of scientific evidence. J Behav Med. 2007 Feb;30(1):77-94. PubMed PMID: 17180640. English.

33. Wertli MM, Rasmussen-Barr E, Held U, Weiser S, Bachmann LM, Brunner F. Fear-avoidance beliefs-a moderator of treatment efficacy in patients with low back pain: a systematic review. The spine journal : official journal of the North American Spine Society. 2014 Nov 1;14(11):2658-78. PubMed PMID: 24614254.

34. Pincus T, Smeets RJ, Simmonds MJ, Sullivan MJ. The fear avoidance model disentangled: improving the clinical utility of the fear avoidance model. Clin J Pain. 2010 Nov-Dec;26(9):739-46. PubMed PMID: 20842017. Epub 2010/09/16. eng.

35. Linton SJ, Shaw WS. Impact of psychological factors in the experience of pain. Phys Ther. 2011 May;91(5):700-11. PubMed PMID: 21451097.

36. Archer KR, Wegener ST, Seebach C, Song Y, Skolasky RL, Thornton C, et al. The effect of fear of movement beliefs on pain and disability after surgery for lumbar and cervical degenerative conditions. Spine (Phila Pa 1976). 2011 Sep 1;36(19):1554-62. PubMed PMID: 21270700. 
37. Wood DW, Haig AJ, Yamakawa KSJ. Fear of movement/(re)injury and activity avoidance in persons with neurogenic versus vascular claudication. Spine Journal. 2012 Apr;12(4):292-300. PubMed PMID: WOS:000304807900006. English.

38. Havakeshian S, Mannion AF. Negative beliefs and psychological disturbance in spine surgery patients: a cause or consequence of a poor treatment outcome? European Spine Journal. 2013 Dec;22(12):2827-35. PubMed PMID: WOS:000327899100020. English.

39. Theunissen M, Peters ML, Bruce J, Gramke HF, Marcus MA. Preoperative anxiety and catastrophizing: a systematic review and meta-analysis of the association with chronic postsurgical pain. Clin J Pain. 2012 NovDec;28(9):819-41. PubMed PMID: 22760489.

40. Macyszyn L, Akbari H, Pisapia JM, Da X, Attiah M, Pigrish V, et al. Imaging patterns predict patient survival and molecular subtype in glioblastoma via machine learning techniques. Neuro-Oncology. 2016 Mar;18(3):41725. PubMed PMID: WOS:000371597700014. English.

41. Emblem KE, Pinho MC, Zollner FG, Due-Tonnessen P, Hald JK, Schad LR, et al. A Generic Support Vector Machine Model for Preoperative Glioma Survival Associations. Radiology. 2015 Apr;275(1):228-34. PubMed PMID: WOS:000353255000026. English.

42. Airaksinen O, Herno A, Kaukanen E, Saari T, Sihvonen T, Suomalainen O. Density of lumbar muscles 4 years after decompressive spinal surgery. Eur Spine J. 1996;5(3):193-7. PubMed PMID: 8831123.

43. Thome C, Zevgaridis D, Leheta O, Bazner H, Pockler-Schoniger C, Wohrle J, et al. Outcome after less-invasive decompression of lumbar spinal stenosis: a randomized comparison of unilateral laminotomy, bilateral laminotomy, and laminectomy. J Neurosurg Spine. 2005 Aug;3(2):129-41. PubMed PMID: 16370302.

44. Deer TR, Kapural L. New Image-Guided Ultra-Minimally Invasive Lumbar Decompression Method: The mild (R) Procedure. Pain Physician. 2010 Jan-Feb;13(1):35-41. PubMed PMID: WOS:000274607600005. English.

45. Kreiner DS, MacVicar J, Duszynski B, Nampiaparampil DE. The mild (R) Procedure: A Systematic Review of the Current Literature. Pain Medicine. 2014 Feb;15(2):196-205. PubMed PMID: WOS:000331184300005. English.

46. Moojen WA, Arts MP, Jacobs WCH, van Zwet EW, van den Akker-van Marle ME, Koes BW, et al. Interspinous process device versus standard conventional surgical decompression for lumbar spinal stenosis: randomized controlled trial. Bmj-Brit Med J. 2013 Nov 14;347. PubMed PMID: WOS:000327155000001. English.

47. Moojen WA, Arts MP, Jacobs WCH, van Zwet EW, van den Akker-van Marle ME, Koes BW, et al. IPD without bony decompression versus conventional surgical decompression for lumbar spinal stenosis: 2-year results of a double-blind randomized controlled trial. European Spine Journal. 2015 Oct;24(10):2295-305. PubMed PMID: WOS:000362320200027. English.

48. Stromqvist BH, Berg S, Gerdhem P, Johnsson R, Moller A, Sahlstrand T, et al. X-Stop Versus Decompressive Surgery for Lumbar Neurogenic Intermittent Claudication Randomized Controlled Trial With 2-Year Follow-up. Spine. 2013 Aug 1;38(17):1436-42. PubMed PMID: WOS:000330362800011. English.

49. Theunissen M, Peters ML, Schouten EG, Fiddelers AA, Willemsen MG, Pinto PR, et al. Validation of the surgical fear questionnaire in adult patients waiting for elective surgery. PLoS One. 2014;9(6):e100225. PubMed PMID: 24960025. Pubmed Central PMCID: 4069058.

50. Weinstein JN, Tosteson ANA, Tosteson TD, Lurie JD, Abdu WA, Mirza SK, et al. The SPORT Value Compass Do the Extra Costs of Undergoing Spine Surgery Produce Better Health Benefits? Med Care. 2014 Dec;52(12):105563. PubMed PMID: WOS:000345294100009. English. 



\section{Chapter 8}

Summary 

Lumbar spinal stenosis (LSS) is a highly prevalent condition and the most frequent indication for spine surgery in elderly patients (chapter 1). Little is known about its prevalence in the general population as a result of inconsistent definitions of LSS and missing reporting in unselected populations. Furthermore, the economic burden of the surgical treatment of LSS is high.

In chapter $\mathbf{2}$ we addressed the association between magnetic resonance imaging (MRI) findings and pain in patients with lumbar spinal stenosis. First, we identified all published articles in a systematic literature search. Four studies were finally included and analyzed. Of these, only two articles reported an association between a MRI parameter and pain outcome. In a second step, we analyzed our own data of the first 150 patients of the lumbar spinal stenosis outcome study (LSOS). Using Spearman correlation coefficients and graphical representations we were not able to identify a statistically relevant association between any of the multiple investigated MRI parameters and buttock, leg or back pain. Even by restricting the analysis to the level of the lumbar spine with the most prominent radiological 'stenosis' no relevant association could be shown. Our study indicated that there is a need for innovative 'methods/techniques' to learn more about the causal relationship between radiological findings and the patients' pain related complaints.

In chapter 3 we appraised arguments reported in randomized controlled trials (RCTs) included in systematic reviews published or indexed in the Cochrane library studying surgical treatments in patients with lumbar spinal stenosis. Eight RCTs out of six systematic reviews listed arguments for the choice of their treatments under investigation. The main argument identified in this appraisal for and against decompression alone in patient with lumbar spinal stenosis was whether or not instability should be treated with (instrumented) fusion procedures. However, as a consequence of a lack of a broadly accepted definition and method of quantification of instability, researchers use different methods to quantify instability. This impedes the appraisal of the clinical impact of study results and the synthesis of results from original studies in a systematic review. Therefore, it is important that researchers and clinicians agree on definitions for important key concepts such as instability and reoperations in a first step. 
Lumbar decompression surgery has been shown to improve quality of life in patients with degenerative lumbar spinal stenosis. In the existing literature the efficacy of lumbar decompression in the obese population remains controversial. To assess whether obese patients benefit after decompression surgery for lumbar spinal stenosis (LSS), we used again the data of the LSOS (chapter 4). One hundred and sixty-six patients met the inclusion criteria and were divided into three body mass index (BMI) category groups according to the World Health Organization (WHO). We found that obese patients reached minimal clinically important difference (MCID) in SSM in 36\% at six months and in $48 \%$ at 12 months. To estimate whether BMI categories had a significant influence on reaching MCID, we fitted a multiple logistic regression model adjusting for levels of laminectomy. The estimated odds ratios for MCID in the obese group were $0.78(0.34-1.82)$ at six months and 0.99 (0.44-2.23) at twelve months. Therefore, we concluded that obese patients can expect clinical improvement after lumbar decompression for LSS, but the percentage of patients with a meaningful improvement is lower than in the group of patients with under-, normal and pre-obese weight at six and twelve months.

In chapter 5 we investigated the effect of catastrophizing on treatment efficacy and outcome in patients treated for low back pain in a systematic review. Heterogeneity in study settings, treatments, outcomes, and patient populations impeded meta-analysis. We found that catastrophizing at baseline was predictive for disability at follow-up in four studies and for pain in two studies whereas three studies found no predictive effect of catastrophizing. A mediating effect was found in all studies $(n=5)$ assessing the impact of a decrease in catastrophizing during treatment. A greater decrease was associated with better outcome. Most studies that investigated the moderating effects on treatment efficacy found no effect $(n=5)$. However, no study investigated the influence of catastrophizing on work-related outcomes including return to work. We therefore concluded that the presence of catastrophizing should be considered in patients with persisting back pain. Furthermore, future research should aim to clarify the role of catastrophizing as a moderator of outcome and investigate its importance for work-related outcomes. 
Finally, in chapter 6 we evaluated the effect of pre- and postoperatively assessed fear avoidance beliefs (FAB) on pain and disability in patients with LSS after decompression surgery. For this study we used again data of the LSOS and included 234 patients. To analyze the influence of $F A B$ on pain and disability we built multiple logistic regression models with a priori selected potential confounders for MCID in SSM symptoms and SSM function at 12 months. Furthermore, we used multiple imputation based on chained to obtain data sets without missing values. Finally, we found baseline high FAB (>16 points) measured by the $F A B$ physical activity subscale (FABQ-P) not to be associated with pain (OR 0.95; $95 \%$ $\mathrm{Cl}$ : 0.55-1.67) and disability (OR 1.11; 95\% Cl: 0.64-1.92) at twelve months' follow-up. For continuous FABQ-P at baseline we found no linear association and for FABQ-P at six months there was an effect of about 5 percent reduced chance for MCID on SSM symptoms (OR 0.95; 95\% Cl: 0.92-0.99) and function (OR 0.96; 95\% Cl: 0.93-1.00) per one unit change at twelve months. In the final multiple logistic regression models patients with high FABQ-P at six months (OR 0.46; 95\% Cl: 0.24-0.91) and high persistent $F A B Q-P$ at baseline and six months (OR $0.34,95 \% \mathrm{Cl}$ : 0.16-0.73) were less likely to report a MCID for SSM symptoms at twelve months. Our analysis found a similar trend for SSM function, however, the results were not statistically significant. Therefore, future studies should address the importance of persistent postoperative fear avoidance beliefs. 



\section{Chapter 9}

\section{Valorization addendum}





\section{Relevance}

The goal of this thesis was to investigate several potential prognostic indicators within the scope of the Lumbar Stenosis Outcome Study (LSOS) [1]. The results of our studies will be used to improve patient outcomes and to contribute to a valid prognostic model in order to estimate the probabilities of different treatment regimes in patients with LSS.

Lumbar spinal stenosis (LSS) is a highly prevalent condition affecting more than 200 '000 adults in the USA [2]. It causes significant pain and disability and has a tremendous impact on the patient's daily life. It is therefore crucial to identify the best treatment option for each patient individually. However, it is a challenging task to diagnose and treat patients adequately. Ideally, patients can be selected for specific treatment interventions by identifying prognostic indicators that are relevant for the course of the disease and can be modified through targeted treatment interventions. Clinicians and patients seek for a causal explanation for pain and disability. Therefore, imaging studies such as Magnetic Resonance Imaging (MRI)-findings are used to identify the pathoanatomical location that may cause the complaints. MRI is the most non-invasive used method to establish the diagnosis of LSS and findings on MRIs are believed to be causally associated with the symptoms patient's experience.

First: We showed that, despite the frequent use of MRI studies and a multidisciplinary effort to define radiological parameters relevant for the diagnosis, no association between the parameters and the pain could be identified. To date, it is not clear which somatic anomalies are causal for the clinical manifestations of the illness. In some patients the diagnosis of LSS is straightforward; these patients present themselves with the typical symptoms of "neurogenic claudication" (pain in buttocks and/or legs provoked by walking or standing and relieved by sitting and bending forward) with a single-level, localized narrowing of the lumbar canal. Symptoms, in particular the combination of symptoms, of LSS are often variable and vague what complicates the diagnosis and consequently the adequate treatment. Stenotic changes in the MRI can be also seen in asymptomatic patients, 
and in patients with multilocular or multilevel stenoses it is not clear which radiological findings are causal for the symptoms.

Our findings are of great importance for patients and clinicians. It is in fact difficult to decide which level of a lumbar stenosis the surgeon needs to decompress to relief patients from their complaints. Our results also explain why, even though findings on MRI studies are believed to be relevant, a substantial proportion of patients do not improve after surgery. Despite the uncertainties, the number of surgical procedures - besides conservative treatment as a first line approach - performed for degenerative LSS has increased steadily over the years with costs reaching USD 1.65 billion per year [3]. LSS is the most frequent indication for spine surgery in patients older than 65 years of age [4]. However, the benefit of the surgery varies widely and one third of patients report no clinically relevant improvement after surgery $[5,6]$. Consequently, the identification of morphological, clinical and psychological prognostic indicators is of great importance and may help clinicians in the choice to individualize treatments.

Second: Studies investigating surgical treatment option in patients with lumbar spinal stenosis provide limited arguments that support an overall framework for the choice of surgical treatment options. Based on our systematic summary of arguments for or against specific surgical procedures a conceptual framework can be postulated that needs to be investigated in future studies. Decompression surgery alone - in particular using minimal invasive approaches - is less invasive but may result in instability, spondylolisthesis and therefore, in higher reoperation rate. In contrast, fusion - with or without instrumentation - results in longer duration of the surgery, more blood loss and longer hospital stay.

Third: Clinical prognostic indicators may help to identify specific subgroups of patients that benefit from personalized treatment approaches. Despite the evidence from other studies in back pain, we found no evidence that obesity should influence the treatment decision in patients with lumbar spinal stenosis. Psychological indicators have been recognized to influence the individual coping strategies in pain. Our study is the first that assessed the causal association between fear avoidance beliefs and treatment outcome in lumbar spinal stenosis. We demonstrate that postsurgical high fear avoidance beliefs - 
beliefs that may be modified by specific interventions - were associated with worse treatment outcome.

\section{Target groups}

\section{Clinicians}

Several findings of our studies are of high relevance for primary care physicians, rheumatologists and surgeons. To date, MRI studies do not help to identify the level or relevance of a lumbar spinal stenosis. We were not able to identify a correlation between pain and MRI findings. Therefore, the treatment decision needs to be based on the clinical findings and the patient's preference. Our studies on other prognostic indicators are also important for rheumatologists and surgeons, specialized in spine surgery and caring for patients with lumbar spinal stenosis. Despite being obese, patients benefited equally from surgery than lean patients. Fear of movement has been shown to be an important prognostic indicator in back pain studies. Although our study showed that preoperative fear may be because of the pending treatment decision / surgery we found persistent fear avoidance beliefs after six months to be associated with worse treatment outcome. Therefore, fear avoidance beliefs should be assessed after surgery and specific treatment should be implemented.

The findings are to some degree also relevant for general practitioners (GPs). Depending on the organization of the health care system GP's care for patients with lumbar spinal stenosis and their recommendations may also influence the patients' decision about the most appropriate treatment.

\section{Researchers}

Our findings provided useful information to researchers on how to deal with a great amount of MRI data as well as their analysis. Consequently, sophisticated statistical methods like machine learning approaches should be applied to learn more about the causal relationship between radiological findings and the patients' pain related 
complaints. Furthermore, researchers should consider other imaging procedures like axial loading or upright MRI as standard MRI methods in patients with LSS.

As a consequence of our surgical framework researchers should investigate long-term outcomes of the drawbacks of decompression surgery alone in relation to instability and reoperation rates. Furthermore, our results on the influence of pre- and postoperative fear avoidance beliefs on postoperative pain and disability should be confirmed by other researchers and in addition, specific treatment interventions should be investigated.

\section{Patients}

Our findings are of great importance for patients. Treatments in LSS are preference sensitive and therefore, highly dependent on patient education and preference. Patients with lumbar spinal stenosis need to be informed that the MRI studies only poorly correlate with their specific symptoms.

\section{Activities}

The results of the studies presented in this dissertation have led to several activities in the field:

We were able to present our results on the impact of obesity on the outcome of decompression surgery (Chapter 4 ) at the $67^{\text {th }}$ annual meeting of the German Society of Neurosurgery (DGNC) where experts (clinicians and researchers) in the fields of neurosurgery and neuro-oncology took part [7]. The subject obesity is highly topical demonstrated by the fact that we were the winner of the poster price (out of over 130).

We also intensified the collaboration with the Institute for Machine Learning at the Swiss Federal Institute of Technology in Zurich (ETHZ), one of the top ten leading universities worldwide, to explore associations between MRI-findings and clinical parameters by applying more sophisticated statistical methods like machine learning approaches or model averaging. Furthermore, we also aim to build an automated computer based sup- 
port system to identify the stenosis underlying the symptoms of the patient. First results will be expected in 2017.

The results of our systematic appraisal investigating the selection of a specific type of operation for surgical treatment of lumbar spinal stenosis (Chapter 3) influenced the research of the LSOS study group using own data; the aim of the new study (currently under review) was to assess which surgical management - decompression alone or decompression plus fusion - provides better outcome in patients with symptomatic lumbar spinal stenosis with or without spondylolisthesis.

Our findings are regularly reported in Continuing Medical Education (CME) meetings in various hospitals and medical institutions in Switzerland.

\section{Innovation}

The findings presented in this thesis are innovative in the following regards:

First: The results on the association between magnetic resonance imaging parameters and pain led to new projects that use - in the field of LSS - quite new approaches like machine learning methods to identify possible interrelationships. Furthermore, innovative automated computer based support systems will be built to identify the stenosis underlying the symptoms of the patient.

Second: We will contribute crucial and previously unknown insights about the importance of the fear avoidance model in patients with LSS thank to our findings of fear avoidance beliefs on pre- and postoperative pain and disability.

\section{Implementation}

The knowledge we have gained from this thesis will have an impact in the development of the prognostic model. The LSOS study aims to derive and validate a prognostic model to estimate the probability of clinically relevant improvement, conditional on the treatment 
Chapter 9

[6]. The model will support clinicians in estimating the expected course of the illness and consequently in recommending patients the optimal treatment.

Furthermore, the results and the insights gained from the study of Chapter 2 will be implemented in the new project we conduct together with the ETHZ and other international collaborators. 


\section{References}

1. Steurer J, Nydegger A, Held U, Brunner F, Hodler J, Porchet F, Min K, Mannion AF, Michel B, LumbSten Research C: LumbSten: the lumbar spinal stenosis outcome study. BMC Musculoskelet Disord 2010, 11:254.

2. Lurie J, Tomkins-Lane C: Management of lumbar spinal stenosis. BMJ 2016, 352:h6234.

3. Deyo RA, Mirza SK, Martin BI, Kreuter W, Goodman DC, Jarvik JG: Trends, major medical complications, and charges associated with surgery for lumbar spinal stenosis in older adults. JAMA 2010, 303:1259-1265.

4. Deyo RA: Treatment of lumbar spinal stenosis: a balancing act. The spine journal : official journal of the North American Spine Society 2010, 10:625-627.

5. Atlas SJ, Keller RB, Wu YA, Deyo RA, Singer DE: Long-term outcomes of surgical and nonsurgical management of lumbar spinal stenosis: $\mathbf{8}$ to 10 year results from the maine lumbar spine study. Spine (Phila Pa 1976) 2005, 30:936-943.

6. Weinstein JN, Tosteson TD, Lurie JD, Tosteson A, Blood E, Herkowitz H, Cammisa F, Albert T, Boden SD, Hilibrand A, et al: Surgical versus nonoperative treatment for lumbar spinal stenosis four-year results of the Spine Patient Outcomes Research Trial. Spine (Phila Pa 1976) 2010, 35:1329-1338.

7. Burgstaller JM, Held U, Brunner F, Porchet F, Farshad M, Steurer J, Ulrich NH, Group LS: The Impact of Obesity on the Outcome of Decompression Surgery in Degenerative Lumbar Spinal Canal Stenosis: Analysis of the Lumbar Spinal Outcome Study (LSOS)-A Swiss Prospective Multicenter Cohort Study. Spine (Phila Pa 1976) 2016, 41:82-89. 



\section{Acknowledgements | Dankwoord}

First of all, I would like to thank my supervisor and mentor, Maria M. Wertli. I cannot thank you enough for all the time and effort you invested in this thesis. You were always willing to lend a sympathetic ear to all my questions and problems, you supported and encouraged me in all situations and you also were a constant source of ideas.

I am also grateful to Johann Steurer, director of the Horten Center for Patient Oriented Research and Knowledge Transfer, University of Zurich and UniversityHospital of Zurich, who supported me unconditionally in the last four years and made it possible to write this thesis. Furthermore, I am also grateful to Ulrike Held for her tireless statistical support and help.

I would like to thank Maarten van Kleef to act as a promotor and Hans-Fritz Gramke to act as a co-promotor for this thesis. It was a great honor for me. Thanks are extended to Alfons Kessels who helped with valuable comments and even visited me in Zurich.

I am grateful to Giuseppe Pichierri for his help in designing the layout of this thesis.

I also want to express my gratitude to all co-authors of the included papers in this doctoral thesis. 



\section{Curriculum vitae}

Jakob Martin Burgstaller was born on the 9th of Mai, 1980 in Zurich (Switzerland) where he grew up and attended high school. In 2000 he started dental school at the University of Zurich and graduated in 2005. One year later, in 2006, he went to medical school at the University of Zurich and received his medical doctor degree in 2010. Both his MD and DMD theses he finished in 2011, under direction of Professor J. Steurer. After working as a resident in the departments of anesthesia and radiology, he joined the research group at the Horten Center for Patient Oriented Research and Knowledge Transfer, University of Zurich and UniversityHospital of Zurich, in 2013. 
